\title{
Understanding the Māori Television Service's Policy and Legislation: The First Ten Years
}

By

\section{Katie Freeman - Tayler}

A thesis:

Submitted in fulfilment

of the requirements for the degree

of Master of Arts in Media Studies.

Victoria University of Wellington

June 2014. 


\section{Abstract}

The Māori Television Service emerged in 2004 after many years of political agitation by Māori for the New Zealand government to protect and promote Māori language and culture. Given the subsequent broadcaster's role in promoting te reo me ngā tikanga Mãori, this research project seeks to answer the questions: what strategies for language revitalisation are revealed in the Māori Television Service's governing policy documents produced from 2003-2013, and how are the Māori Television Service's strategies for language revitalisation informed by the operating environment of the broadcaster? To answer these questions, discourse analysis of the Māori Television Service's governing policy documents, and those which inform it, is used to reveal the broadcaster's strategies for language revitalisation. These documents are contextualised in relation to the wider Māori language struggle, the New Zealand broadcast industry, and socio-political, cultural and economic shifts between 2003 and 2013. Such contextualisation demonstrates the purpose of the broadcaster's strategies for language revitalisation, how and why these strategies have changed and how these shifts reflect the Māori Television Service's negotiation of different stakeholders.

Research findings suggest that the Māori Television Service has deployed a range of strategies that enable it to meet its legislative obligations as well as respond to community and industry stakeholders. These strategies include building an audience for its language programming content, operating as a financially prudent Māori organisation, and developing programming strategies in light of technological shifts. The thesis argues that these strategies contribute to the naturalisation and normalisation of te reo me ngā tikanga Mãori within the national imaginary, and that these reflect key tactics for language revitalisation as set out in the 2003 Māori Language Strategy. The thesis also identifies a shift from the Māori Television Service's focus on language programming quantity to language programming quality, and a shift to focusing on te reo speakers over a broad viewer base, across the ten year period of the broadcaster's existence. The thesis aligns these more recent language programming strategies in relation to current changes in language revitalisation activities. In revealing the competing pressures faced by the broadcaster, this thesis highlights the role the Māori Television Service has played in increasing the symbolic value of te reo Mãori, as well as how it has contributed to language revitalisation strategies in sectors beyond broadcasting. 


\section{Acknowledgements}

This research was supported by a scholarship from the Marsden Research Project 'Onscreen Indigeneity: A Case Study of Māori Television'

Although this thesis bears my name it would not have been possible without the help and support of many people.

I would like to express my sincere thanks to my supervisor, Jo Smith, whose continual support, guidance, encouragement, patience and work in the field has enabled me to achieve this.

I also want to extend my thanks to other members of the Media Studies staff and my fellow SEFTMS postgraduate students whose academic and moral support has been unwavering.

To my Archives New Zealand team, you have kept me sane. Your continual distraction, reassurance and fun has allowed me to persevere.

Thank you to all my family and friends who have barely seen me in the last six months but still remember to send me encouraging messages, are patient when I use my thesis as an excuse, keep me fed and who are there for a kōrero when needed. Your support and advice has been invaluable this past year and I am sorry for always talking about my thesis.

My special thanks go to Ellie, Stephy, Lana, Jono, Alex, Lisa and Nicole. 


\section{Table of Contents}

$\begin{array}{ll}\text { Abstract } & 2\end{array}$

Acknowledgements 3

Introduction $\quad 5$

Chapter One: Television and the Demise and Uplift of 10 Te Reo Māori

Chapter Two: Te Reo Māori Programming

Chapter Three: Strategies for Audience Engagement and

Language Revitalisation

Chapter Four: The Impact of Socio-Political, Cultural and

Economic Pressures on the MTS

Chapter Five: The MTS and its Function in the Māori

Language Sector

Conclusion

104

Reference List 


\section{Introduction}

[T] he massive influence of English at school, in the neighbourhood, through radio, television, and the movies has had the same effect where the Māori language is concerned as pollutants have on the health of oysters in an oyster bed: when the environment becomes polluted beyond a critical point, neither the oysters nor their linguistic counterpart can survive. (Richard Benton, 1985a, p. 4)

Some New Zealanders may say that the loss of Māori language is unimportant. The claimants in reply have reminded us that the Māori culture is a part of the heritage of New Zealand and that the Māori language is at the heart of that culture. If the language dies the culture will die, and something quite unique will have been lost to the world. (Waitangi Tribunal, 1986, p. 1)

New Zealand is a settler-nation with the Treaty of Waitangi (hereafter the Treaty) often cited as the founding document. The Treaty was signed on 6 February 1840 between the British Crown and Māori representatives. According to Augie Fleras and Peter Spoonley (1999), the purpose of the Treaty was to enable a place in New Zealand for two peoples with equal rights (p. xii). However, some argue the Treaty remains an "incomplete project" because there are continuing struggles between Māori and the Crown over the recognition of Treaty principles, which need to be addressed in order to honour the rights guaranteed to Māori by the Treaty (Smith \& Abel, 2008, p. 2). One area where these struggles can be seen is with regard to language. Until the early 1900s the native Māori language was a living language. Over time and as a result of colonising policies te reo Māori (the Māori language) has reached a crisis point which, if not addressed, will mean that the Māori language risks being "lost to the world" (Waitangi Tribunal, 1986, p. 1). The precarious state of te reo Māori represents a site where the Treaty has not been honoured as Article Two of the Treaty guarantees Māori protection of their taonga (treasure) including their language (Waitangi Tribunal, 1986, p. 23). In order to rectify this and protect Māori language and culture, language experts state that te reo Māori needs to be heard in key areas of the everyday, including television (Benton 1985c; Fishman 1997; 2001; Hartley 1999; 2008). To help honour the Treaty, the Māori Television Service (Te 
Aratuku Whakaata Irirangi Māori) Act 2003 (hereafter MTS Act 2003) was established in law, and was required to "promote te reo Māori me ngā tikanga Māori" (sec. 8.1). The MTS Act 2003 defines "te reo Māori me ngā tikanga Māori” as the Māori language and its "customary values and practices" (sec. 6). This means that the Māori Television Service (MTS) is responsible for providing a television service that, before all other aims, works to protect the Māori language and the cultural customs attached to it.

Given this mandate, this research project poses the question: what strategies for language revitalisation are revealed in the MTS's governing policy documents produced from 2003-2013? Existing literature suggests television is integral to the revitalisation of minority languages (Bell 2010; Benton 1985c; David 2010; Fishman 1997; 2001; Hartley 1999; 2008; Lysaght, 2010). However, this is a difficult task because the imperatives of the television industry as well as the MTS Act 2003, require the MTS to use a minority language to make popular television for the majority. Similarly, the MTS's mandate of contributing to te reo Māori revitalisation through television is made more difficult because it cannot be separated from the political and cultural pressures that it is inherently linked to due to the broadcaster being a consequence of the Treaty claims process. Due to these tensions, this research project poses a second question: how are the MTS's strategies for language revitalisation informed by the operating environment of the MTS? In addressing these questions, this thesis considers how technological, socio-political, cultural and economic factors have influenced the MTS's governing policy. Based on this analysis, I argue that the strategies for te reo Māori revitalisation which the MTS has employed are shaped by the competing interests of the state, Māori, notions of a public and the wider broadcasting sector. I also argue that the MTS's strategies for language revitalisation have shifted from 2003 to 2013 from a focus on quantity and a broad viewing audience to an emphasis on quality and more targeted audience, and that these shifts reflect the MTS's negotiation of changing technological, socio-political, cultural and economic pressures. This thesis also acknowledges the role the MTS has played in increasing the symbolic value of te reo Māori, as well as how it has aided in creating an environment which can continue to support the revitalisation of the Māori language throughout sectors beyond broadcasting. 


\section{Method}

In order to demonstrate what the MTS's strategies for language revitalisation are, why they exist and why and how they have changed over a ten year period, a mixed methodology will be used. Primarily this thesis will carry out discourse analysis of the MTS's policy documents produced during 2003-2013. Discourse analysis of policy documents involves reading through documents that have been created by various institutions and examining the language, and the organisation of language, deployed in the documents. Discourse analysis assumes that the language of a text is not neutral and language is both constructed and constructive (Gill, 2007, p. 58). This is because, as Rosalind Gill (2007) argues, "discourse does not occur in a social vacuum" but is inflected by the greater environment in which it is created (p. 59). Accordingly, the discourse analysis conducted in this thesis provides a means for understanding the intentions of the MTS and how these intentions are shaped by the wider context surrounding the broadcaster. Specifically, this thesis examines how political, social, economic, cultural and technological discourses are articulated in the documents with regard to the MTS's governing mandate of language revitalisation. This is because these discourses are key to understanding the different stakeholders' influence on the Service. The discourse of the MTS's different policy documents will also be compared and contrasted so changes and consistencies between documents produced during 2003-2013 can be identified. This analysis highlights shifts in the MTS's strategies for language revitalisation during this period. The thesis situates the MTS's policy documents in relation to existing literature on the emergence of Māori television, its role in language revitalisation and larger socio-political, cultural and economic factors that help shape the MTS. The discourse analysis of policy documents provides a theoretical framework for analysing the pressures the MTS negotiates in a contemporary settler-nation and how these wider influences condition the MTS's practices.

The key documents to be analysed are the MTS's Statements of Intent and Annual Reports across a ten year period. The purpose of the MTS's Statements of Intent are to "provide information about what outcomes Māori Television intends to pursue and how" (MTS, 2004b, p. 6). The Annual Reports are created in order to hold the MTS to account for their spending and outputs, ensuring that they are able to 
justify these expenses (MTS Act, 2003, sec. 41). Consequently, they provide a strong basis for understanding how the MTS responds to the Government imperatives stated in the MTS Act 2003, as well as how the broadcaster's objectives have changed in response to the MTS's operational environment and community interests. Other documents analysed and considered in relation to the Statements of Intent and Annual Reports, include the MTS Act 2003, the MTS Amendment Act 2014 and the MTS 2009 Review of Regulation. These provide a broader context for understanding how the MTS's governing discourses have changed over time. This methodology provides a working framework for addressing the primary research questions: what strategies for language revitalisation are revealed in the MTS's governing policy documents produced from 2003-2013 and how are the MTS's strategies for language revitalisation informed by the operating environment of the MTS?

\section{Organisation of Material}

This thesis seeks to demonstrate how the MTS's strategies for language revitalisation present in its Statements of Intent and Annual Reports, and the changes to these since 2003, are the result of the differing interest of the MTS's stakeholders which the broadcaster must negotiate. This analysis is broken into five chapters which each focus on a different aspect of the MTS's language revitalisation policy and the factors which influence its governing documents. Chapter one, entitled "Television and the Demise and Uplift of te Reo Māori", historicises the emergence of the MTS in the wake of an impoverished Māori media environment. This chapter considers the role of television in the uplift of minority languages and the influence of different stakeholders on the Service. This chapter draws on literature in the fields of linguistics and New Zealand television studies and it combines this literature with research on the situation of te reo Māori in New Zealand. Chapter two, "Te Reo Māori Programming", conducts an analysis of the MTS's policy to examine the contribution the MTS has made to increasing te reo on New Zealand television screens. It also links its programming strategies to the techniques for language revitalisation which are outlined in the 2003 government Māori Language Strategy (MLS). The chapter also considers the MTS's shift in focus from increasing the quantity of te reo programming in the early period of its existence to an emphasis on the quality of te reo programming from 2013 onwards. This shift is contextualised with regards to the 
influence of Māori interests on the broadcaster as outlined in the MTS's 2009 Review of Legislation. Chapter three, "Strategies for Audience Engagement and Language Revitalisation", examines the MTS's audience engagement strategies and how these contribute to language revitalisation, and why they have changed since 2003. The chapter examines the MTS's broad viewing strategy. The chapter uses the Service's Annual Reports and Statements of Intent to demonstrate why a broad viewing audience is beneficial for language revitalisation, as well as to show what strategies the MTS has used to create a broad audience. This chapter also considers (and expands upon in the following chapter) the limitations of broad appeal as a strategy but argues that this technique is crucial to language revitalisation. Chapter three also discusses the MTS's response to the emerging digital television environment in which it now operates and demonstrates how embracing digital technologies might enhance language revitalisation objectives. Chapter Four, entitled "The Impact of SocioPolitical, Cultural and Economic Pressures on the MTS", draws on discourse analysis of documents, alongside scholarship concerning Māori media and the New Zealand television industry. This mixed methodology is used to argue that the MTS's dependence on the state, as a result of funding and the Treaty of Waitangi, means it is influenced by wider pressures of the state and public. Finally, chapter five, "The MTS and its Function in the Māori Language Sector" argues that the MTS's strategies for language revitalisation have increased the symbolic value of the Māori language. The chapter draws on research on the Māori language sector taken from various policy documents to demonstrate the important role of a Māori language broadcaster for the revitalisation of te reo Māori. It also considers arguments made in previous chapters and expands on these to highlight the MTS's productive influence on Mãori and the New Zealand broadcast industry. In analysing the MTS's policy documents, findings suggest the MTS has deployed a range of strategies for language revitalisation which are informed by the wider environment of the Service and enable it to meet its legislative obligations and to respond to community and industry stakeholders. 


\section{Chapter One: Television and the Demise and Uplift of te Reo Māori}

\section{Introduction}

The MTS's primary aim, as outlined in the MTS Act 2003, is to promote te reo Māori. This is because the Māori language is in danger of being lost and language experts have identified television as crucial to the protection of te reo Māori (Benton 1985c; Fishman 1997; 2001; Hartley 1999; 2008). To illustrate this argument, this chapter discusses the history of te reo Māori and how it went from being a living language to one at risk of extinction. Secondly, this chapter considers factors involved in revitalising a minority language, focusing on the importance of television particularly to this process. This chapter also explains how the New Zealand television industry, prior to the establishment of the MTS, created an environment unfavourable to te reo Māori revitalisation. Specifically, it considers how the lack of will for Māori programming in the television industry, coupled with a deregulated and commercially driven television environment, has historically marginalised Māori programming on New Zealand television. This discussion will occur alongside an analysis of how Māori groups attempted to assert their Treaty rights and insert a Māori presence into the New Zealand television environment. Finally, this chapter outlines the Government's attempts to overcome shortfalls of the New Zealand broadcast and Māori language sectors. It will discuss the steps taken towards the eventual establishment of the MTS, as well as government-wide measures that were implemented in order to protect te reo Māori. However, it will be acknowledged that despite progress towards the revitalisation of te reo Māori, public and state interests make this a difficult process. This discussion will demonstrate why protecting and promoting te reo Māori me ngā tikanga Māori is the organising factor of the MTS and this chapter provides a platform for chapter two's discussion of how the MTS works to support the promotion of te reo Māori.

\section{History of te reo Māori}

At the end of the nineteenth century te reo Māori was the primary language spoken by Māori. Although at this time many Māori were bilingual, te reo Māori was used as the main means of communication in Māori social, commercial and political life 
(Waitangi Tribunal, 2010, p. 393). However, from the early twentieth century onwards, the effects of colonisation began to have an insurmountable impact on the health of te reo Māori. This was because education was conducted almost entirely in English as children were forced to leave "te reo at the school gate" and were punished if they did not do so (ibid.). This had flow-on effects as the children of this education system spoke to their offspring primarily in English as they saw it as the socially acceptable language and did not want their own children to be punished and outcast as they were. This process of monolingualism was accelerated from the 1940s to the 1970 s as the effects of education polices were compounded by other colonising policies. For example, policies such as 'pepper-potting' resulted in the Māori population being dispersed amongst predominantly non-Māori communities to discourage residential concentrations of Māori (ibid., p. 394). As a result of this policy, and others which privileged English as the dominant language in society, a significant language shift from Māori to English during the twentieth century occurred and te reo Māori was no longer seen as the preferred language for social interaction. A report on the state of te reo Māori released in 1975 noted that while 90 per cent of children could speak te reo Māori in 1900 by 1975 this had declined to 5 per cent and only 18 per cent of all Māori were fluent speakers (ibid.).

This situation caused grave concern among Māori which resulted in the emergence of Māori language advocacy groups such as Te Reo Māori Society and Ngā Tamatoa. These groups petitioned government and raised awareness of the need for te reo Māori revitalisation. In 1972 a 30,000 signature petition to Parliament called for te reo and tikanga Māori to be promoted in schools (Middleton, 2010, p. 148). This milestone began the annual Māori Language Day which in 1975 became Māori Language Week. This was followed by other petitions including another 30,000 signature petition in 1978, this time from Te Reo Māori Society calling for a Māori television production unit, and a petition signed by 2,500 people in 1981 calling for te reo Māori to be made an official language of New Zealand (Waitangi Tribunal, 2010, p. 395). In 1985 the Te Reo Māori Claim (Wai 11) lodged by Te Huirangi Waikerepuru and Ngā Kaiwhakapumau i te Reo (the Māori Language Board of Wellington) recommended that "te reo Māori should be recognised as an official language throughout New Zealand for all purposes" (Waitangi Tribunal, 1986, p. 7). The Claim 
was made on the basis that the Crown had failed to meet its Treaty obligations in protecting all taonga as guaranteed under Article Two of the Treaty.

There were a number of groups and individuals present at the Waitangi Tribunal (hereafter Tribunal) hearings who sought to emphasise the importance of the protection and uplift of te reo Māori. Dr. Richard Benton, representative of the Māori Unit of the Council for Educational Research, argued that the major causes of language loss:

[S]tem from the fact that language is first and foremost a social phenomenon. Languages do not flourish in a social vacuum, and they are learned and established most effectively through use in a wide variety of contexts. Social changes in recent New Zealand history have greatly reduced the contexts in which Māori speakers can use their language. (1985a, p. 4)

In further support for the need to protect te reo Māori, the Wai 11 report found that many claimants argued that "the Māori language is at the heart of that culture" and therefore, "if the language dies the culture will die, and something quite unique will have been lost to the world" (Waitangi Tribunal, 1986, p. 1). Discussing the Wai 11 Claim, Māori academic Leonie Pihama noted that:

The Waitangi Tribunal found that the Māori language is the embodiment of the particular spiritual and mental concepts of the Māori. It was not to be touted merely as a Māori mascot for overseas dignitaries as it is central to the culture. It therefore is a taonga, which has to be protected by the Crown." (n.d., p. 11-12).

These points of view highlight the idea that te reo Māori revitalisation does not just enable Māori to communicate but that this communication is the basis of te ao Māori (the Māori world). Without protection of the language Māori culture will cease to exist, emphasising the gravity of the need for the language, and its correct and customary usage, to be protected. The Tribunal also stated that the Treaty "obliges the Crown not only to recognise the Mãori interests but actively protect them" (emphasis added, ibid., p. 12). The emphasis on the use of the word "actively" suggests that the Crown must provide adequate means through which the Mãori language can be protected. In 1986 the Tribunal upheld the Claim that Māori language was a taonga. Consequently, in 1987 the Māori Language Act made te reo Māori an official language of New Zealand and Te Taura Whiri i te Reo Māori (the Māori Language Commission) was established to oversee the Māori language sector. 


\section{Broadcasting and Minority Language Uplift}

During the Wai 11 Claim's court proceedings, education and broadcasting were recognised as two integral sectors for the promotion of te reo Māori. The importance of these sectors in the revitalisation of language has since been reinforced by other reports released by government. For example, the 2011 Wai 262 report which considers "the place of Māori culture, identity and traditional knowledge in New Zealand's laws, and in government policies and practices" (Ministry of Justice, 2011) and the 2011 Te Reo Mauriora Report commissioned by Te Puni Kōkiri (TPK) (the public sector organisation responsible for Māori interests) which was concerned with answering the question: how can the Māori language be made safe? In addition to these reports, literature and research also illustrates the importance of education and broadcasting to revitalising a minority language (Bell 2010; Benton 1985a; 1985b; 1985c; Fishman 1991; 1997; 2001). Fishman (1997) argues that "endangered languages become such because of the lack of informal intergenerational transmission and informal daily life support," and he argues that what is needed as part of this "daily life support" are education and media policies that promote minority languages (p. 90). He is quick to highlight, however, such policies alone will not revitalise a language, as the language needs to be embraced by a number of groups and sectors of a given society (ibid.). This is because, as Benton (1985a) argues, language is a "social phenomenon" (p. 4). In order for it to thrive it must exist in those areas that are a banal part of the everyday, allowing it to become a living language.

Te reo Māori uplift through broadcasting was a key focus of the Wai 11 Claim. This is because, according to media scholars such as John Hartley (1999; 2008), television is a teacher of cultural attitudes. This means that if a language is spoken or heard on broadcast mediums such as television and radio, this legitimates the language, encouraging it to become an accepted part of the everyday. This argument is supported by linguists (Bell 2010; Benton 1985c; Hourigan 2003; Moriarty 2009) who argue that television is necessary for cultural and linguistic survival and therefore is a specific need for minority languages as it helps them to compete with the dominant language. At the Wai 11 hearings, Benton argued that the lack of te reo 
Māori on mainstream television had been an important force in the demise of te reo Māori (Benton, 1985a, p. 7). His argument was based on his belief that:

The television set undoubtedly constitutes a powerful force for the socialisation of all family members, and particularly the young. It occupies a central place in the life of many families... [However], it is still almost entirely an English medium, and constitutes a powerful counterforce within the home to the efficacy of Māori language revitalisation efforts. The medium unremittingly whispers, shouts, and displays its message 'get with it; only English really counts'. (Benton \& Benton, 2001, p. 429).

Since Benton made his case for the revitalisation of te reo Māori in 1985 it must be noted that there have been a number of changes to the New Zealand television environment that potentially reduced the prominence of television in New Zealand homes. In 1985 the New Zealand television environment consisted of two channels, both operated by Television New Zealand (TVNZ) (Dunleavy and Joyce, 2011, p. 43). Now there are a number of channels, provided by multiple networks, available to viewers, making the television sector more competitive for viewers. Furthermore, with the proliferation of new technologies in the television industry, this is also resulting in the fragmentation of audiences. Thus, the presence of Māori content on television or the creation of a stand-alone Māori television channel, would have had a more substantive impact on the New Zealand television environment and language uplift in 1985. However, television is still important to language revitalisation but the current television environment means the MTS must ensure that it attracts and maintains audiences, and engages with new technologies, to be an effective mechanism for language revitalisation which will be discussed in chapter three. Benton also argues that crucial to this process of naturalising the Māori language is children's programming in te reo Māori because:

[Children] are receptive to new sounds and symbols. It is said that children up to ten years of age find it easy to learn two or more languages simultaneously. In the diplomatic world it is no uncommon experience to find young children talking one language to their parents and another to household staff. There are cases on record of small children mastering three or more languages at once. (Waitangi Tribunal, 1986, p. 12)

The receptiveness of children to new languages suggests an urgent need for professionally produced programming with extensive Māori content on television for children (ibid.). Therefore, giving more prominence to te reo Māori through broadcasting encourages a climate in which the speaking of a language other than 
English can become a normal part of New Zealand life and these arguments remain valid even in the current television environment.

Television is also important to language uplift because it can be used to provide content that teaches languages to all age levels through language learning programming (Moriarty, 2009, p. 141). Television also introduces new words and keeps a language dynamic (Moriarty 2009; Lysaght, 2010). This kind of programming is a key feature of a number of Indigenous and minority language television channels including; the Welsh S4C, Irish TG4 and the MTS. These broadcasters all provide a number of programmes that are designed to encourage the process of language acquisition. Furthermore, television is a key language learning device for adults as it allows those not in the formal education system the opportunity to learn, as well as fostering language revival beyond school (Fishman, 2001, p. 14-15). When this discussion of the significance of television to the uplift of minority languages is considered in relation to the New Zealand television environment, the need for increased te reo Māori programming in the broadcast sector becomes clear.

\section{New Zealand Television Environment and Te Reo Māori}

Prior to 2004, Māori programming was seen on New Zealand television screens; however, this programming was sparse. Although a general lack of will within the industry was one reason for this, the deregulated and commercially driven television environment exacerbated mainstream television channel's aversion to delivering Māori content. This state of the New Zealand television industry, as Benton (1985c) argues, did not provide adequately for the uplift of te reo Māori but instead was another factor in its demise.

In the first two decades of television in New Zealand, Māori were rarely seen on television and when they were it was as light entertainment or cultural performance (Stephens, 2004, p. 108). Jane Middleton (2010) notes there were infrequent departures from this, for example, in 1974 when "an independent production of the legend of Uenuku was presented entirely in Māori” (p. 148). However, programming such as this was always the exception. Prominent Māori journalist and broadcaster Derek Fox (2001) noted that when he began working in the broadcasting industry during the 1970s: 
Māori people were rarely seen on television, and then usually as fugitives from the law, described as being 'of part-Māori descent'. The only other occasion Māori might appear on television was when performing traditional song and dance, either to welcome the Queen of England when she arrived on her infrequent visits, or on Waitangi Day. There were no television programmes made especially for the Māori population. The Māori language was almost never heard on the airwaves, and the whole spectrum of social and political issues important to Māori people were largely ignored by radio and TV. (p. 261)

This is supported by media practitioner and commentator Tainui Stephens (2004) who commented that when he first started working for TVNZ:

There was no Māori programming department... Our bosses were Pākehā [New Zealanders of European descent] and they believed that Māori programming should provide a 'window' onto the Māori world. Looking back, I take this to mean that our programmes were wanted in order to display and explain ourselves to people who were not Māori. (p. 108)

These quotes highlight that not only was there a lack of Māori programming on screen, but this programming was often for a general viewing audience which Stephens links to the industry being a prominently Pākehā industry. Māori and te ao Māori was not only underrepresented on television but often misrepresented or stereotyped. Many authors (Abel 1997; 2008; Fox 1992; Spoonley and Hirsch 1990; Walker 2004) have documented how Māori media representations have often been stereotypical and negative. Sue Abel argues that this is the result of the continued prevalence of a monocultural ideology in New Zealand, which causes Māori and things Māori to be excluded or presented as a threat to the majority, or Pākehā view (Abel, 1997, p. 19). Misrepresentation and underrepresentation of Māori has been imperative in fuelling Māori struggles for agency over technologies of representation. As the previous section highlights, excluding, marginalising and misrepresenting te ao Māori in the mainstream media creates an environment unfavourable for language revitalisation as living languages need to be seen and heard.

Although the representation of Māori and te ao Māori on New Zealand television screens was minimal and often distorted prior to the establishment of the MTS, there have been departures from this. One of the first Māori programmes to screen was Tangata Whenua (1974), a six-part documentary series directed by Barry Barclay and written by Michael King that screened in a primetime Sunday evening timeslot. Each episode chronicled a different iwi (tribe) and the issues and customs 
salient to them (NZoS, 2013b). The New Zealand Broadcasting Corporation (NZBC) believed that the series possibly did "more towards helping the European understand the Māori people, their traditions and way of life, than anything else previously shown on television" (ibid.). Stephens (2004) describes Tangata Whenua as the first substantive Māori programme, providing the ultimate 'window on the Māori world' (p. 108). What he means by this is that prior to Tangata Whenua there was nothing on New Zealand television screens that portrayed a fulsome account of te ao Māori. Tangata Whenua was also important, Fox (2001) argues, because it was not produced by TVNZ but by an individual production company, run by prolific film maker John O'Shea (p. 262). This was significant for Fox (2001) as he believed that there was no will within the state broadcasting system to deal innovatively with Māori programming (ibid.). He noted that when he was working for TVNZ and approached a producer to discuss a potential story he was told by the producer that he had "done his Māori story for the year," highlighting the reluctance of mainstream broadcasters to produce Māori content (MTS, 2014b). While television series, such as Tangata Whenua, were screened, it was not until the 1980s, two decades after television's arrival in New Zealand, that regular Māori programming was established.

The first Māori programme to be regularly screened on New Zealand television was Koha (1980-1989) which began screening in 1980 on Sundays at 4pm. By mid-1981, Koha had moved to a primetime 6pm Monday timeslot followed by a Sunday 6.45pm slot (Middleton, 2010, p. 150). Koha was a 30-minute English language magazine programme directed by Ray Waru and presented by various hosts including Tainui Stephens, Derek Fox and Merata Mita. According to New Zealand on Screen (2013a) it explored everything from Māori tribal and natural history to the preparation of food, as well as social problems and te reo and tikanga Māori. Despite the importance of Koha in establishing a place for Māori on mainstream television, Māori involved in the production of the programme believed that there was a tension between Māori and TVNZ's perceived function of the programme. Fox (2001), from his perspective as a Māori presenter, believed that the show lacked the resources necessary to produce something more than simply "a soft, cute window on Māori society" (p. 262). Fox, in saying this, emphasised why Māori needed their own space in order to create Māori programming by, for and about Māori. Another important addition to the television landscape during this period was the establishment of the 
Māori news bulletin, Te Karere (1983-). Fox (2001) considered Te Karere integral to ensuring the continued presence of Māori on mainstream television and the preservation of te reo. It started as a two-minute news bulletin that was produced as part of the 1982 Māori Language Week. It was New Zealand's first regular Māori news broadcast and is now a twenty-minute news bulletin screened on TV One at $4.40 \mathrm{pm}$ each day, entirely in Māori with English subtitles. Fox and Whai Ngata were integral in its creation, sharing the roles of presenter, editor, reporter and producer (Walker, 2004, p. 272). Despite its successful reception, particularly amongst Māori, Te Karere had to fight for resources and few were satisfied with the time at which it is transmitted. This was because it was broadcast during children's programming hours, and not during primetime when it could have reached more viewers (Fox, 1990, p. 104; Stephens, 2004, p. 109). Such issues in the New Zealand broadcast industry are what further motivated Māori to seek their own space for representation on television.

Another flagship Māori programme created by Whai Ngata was Waka Hūia (1987-2009). It was produced entirely in te reo and provided a means of showcasing and archiving "iwi and hapu life and history" (Stephens, 2004, p. 109). Waka Hūia was also significant as it was the first programme to emerge from the Māori Production Unit, which was established as part of TVNZ in 1980. The Māori Production Unit was set up to specialise in the production of Māori content for TV One and TV2. However, despite this initiative to expand Māori programming, Trisha Dunleavy and Hester Joyce (2011) describe how few trainees were given the opportunity to specialise in Māori programming (p. 48). As a result the Unit did not develop distinct Māori values and perspectives, making it flawed in Māori eyes (ibid.). Furthermore, despite the establishment of the Unit, Māori broadcasting remained under resourced and was approached from a low cost angle (Fox, 2002, p. 264-265). This under-resourcing was an approach that continued throughout the pre-Māori Television Service era (ibid.).

Although there was growth in Māori broadcasting from the 1970s onwards, these attempts were sporadic and sparse, with Māori programming never having a clear place in New Zealand's television environment. According to Fox (2001), in 1993 "the number of Māori or Māori-related programmes on television was less than 
one per cent of the total broadcast time" (p. 261). Stephens (2004) reiterates this when he states that before the emergence of the MTS there were approximately only fifteen hours of Māori programming on television (including repeats) per week (p. 108). This discussion on early Māori programming also highlights that Māori involvement was integral to the production of Māori television texts. Each of these early programmes relied on Māori involvement and were hindered by the lack of will of mainstream broadcasters for Māori programming. Accordingly, if Māori were to revitalise te reo Māori they needed their own access to the airways.

\section{The Treaty in Broadcasting}

In order to gain access to the airwaves Māori had to explore legal options. The 1985 Wai 11 Claim was the first site where the government was held accountable for their role in language uplift through television. The Wai 11 report argued that "the Broadcasting Corporation has not provided adequately for Māori radio listeners and television viewers" and that "the Māori language has been harmed by the predominance of English on radio and television” (Waitangi Tribunal, 1986, p. 39-40). Furthermore, it stated that "it is consistent with the principles of the Treaty that the language and matters of Māori interest should have a secure place in broadcasting" (ibid., p. 41). Claimants urged the Tribunal to recommend that existing television channels be required to broadcast a minimum allocation of te reo Māori and provide adequate opportunities for Māori broadcasters (ibid., p. 41). Although the report highlighted the importance of broadcasting for the wellbeing of te reo Māori, the report did not give any specific directives on how to promote and protect language through broadcasting. The Tribunal made it clear that it did not want to impinge upon the functions of the Royal Commission on Broadcasting (also known as the Broadcasting Tribunal) (ibid.). Consequently, in the decade following the Wai 11 report, progress towards increasing a Māori presence in broadcasting was slow and fraught.

In 1985, the same year that Te Huirangi Waikerepuru and Ngā Kaiwhakapumau i te Reo lodged the Wai 11 Claim, the Broadcasting Tribunal (the organisation responsible for the provision of radio and television licenses) announced it was accepting applications for a third channel warrant. In response to this, Māori attempted to exert their Treaty rights in relation to broadcasting by 
presenting an application to the Broadcasting Tribunal for the third channel warrant. Some Māori saw this as an opportunity to increase the amount of Māori content on television and gain control over their media representation. The New Zealand Māori Council drafted an application under the name Aotearoa Broadcasting System (ABS). ABS's application included support from the Broadcasting Corporation of New Zealand (BCNZ, the organisation responsible for overseeing television in New Zealand at this time) who agreed to provide funding for ABS. However, at the last minute the BCNZ withdrew this funding. As a result, ABS was disadvantaged in its application as it lost the financial support necessary to create such a channel and the late withdrawal of the funding also meant alternative funding solutions could not be sought (Pihama and Mika, 2011, p. 180). Consequently, this resulted in ABS being unsuccessful in presenting its bid to the Broadcasting Tribunal. The withdrawal of support for ABS by the BCNZ also reflects the Crown's failure to actively meet its Treaty obligations that were highlighted by the Wai 11 Claim, as the BCNZ was a government agency (ibid., p. 181). What the application did make clear, was that there was tremendous support for the establishment of a national Māori television service (ibid.). Correspondence between ABS and BCNZ recognised this: "The support you have obtained - from the Māori council, Kōhanga Reo Trust, tribunal authorities, and two thousand individual members of ABS must be acknowledged" (ibid.). ABS's attempted bid also highlighted that other applicants had little or no Māori content stipulations in their applications, which had positive ramifications as later all applicants began to develop Māori dimensions (Fox, 2001, p. 130).

When commercial broadcaster TV3 successfully obtained the third channel warrant and began broadcasting in 1989, an obligation to include Māori content on the network was outlined. The Broadcasting Tribunal stated: "The warrant holder...shall have regard to the importance of reflecting a Māori dimension in programming and presentation" (Pihama, n.d., p. 7). Despite this, as a commercial company, TV3 has had to ensure that it broadcasts commercially viable programming and, consequently, TV3 has often prioritised commercial imperatives over cultural content. Therefore, despite the Broadcasting Tribunal's Māori content stipulation, TV3 has failed to significantly contribute to an increase in Māori content on New Zealand television screens. In 2013, of TV3's locally produced content less than 1 per cent was Māori programming (NZoA, 2013b, p. 11). Considering that a commercial 
broadcaster was chosen as the successful applicant for the third channel warrant the argument could be made that the withdrawal of funding by the BCNZ was the result of the third channel warrant's purpose being to create a competitive television market. This would have disadvantaged ABS's bid due to its focus on cultural content being at odds with commercial imperatives. Consequently, Leonie Pihama and Mika believe the ABS's unsuccessful bid at best could "be considered a lost opportunity for the development of Māori broadcasting" (Pihama and Mika, 2011, p. 181). However, the choice not to support the bid also highlighted the need for a future Māori television service to seek sound government support and funding, in a competitive commercial television market.

Another pivotal point in the struggle for greater representation of Māori in broadcasting was the Wai 150 Claim. The Claim was lodged in December 1988 by Sir Graham Latimer on behalf of the New Zealand Māori Council and by Ngā Kaiwhakapumau i te Reo, with the intent of preventing an amendment to the 1976 Broadcasting Act (Pihama and Mika, 2011, p. 182). This amendment would allow the Crown to transfer the assets of the BCNZ to new State Owned Enterprises, Radio New Zealand Limited (RNZ) and TVNZ. The Claim was founded on the argument "that the restructuring of New Zealand broadcasting, and its consequent privatisation, would have a detrimental effect on the survival of te reo Māori" by creating a commercial environment that would foster further denial of Māori access to the airwaves (ibid.). The Claim argued that the sale of radio spectrum without consultation with Māori would be in breach of the Treaty and sought to prevent the transfer until appropriate measures for Māori broadcasting were implemented (Waitangi Tribunal, 1990, p. 810). Wai 150 was upheld by the Tribunal on the grounds that:

The broadcasting media, radio and television, play a key role in the maintenance or loss, development or stagnation of language and culture, not only by what they do, but by what they do not do. The virtual absence of Māori language from radio and television has been a potent factor in the decline in the number of fluent speakers of Māori over the last forty-years, to the point where survival is problematic. This must be rectified. (p. 36)

Despite this ruling, the Government was not prepared to delay the tendering process. In response to this the Wai 150 claimants took the Claim to the High Court in 1991 for a judicial review. The High Court found in the Crown's favour with regard to radio frequencies; however, the Claim with respect to television assets was adjourned so as 
to allow the Crown the opportunity to put in place satisfactory measures to protect te reo Māori through broadcasting if the assets were transferred (TMP, 2014). Later, the Crown acknowledged this condition and the transfer of television assets were allowed. This judgement regarding the transfer of television assets did not satisfy the claimants and they appealed to the Court of Appeal and then in 1992 to the Privy Council, New Zealand's then-court of last resort. The Claimants' argument was based on section 9 of the State Owned Enterprises Act 1987 which required the Government to act in a manner that is consistent with the principles of the Treaty (Pihama and Mika, 2011, p. 183). The Court however, argued that the Crown could fulfil its obligations using alternative assets and that the Crown could have considerable control over the state-owned enterprise (SOE) (ibid., p. 184). Although the Privy Council dismissed this appeal in 1993, the Privy Council in its decision reminded the Crown that under the Treaty it was responsible for the active preservation of te reo Māori and that this must continue to be done despite the transfer of assets (ibid., p. 186).

\section{Deregulation and Reform}

Despite the Wai 150 Claim's attempt to prevent the commercialisation of the New Zealand television industry, this commercialisation occurred leading to the further marginalisation of Māori on television. Throughout the 1980s intense neo-liberal reform took place across all sectors of the New Zealand economy. As the transformation of TVNZ into a SOE and the sale of the third channel warrant to privately owned commercial company TV3 exemplify, broadcasting was no exception to these neo-liberal reforms. The establishment of TVNZ as a SOE meant that it was to be governed by market logic with its primary imperative being to maximise profit (Dunleavy, 2005, p. 213). TVNZ was now positioned as "an income earning asset rather than a provider of cultural goods" (ibid. p. 214) with the removal of its programming stipulations being replaced by an imperative to return a dividend to Treasury (Norris and Pauling, 2012, p. 11). Jonathan Hunt (Minister of Broadcasting 1984-87) claimed that TVNZ could both operate as a commercial business and reflect New Zealand's identity and culture (Pihama, n.d., p. 6). However, it was clear to many others in the broadcasting industry that the primary objective of TVNZ as a SOE has been to "operate under economic principles and therefore its 'social responsibility' 
role is not given priority" (ibid., p. 6). Due to these actions New Zealand's entire freeto-air (FTA) television environment was now based on the market logic of profit maximisation. TVNZ and TV3 achieve this through a business model of spotadvertising, where revenue is garnered through the sale of audiences to advertisers and, consequently, audience attention is paramount. Due to this, locally produced content that costs significantly more to create, and which often has a lower viewership than imported content with already established audiences, is often forgone (Dunleavy, 2005, p. 2-5). This has resulted in the further marginalisation of Māori programming as it has a high opportunity cost, making it an unattractive option for profit driven broadcasters. Even when Māori programming was screened on the FTA networks, these programmes were often placed in non-commercial slots, such as Sunday mornings, in order to prevent a loss of profits to the commercial networks that screened them. Although the placement of Māori programming on Sunday mornings provided a slot for Māori programmes, programming at this time was often taken off air and replaced by "activities deemed more important to the general audience," such as sporting events (Pihama, n.d., p. 8). Placing programmes in these time slots also resulted in minimal audience exposure limiting their ability to naturalise and normalise te reo Māori. Without a designated onscreen space for Māori within this commercial environment, the dearth of Māori programming and the demise of te reo Māori were perpetuated.

In recognition of the challenges that a deregulated, commercial media market presented for programming such as local drama, children's, documentaries and minority programming, the Government did attempt to put in place some minimal forms of regulation (Dunleavy, 2005, p. 218). The Broadcasting Act 1989 (introduced by a Labour Government) established the Broadcasting Commission (which soon after rebranded itself as New Zealand on Air) which was set up to provide contestable funding to all national FTA broadcasters for projects of a 'public service nature' (ibid.). Specifically, the Broadcasting Act 1989 required New Zealand on Air (NZoA) to support programmes about New Zealand and New Zealand interests and programmes that promoted Māori language and Māori culture (sec. 36.1(a)). Recognising the need for regular Māori television content the Government established a separate agency, Te Māngai Pāho (TMP) in August 1993. TMP’s role was to promote Māori language and Māori culture by "making funds available on the 
terms and conditions that it thinks fit" (Broadcasting Act, 1989, sec.53b). It is important to note that despite the creation of TMP, NZoA still sees itself as playing a role in the commissioning of Māori programming content for mainstream television (Middleton, 2010, p. 157). Regardless of these attempts to increase Māori programming onscreen, little progress was made until 1996 when the Aotearoa Television Network (ATN) was established.

The ATN was New Zealand's first Māori television service and was created in response to the shortfalls of the New Zealand broadcasting industry and because of the Crown's obligations as a Treaty partner to actively protect te reo Māori. However, its existence was short and fraught as the budget and limited time frame for which to create the channel posed insurmountable challenges. TMP were in charge of the tendering process and were to allocate 2.6 million to the successful bidder, who on winning the bid had just seven weeks to establish a network that was to broadcast "three hours of original Māori television seven nights a week for thirteen weeks" (Burns, 1997, p. 12). This was deemed an impossible task as "virtually everybody in the industry, including Māori broadcasters, said it couldn't be done" (ibid.). Despite this, ATN went to air on 1 May 1996 as scheduled, providing what Jo Smith and Sue Abel (2008) have described as "high-quality Māori language programming" (p. 3).

Although it went to air as scheduled, the ATN was shrouded in controversy. Chronic under funding was a key issue that many argue led to its demise (Burns 1997; Fox 2001; Middleton 2010). The ATN was provided just $\$ 8,000$ per hour of programming which was low by industry standards, especially when at the time TVNZ was receiving \$29,000 per hour of Māori programming from TMP (Burns, 1997, p. 8). The limited time in which the Service was to be established also posed a challenge, along with its limited transmission reach. On winning the bid the ATN had seven weeks to build and equip studios, recruit staff and make enough programmes to at least fill the first week on air (ibid., p. 59-60). Poor governance exacerbated the situation with the ATN's first chief executive (CEO) being removed by TMP and being replaced by unfavoured candidate Derek Burns (ibid., p. 72-73). However, what is believed to have been central to the broadcaster's demise was the "political and media scrum over perceived spending irregularities that were never proven" (Middleton, 2010, p. 160). Consequently, the channel is now best remembered for the 
expensive taste in underpants of Tukuroirangi Morgan, Director of ATN, (Burns, 1997, p. 89), rather than the "interesting content" (Horrocks, 2004, p. 36) and "high-quality" programming (Smith \& Abel, 2008, p. 3) commentators believed it had produced. Lessons were learnt from the failed experiment, as Trisha Dunleavy (2008) argues that "what the failure of ATN taught politicians, policy-makers and Māori broadcasters was that the next time an Indigenous network was attempted it would require a more appropriate public funding package that could be sustained over several years," an appropriate time period leading up to the establishment of the service and a sound structure of governance (p. 805). The recognition of these lessons would be central in the eventual establishment of the MTS.

\section{Towards a Māori Language Strategy}

As some progress was made towards increasing the presence of te reo Māori in broadcasting during the 1990s, successive governments also took small steps in other areas in an effort to revitalise te reo Māori. For example, citizenship documents were released in te reo Māori, New Zealand passports started using te reo Māori on its inside pages in 1994 and in 1996, the census was released in the Māori language. Also, in 1997, Cabinet allowed Māori Members of Parliament (MPs) to speak in Parliament in te reo Māori and an interpreter was provided for those who wished to do so. In the education sector, the total number of students in te reo Māori bilingual and immersion schools peaked in 1999 at 30,793 which included 18.6 per cent of all Māori school students (Waitangi Tribunal, 2010, p. 399). However, this growth in the te reo Māori education sector was not the direct result of government policies, but significantly implemented by Māori themselves through what has become known as the Kōhanga Reo movement. Despite these small efforts being made to normalise and promote te reo Māori, little was actively done by government in the decade following the Māori Language Act's establishment.

Eventually in 1999 the Government created a Māori Language Strategy (MLS). It was primarily created to bring some coordination to a sector that had evolved in a relatively unplanned way since the 1970s. Paraphrased, the initial aims of the policy were to:

- increase opportunities to learn te reo Māori; 
- improve proficiency levels in speaking, reading and writing and listening to te reo Māori;

- increase the number of situations in which Māori can be used;

- enable te reo Māori to be used for a full range of modern activities;

- foster people's attitudes towards the language so that Māori-English bilingualism becomes a valued part of New Zealand society.

Aside from stating these aims, the strategy provided minimal discussion of how to achieve them and the Government began working on a revised plan later the same year. The new MLS would be more comprehensive and based on research into the health of the Māori language and consultation with various stakeholders.

TPK was placed in charge of formulating this new strategy. Firstly, in 2001 TPK commissioned Statistics New Zealand to conduct a survey on the health of te reo Māori. This survey was completed by 5,000 adults who identified themselves as Māori. It found that of those surveyed, 9 per cent could speak te reo Māori 'well' or 'very well' and a majority, 58 per cent, could speak 'no more than a few words or phrases' (Statistics New Zealand, 2002). ${ }^{1}$ This report informed a revised MLS which in 2002 was discussed with those institutions that were thought key to the strategy's success. This included representatives of Māori broadcasting organisations and Māori education organisations, general Māori groups and relevant government organisations such as the Ministry of Culture and Heritage (MCH) and the Ministry of Education (MoE). Following these general consultations a small group of language experts and kaumātua (Māori elders) discussed the findings and drafted the 2003 MLS. This was then put to iwi in 14 regional consultation hui (meeting) and the general public were also asked for submissions, culminating in a MLS which was released in October 2003 after being approved by Cabinet.

The primary aim of the 2003 MLS was to successfully revitalise te reo Māori through the active involvement of a number of organisations. This MLS was particularly important as it was the first organised, well researched and funded strategy of its kind. The 2003 MLS vision was that:

\footnotetext{
${ }^{1}$ Respondents were asked to classify themselves into one of the following for each of the language skills of speaking, listening, reading and writing; very well, well, fairly well, not very well and no more than a few words or phrases (Statistics New Zealand, 2002).
} 
By 2028, the Māori language will be widely spoken by Māori. In particular, the Māori language will be in common use within Māori whānau, homes and communities. All New Zealanders will appreciate the value of Māori language to New Zealand society. (TPK and Te Taura Whiri i te Reo Māori, 2003, p. 5).

This was to be achieved through five techniques:

- strengthening language skills

- strengthening language use

- strengthening education opportunities in the Māori language

- strengthening community leadership for the Māori language

- $\quad$ strengthening recognition of the Māori language.

While these techniques are similar to that identified by the 1999 MLS, there is a key difference in the 2003 MLS as it identifies the key government agencies to be actively involved in the implementation of these aims. These agencies were TPK, Te Taura Whiri i te Reo Mãori, TMP, MCH, MoE and the National Library of New Zealand. Each agency was to be responsible for an area or areas where language revitalisation could occur, such as Māori language education or Māori language broadcasting. The agencies were required to provide an outline of how they would work to support these goals and the overall vision of the MLS. Despite these attempts to organise clear goals, the extent to which these were carried out by each agency varied as chapter five will highlight. However, it must be emphasised that there was an attempt by government to implement a strategy and this strategy attempted to mobilise language revitalisation across various sectors.

\section{Māori Television Service (Te Aratuku Whakaata Irirangi Māori) Act 2003}

In the same year that the Government launched the revised MLS, significant progress was also made towards the creation of a stand-alone Māori Television service. In 2003 the MTS Act was passed. The primary purpose of the legislation was to provide a permanent space for Māori programming on New Zealand's television screens because a "principal function of the Service is to promote te reo Māori me ngā tikanga Māori" (MTS Act, 2003, sec.8.1). Unlike the ATN, this action "was accompanied by an appropriate level of public funding...and a two year period prior to launch, during which to establish MT's [Māori Television's] management structure, transmission and production facilities, and a stockpile of programmes" (Dunleavy and Joyce, 2011, 
p. 177). In providing adequate time, money (allocated to the Broadcaster by the Ministry of Māori Affairs and TMP), as well as legislation to affirm a continued place for Māori broadcasting, a legitimate and more stable space onscreen for Māori and the active protection of te reo Māori could be finally realised. Eventually, on the 28 March 2004 Māori Television aired. Since then, as this thesis will demonstrate, the MTS has carved out a space for the retention and revitalisation of te reo Māori on New Zealand television screens. Yet, even with more appropriate funding than that received by the ATN and stronger governance, as well as legislation to affirm its presence, the launch of the Service was not supported by all, and consequently, the environment from which the MTS emerged has continued to influence the MTS's actions.

\section{Political and Public Environment of the MTS's Emergence}

The creation of the MTS and launch of the MLS could be understood as a positive shift in state-Māori relations because Māori and the state (a colonising force that had traditionally elided Māori rights) were working together to protect Māori culture. Other factors surrounding the emergence of the Service highlight, however, that while the state was willing to recognise some rights of Māori, others continued to be denied. In the same year Māori Television first aired the Government passed the Foreshore and Seabed Act 2004, which was strongly opposed by Māori and effectively denied Māori Treaty rights. In addition, the Māori Party was established in 2004 on the premise that Māori rights were not adequately represented and upheld by any current political party (Smith and Turner, 2013, p. 271). Furthermore, the MTS was launched into a public and political climate that was hostile towards Māori initiatives. When these actions, and the political environment into which the Service was launched are considered, then this provides a framework for understanding the competing pressures the MTS must negotiate which shape its strategies for language revitalisation.

Although the MTS could not exist without government legislation and funding, the provision of these necessary requirements did not mean that the MTS went uncontested in the political arena. As acknowledged above, it took over three decades of agitation and protest by Māori against the state before Māori Television first aired in 2004. Successive governments have spent a considerable amount of time and 
money (rumoured to be approximately $\$ 50$ million) attempting to stop the launch of a Māori television service (Smith \& Abel, 2008, p. 8). Furthermore, when the state did facilitate the launch of the first Māori television broadcaster (ATN), as noted, it provided the institution with limited time and funding which many commentators argue lead to the channel's short-lived and controversial life (Burns 1997; Dunleavy and Joyce 2011; Fox 2001; Middleton 2010). When plans for the MTS were launched in early 2000, the Government stalled the process. Initially the MTS was to be launched in mid-2002, but due to bureaucratic impediments it was prevented from airing until 2004 (Walker, 2004, p. 371-372). To add further anxiety to the launch of the Service, opposition politicians framed the channel in a negative light and this opposition from within Parliament was publicised in the mainstream media. In August 2001 the New Zealand Herald reported how opposition National Party MP Murrary McCully stated that the "amount to be spent delivering three hours of Māori TV a day to a small audience would build 500 houses a year" (cited in Walker, 2004, p. 371). This rhetoric played on a discourse which already existed in New Zealand of Māori initiatives being separatist and at the expense of, rather than a benefit for New Zealanders, as Māori are often positioned outside of the national 'us' (ibid.). Furthermore, on 8 March 2004, the same month that Māori Television first aired, the New Zealand Herald reported that deputy leader of the Opposition, Gerry Brownlee, announced that a National-led Government would close the broadcaster down when it came to power (cited in Abel, 2011, p. 129).

The negative political discourses that surrounded the MTS's emergence were further exacerbated by a longstanding form of public discourse that focuses on the idea of "Māori inability to manage public institutions and their finances" (Smith \& Abel, 2008, p. 3). This ideology is constructed and perpetuated by the mainstream media, such as in the media coverage surrounding the ATN and Ranginui Walker (2004) documents how the launch of Māori Television was subject to similar media scrutiny. This is exemplified by such headlines taken from the New Zealand Herald in 2002 and 2003 as "Māori TV must clean up its act", "Audit of Māori projects called for" and "Māori TV heads should roll" (Walker, 2004, p. 376). These headlines demonstrate how the media was focused on the possibility of the Service's failure as opposed to its intentions and aspirations (Smith \& Abel, 2008, p. 3). This negative media coverage, combined with negative attitudes of some politicians towards the 
Service which were also aired in the media, are important considerations for the MTS. This is because as the following chapters will demonstrate, these pressures were crucial in the development of the MTS's strategies for language revitalisation.

\section{Conclusion}

Despite te reo Māori thriving as a living language in the early twentieth century, by the last decades of the twentieth century the Māori language was in danger of being lost. In fear of losing their language Māori petitioned and took legal action against the Government in an attempt to regain their voice. During this legal battle for recognition of te reo Māori and its protection, television was identified as a key sector where te ao Māori needed to be seen and heard if te reo Māori was to ever become a living language again and the culture was to be revived.

The New Zealand television environment prior to 2004 did not provide adequate resources for this to occur. Although there were a number of crucial programmes, such as Tangata Whenua, Te Karere and Koha, which were integral in showing the potential for what Māori television programming could contribute to diversification onscreen, the effectiveness of these programmes was limited. The lack of political will of successive governments and lack of desire in the industry itself had meant that Māori programming had never been a consistent feature of the New Zealand television schedule. Furthermore, the deregulated, commercial nature of New Zealand's television industry has continued to foster an environment unfavourable for the screening of Māori programming due to its cultural content often making it commercially unviable. Due to these challenges, in order to be represented on television Māori had to fight the battle for their representation through the courts, and despite widespread support for a Māori television service, this still took three decades before notable progress was made.

Eventually, movement towards the recognition of te reo Māori and its importance in New Zealand did occur. While the 2003 MLS represents a significant step towards language revitalisation, the establishment of the MTS Act 2003 in the same year was of equal importance to this cause. As this thesis will argue, the MTS Act 2003 and the television service that this has produced, are important for the revitalisation of te reo me ngā tikanga Māori. The following chapter contextualises 
the MTS's te reo programming in relation to the 2003 MLS and the role of television in language revitalisation. The following chapters also highlight that like the actions which lead to the establishment of the Service, the MTS cannot contribute to the revitalisation of te reo Māori without negotiating the pressures of the environment in which it exists, particularly public and political sentiment towards the Service. This chapter thus demonstrates that the MTS's strategies for language revitalisation need to take an ecological approach and work with and against the tensions of stakeholders of the MTS. 


\section{Chapter Two: Te reo Māori Programming}

\section{Introduction}

The MTS Act 2003 requires the MTS to contribute to the revitalisation of te reo Māori. Yet, the MTS Act 2003 does not provide an outline for how this should be achieved, nor does the Government Māori Language Strategy (MLS) of 2003. The 2003 MLS highlights techniques for te reo Māori revitalisation including:

- strengthening language skills

- strengthening language use

- strengthening education opportunities in the Māori language

- strengthening community leadership for the Māori language

- strengthening recognition of the Māori language.

What the strategy does not do is explicitly state how the organisations responsible for the implementation of these techniques should incorporate them into their language revitalisation plan. Instead, the individual government organisations responsible for implementing the MLS (Te Puni Kōkiri, Te Taura Whiri i te Reo Māori, Te Māngai Pāho, the Ministry of Culture and Heritage, the Ministry of Education and the National Library of New Zealand) were required to integrate these techniques effectively into their operational plans as they thought best.

This chapter will consider how the MTS has effectively implemented a strategy that allows for te reo Māori to be revitalised. The chapter suggests that, in order to revitalise te reo Māori, the MTS increased recognition of the Māori language by using te reo Māori throughout its schedule. It has also done this by providing content that caters to all levels of te reo speakers, further allowing audiences to learn and advance their language skills. Although providing te reo content is essential to language revitalisation, this chapter also considers how the MTS has shifted its focus from quantity of programming in its initial years to a focus on the quality of programming.

To make this argument, the first section of this chapter consider the quantity of programming provided by the Service and significance of this for language 
revitalisation. The chapter also considers how the programming offered in the schedule contributes to strengthening language skills and educational opportunities, which chapter one and the MLS identifies as a crucial part of language uplift. In order to measure the impact of this content on language revitalisation, studies carried about by TPK and the MTS are discussed and demonstrate the contribution the MTS is making to te reo Māori revitalisation. While the studies discussed in this chapter indicate the MTS is successful in promoting the language amongst those audiences who engage with the Service, chapter three will expand on why audience engagement is key to language revitalisation.

The second section of this chapter argues that the Government's 2003 MLS and the MTS Act 2003 do not account for the quality of the language and the importance of language quality to the revitalisation of te reo Māori. This section of the chapter considers why the quality of the language broadcast is a key concern for Māori language advocates and how this concern is shaping the current focus of the Service's programming practices. In discussing the shift in focus from quantity to quality this chapter will also demonstrate how the MTS is influenced by the key stakeholders of government and Māori.

\section{MLS and the MTS's Schedule}

Examining the quantity of programming broadcast by the MTS provides an example of how the MTS is contributing to language revitalisation. Due to the significant absence of te reo Māori on television prior to the arrival of the MTS, as outlined in chapter one, an initial imperative for the MTS was focusing on the quantity of te reo Māori broadcast. This was considered key to language revitalisation because, as noted in the Government's 2003 MLS, in order to revitalise te reo Māori the use of the Māori language needs to increase and thus allowing for it to become recognised and as chapter one argues, normalised. In 2004 the MTS broadcast 7.9 hours of programming on average per day, of which more than 50 per cent was in te reo Māori (MTS, 2005a, p. 28). In following years the MTS aimed to expand this programming and by 2007, the MTS was screening on average 9.1 hours of programming per day, of which 55 per cent was in te reo Māori (MTS, 2007b, p. 25). Despite these increases, the MTS continued to expand its programming further, especially the options available to those fluent in te reo Māori (allowing them to enhance their language 
skills). In 2008 the MTS launched its second channel, Te Reo. Te Reo is dedicated to broadcasting only in the Māori language and was "developed as a strategy to further enhance the profile and status of te reo Māori" (MTS, 2008b, p. 3). This is a technique for language revitalisation identified in the 2003 MLS which states that strengthening recognition of te reo Māori is key to language revitalisation. In its first year on air Te Reo broadcast 295 hours of content, entirely in te reo Māori (ibid., p. 4). The channel's output has steadily increased and in 2012 the Te Reo channel broadcast 2374 hours of full Māori language immersion programming (MTS, 2013b, p. 11). Although there were concerns that the launch of Te Reo would decrease the amount of Mãori language content on the MTS's flagship channel, this has not been the case. In 2012, Māori Television screened a total of 3433 hours of programming, of which 57 per cent was in te reo Māori (ibid.). There were also concerns that the channel's creation would enable the Māori Television channel to be used to pursue mainstream audiences, as opposed to a Māori audience, for whom the MTS was created. When chapter three's discussion of the MTS's inclusive strategy is considered this argument could certainly be made. However, as chapter four will highlight, the MTS is subject to competing pressures and broadcasting to a mainstream audience can still support Māori visions for the channel. Furthermore, as this chapter highlights, the Māori Television channel continues to provide a high levels of te reo content and programming for Māori speakers, including full immersion programming.

Not only has the MTS's te reo Māori content increased but the MTS has ensured this content is consistently screened when the majority of viewers are watching. In accordance with the MTS Act 2003, the MTS must use primetime slots to "broadcast mainly in te reo Māori" (sec 8.2(a)). According to all of the MTS's Annual Reports, since 2004 the MTS has always broadcast more than 50 per cent of its content during primetime in te reo Māori. This output continues to grow as outlined in its 2013-2016 Statement of Intent (SOI) which states "Māori language content and broadcast hours are key outputs for Māori Television" (p. 9). Because of this, minimum language and broadcast targets are being implemented to ensure that throughout its schedule, not just in primetime, more than half its content is in te reo Māori (MTS, 2013a, p. 9-10). This is significant because from 2004-2013 the MTS's Annual Reports and Statements of Intent have focused on broadcasting targets primarily for te reo Māori content in primetime. The MTS also increased the 
broadcast hours of Te Reo in 2012 (MTS, 2013a, p. 4) and, as the following chapter will discuss, the MTS is also extending access to its content by enabling it to be viewed on multiple platforms. These statistics and actions highlight that the MTS is increasing the amount of te reo heard on New Zealand television screens and broadcasting in times when viewers are available to watch (conventionally understood as primetime, $6 \mathrm{pm}-10: 30 \mathrm{pmf}$ ). This has the potential to enhance the status of te reo Māori through increased use which fosters increased recognition. For some, broadcasting a little over half of its content in te reo Māori during primetime may not be considered enough for a broadcaster whose reason for existence is language revitalisation. Yet, as following chapters argue, broadcasting entirely in te reo Māori is likely to marginalise many Māori and non-Māori and this can also hinder language revitalisation. Consequently, a compromise between the two must be reached in order for language revitalisation to occur.

While overall programming statistics provide one means for exemplifying the MTS's dedication to language uplift, a consideration of the type of programming that makes up these statistics provides further insight into how the MTS is contributing to the revitalisation of te reo Māori. Children are a key target group for the MTS because, as the previous chapter acknowledges, children with their aptitude for language learning and role in intergenerational transmission are crucial to the language revitalisation process. This is recognised in the MTS's Act 2003, which identifies children as a key audience that the MTS must provide for (MTS Act, 2003, sec 8.2(c)). The MTS recognises this and has always provided children's programming in its schedule. In 2004 the MTS broadcast an average of two hours of children's programming per day (MTS, 2004a, p. 32). The MTS has since expanded its offerings and now, across both channels, it screens 20 hours of programming targeted at children on average per week (MTS, 2012b, p. 10). It also ensures this programming is placed in time slots suitable for children (between 2:30pm and 6pm). Despite this increase, the MTS continues to develop further ways to engage children. In May 2014 it launched New Zealand's first ever web series aimed at children, Nia's Extra Ordinary Life. While Nia's Extra Ordinary Life, which follows ten-year-old Nia in her hometown of Tinopai, is aimed at children with little or no te reo skills, in 2014 the MTS will also broadcast two new full immersion Māori language programmes aimed at children on the Te Reo channel; Dora the Explorer and SpongeBob SquarePants. 
Dora the Explorer will be translated into a national and thus standardised form of te reo Māori so the target audience of children aged one to five can be exposed to the language at a young age when language acquisition is easier. Whereas, for SpongeBob SquarePants, each character will have a different iwi dialect as the series has a wider audience (MTS, 2013c). Māori language expert and co-ordinator of the project, Pania Papa, stated, "this will teach tamariki [children] that there are differences within the language and help revitalise the different dialects" (ibid.). This is important in enhancing the skills of children who already speak te reo, as well as key to upholding the integrity of the language, an issue discussed in more detail below (ibid.).

In compliance with the MTS Act 2003 the MTS is also required to provide programming for those learning te reo Māori. Techniques one and three of the 2003 MLS acknowledge that in order for the language to be revitalised, people's language skills must be strengthened and educational opportunities for learning te reo Māori increased. In its first full year on air approximately 274 hours was devoted to Māori language learning programming (MTS, 2005b, p. 27). This offering has remained consistent with the MTS screening approximately 276 hours of original Māori language learning programming in 2012 (MTS, 2013b, p. 10). These programmes were targeted at all levels of learners including, children, beginners and intermediate-advanced learners through programmes such as Pūkoro, Tōku Reo and Ako respectively. This content enables all age groups to participate in language uplift. This is crucial to language revitalisation because as Fishman (1997) argues, the language must be used between generations in order for it to become a living language and people's skills must be strengthened according to the 2003 MLS. This programming has also been recognised for its quality and contribution to language revitalisation with Ako receiving a nomination for Best Māori Language programme at the Qantas Film and Television Awards in 2010. The MTS continues to improve its contribution to language uplift through educational programming. Its latest strategy has been the 2012 implementation of a schedule of daily language tuition programming from 10:00am-3:00pm on week days, which provides resources for viewers to up-skill and develop their language proficiency (MTS, 2013b, p. 4).

While programming that is targeted at language learners is important to the language revitalisation process, the MTS is also conscious that in order to keep a 
language alive it must engage with, and cater to those, already fluent in te reo Māori. This is key to intergenerational language use and even those already fluent should be provided with the opportunity to strengthen their language skills via te reo Māori programming. The launch of the Te Reo channel in 2008 was a key strategy for achieving this as Te Reo was developed to further enhance the profile and status of te reo Māori and caters to the specific needs of the MTS's core audience, "those being fluent Māori language speakers and second language speakers” (MTS, 2008b, p. 3). This channel includes programmes such as: Waka Huia, which documents key moments in Māori history and the figures present in them; E Tū Kahikatea, which provides a space for prominent kaumātua to share their stories and memories of Māori history; and Kōwhao Rau, which provides a space for Ngāpuhi kaumātua who may not otherwise be heard to share their stories. These programmes engage those fluent in te reo Māori and also enable the MTS to collect and archive the Māori language by creating a database of oral histories which is important for guaranteeing the integrity or tikanga of te reo Māori (to be discussed in detail below). The awards that programmes on the Te Reo channel have received exemplify that the MTS is not just making content to meet its language objectives. The awards suggest that it ensures its programming is of the highest standard so it attracts the widest possible audience, without compromising the integrity of te reo Māori. Programmes screened on the Te Reo channel that have received awards include E Tü Kahikatea and Whare Taonga which won the Qantas NZ Film and Television Award for the Best Māori Language Programme in 2010 and 2012 respectively. In providing a majority of programming in te reo, as well as ensuring that this programming is of a high-quality and caters to a variety of groups, including children, those learning te reo and fluent speakers, the MTS is actively supporting a number of the Government's 2003 MLS techniques. In doing so, this enables the Service to meet is primary goal of contributing to the revitalisation of te reo me ngā tikanga Māori.

\section{Measures of Success}

Although statistics illustrate how the MTS is attempting to contribute to strengthening te reo Māori, it is difficult for the MTS to measure whether these strategies are effective at contributing to an increase in speakers of te reo Māori. For most broadcasters, ratings are the primary statistic that is privileged and are the 
means through which an understanding of the impact and success of a broadcaster can be garnered. However, for the MTS, as a non-commercial broadcaster with a cultural mandate, ratings or audience numbers are not the most important statistic. Although, as chapter three will argue, ratings and audience growth does influence the MTS as an audience is needed to revitalise a language, what the broadcaster states is most important in its measure of success is how well its content contributes to language revitalisation. This is reflected by such discourse as; "Although ratings remain an important component of measuring our performance, ultimately the performance of Māori Television will continue to be benchmarked against the strengthening of Māori language and culture" (MTS, 2007b, p. 11); and "ultimately our future performance will be measured by our effectiveness as an organisation that makes an important contribution to te reo Māori" (MTS, 2008b, p. 9). Measuring the MTS's contribution to language revitalisation is difficult because, as chapter one highlights, there is no one factor that allows a language to be revitalised. Research undertaken by TPK in 2006 and 2011 provides a means for the MTS to see how it is contributing to te reo Māori revitalisation. TPK's 2006 Report on the Health of the Māori Language found that 95 per cent of Māori and 70 per cent of non-Māori agreed that the MTS was a "good thing" for the revitalisation of te reo Māori (TPK, 2008, iv). Additionally, research released in 2011 by TPK found that "those people who are using the Māori language more than they did twelve months earlier have consistently higher rates of Māori Television viewership than others" (TPK, 2011, p. 2). It also found that people who were learning te reo Māori were actively watching the MTS and that even those with a 'high proficiency' in te reo Māori were improving their skills through watching the Service (ibid., p 3-4). Overall the 2011 Report claimed that the MTS was having a "marked positive contributing impact on Māori language revitalisation" (ibid, p. 4). The MTS has also undertaken its own research to gauge its contribution to te reo Māori revitalisation. Its 2013 Annual Report states that 57 per cent of Māori and 25 per cent of New Zealanders asked agreed their understanding of Māori language had improved by watching the MTS (p. 10). It also found that interest in learning the Māori language increased by watching the MTS with 51 per cent of Māori and 19 per cent of New Zealanders canvassed agreeing with this statement (ibid.). These statements and statistics indicate that the strategies the MTS has employed to revitalise language are considered effective strategies for enabling and 
encouraging audiences to strengthen their language skills. However, as chapters three and five will highlight, when audience numbers and the present health of te reo Māori is considered, this situation is perhaps not as optimistic as these statistics suggest.

\section{The MTS's Māori Language Plan}

In order to provide itself with measurable goals for which to track its contribution to the 2003 MLS and Māori language uplift, the MTS has also undertaken the development of its own MLS. The MTS's own MLS was intended to complement the Government's 2003 MLS. Although details of the MTS's Māori language strategy to date have not been formally released, the MTS's Statements of Intent and Annual Reports do suggest that the plan is being created so the MTS has some direct and measureable goals for it to achieve. This is evident in the 2010 Annual Report which argues that the purpose of the MTS's Māori language strategy is to ensure that the MTS is accountable for the quality and quantity of te reo on the service and that the MTS's programming meets its statutory objective of revitalising te reo Māori (p. 1011). As chapter five will highlight, it seems likely the MTS will release its Māori language strategy in 2014 when the Government's revised MLS is announced. This would allow it to align itself with government and other agencies te reo Māori revitalisation plans. However, it could also be argued that this increased effort to develop a Māori language strategy reflects the MTS attempting to prove its legitimacy because, as chapter four will outline in detail, the MTS's actions cannot be separated from government imperatives and proving its worth could be key to the future of the Service.

\section{Quality}

Although quantity of te reo content is one measure of the broadcaster's contribution to language revitalisation, the MTS's also needs to ensure that what is being broadcast is of high-quality. This is because the MTS is a high-profile organisation that is key to language learning and therefore, if the quality of the language is not upheld, this can compromise both the integrity of te reo Māori and the MTS. While the MTS Act 2003 states that the MTS must be a "high-quality" broadcaster, it does not make any reference to what is meant by this (sec. 8.1). High-quality in the context 
of the MTS Act 2003 could refer to various aspects of the broadcaster's practice. This is evident in a report made for NZoA by academic Peter Thompson (2006) which identifies six different dimensions of quality in broadcast television including the quality of: media institutions, production, content, distribution, audience and reception. Furthermore, the Government's 2003 MLS does not make references to the role of quality in language revitalisation, suggesting this is not an essential part of language revitalisation even though the language experts discussed below argue that this is not the case. Despite this, the MTS does note the broadcaster is dedicated to ensuring that "New Zealanders experience quality reo and tikanga Māori" (MTS, 2004 b, p. 14) and that it is continuing to improve and maintain its reo quality to ensure "the integrity of te reo and tikanga Māori is maintained throughout the programming schedule" (MTS, 2006a, p. 12). This suggests that for the MTS, highquality has been interpreted as the quality of te reo broadcast by the Service. Some of the previously discussed actions of the broadcaster highlight the MTS's dedication to promoting quality language through such means as archiving the language in its programming for future generations, ensuring that different dialects of the reo are heard on screen and through developing a Māori Television Service Māori Language Plan. The MTS also attempts to ensure its language meets quality expectations by consulting with iwi and hapu so as to "ensure that the dialectical and cultural diversity of Māori is reflected in its programming, and [to] safeguard and enhance the cultural integrity of the programming" (MTS, 2008b, p. 12). However, no evidence of how this is done is provided in their Statements of Intent or Annual Reports. Another means through which quality is checked by the MTS is by working with Te Taura Whiri i te Reo Māori who review the programmes to ensure they are appropriate for the revitalisation and learning of te reo Māori (MTS, 2006a, p. 25). Engaging with Te Taura Whiri i te Reo Māori, and other stakeholders such as the MTS's kaumātua, TMP, TPK, Ngā Aho Whakaari (the Māori screen production body) and language experts, provides a check on Māori programming to ensure that it is of an appropriate level of quality to be broadcast for the purpose of language uplift. Due to the vague notions of "high-quality" put forth in its governing policy documents and, as the following section will highlight, the importance of maintaining the quality of te reo to the integrity of the language, the policy team created to undertake the review of the MTS 
Act 2003 saw addressing the issue of the quality of te reo broadcast as a primary issue.

\section{Review of Legislation}

The MTS Act 2003 was required to undergo a review five years after the genesis of the broadcaster in order to assess its operation and effectiveness. The purpose of this review, as outlined in section 56 of the MTS Act 2003, was to "consider the extent to which the legislation currently enables the MTS to meet the aspirations set out in the Preamble: namely that the Crown meets its Treaty-based commitment to protect, preserve and promote te reo Māori through the establishment of the MTS" (TKOM, 2009, p. 2). This review was carried out by Te Kāhui O Māhutonga (TKOM), an independent panel established by TPK for the purpose of completing the review. The review panel consisted of Tainui Stephens, Hone Edwards and Jane Hūira whose combined expertise included experience in broadcasting legislation, the television industry and te reo Māori. The findings of this review were submitted to Parliament with recommendations for changes to the legislation. While the report contextualises and recommends a number of alterations to the MTS Act 2003, this chapter will focus on how the review addressed the issue of quality. A number of the other key recommendations made in the report will also be considered throughout this thesis.

As the report acknowledges, television is regarded as a powerful medium and therefore the work of the MTS is significant in the regeneration of te reo Māori (TKOM, 2009, p. 11). Although the review acknowledges that the programming schedule of the MTS does promote Māori language and culture, TKOM's research found the legislation did not have any provision regarding the quality of language on air. For some stakeholders this was a concern as they believed "there needs to be higher standards regarding language" due to the pedagogical function of the MTS (ibid.). Also, without language standards, the MTS "unwittingly entrenches and normalises incorrect Māori language, rather than offer quality language for the benefit of Māori language learners and others" (ibid., p. 13). Furthermore, by unintentionally broadcasting incorrect reo, some Māori raised concerns that this could lead to the dilution of the 'Māoriness' of the language because as Sir James Hēnare said, "words are the clothing of our thoughts" meaning the language is not just words but should also reflect a Māori way of thinking (ibid.). While it is difficult 
to measure language outputs besides quantitative data such as amount of words or minutes of te reo Māori spoken on air, TKOM attempted to reconcile this problem. The panel recommended a change be made to section 8 of the MTS Act 2003 so it would state: "language that is correct in articulation and appropriate in expression" in order to increase the MTS's accountability with regard to quality (ibid., p. 14). This recommendation is aimed at enhancing the MTS's function of promoting te reo Māori me ngā tikanga Māori.

\section{MTS Act Amendment}

In November 2013, the MTS Act Amendment Bill was debated by Parliament and these proposed changes present in the Bill were a result of the recommendations made in the TKOM report. One of the principal changes that resulted from the Bill was an amendment to section 8 of the MTS Act 2003, which outlines the functions of the service. The Amendment changed a principal function of the MTS to, the "protection and promotion of te reo Māori me ona tikanga Māori" (emphasis added, MTS Act, 2013, sec. 8). The italicised word represents the change from the MTS Act 2003 and this change, as defined in the MTS Amendment Act 2014, has altered the purpose of the broadcaster to the promotion of the Māori language and its accepted and customary usage (ibid., sec. 6). This Amendment is thought to "strengthen the focus of Māori Television on its work to promote the Māori Language" by ensuring that the context in which the language is used and how it is used enhances the integrity of te reo Māori (Sharples, 2013a). For former MP Claudette Hauiti (2013) this means "programmes like Mister Ed dubbed over in te reo Māori are no longer acceptable" as "the context must enhance the mana and integrity of the reo" and in the context of dubbed programming this could compromise the cultural authenticity of the language (in Hansard, 2013). Furthermore, co-leader of the Māori Party Pita Sharples believes this change recognises that te reo Māori is a part of the culture, and not something that exists side by side with Māori customs but embodies them (ibid.). This change represents a shift in the MTS's governing policy towards one that focuses on the quality of te reo Māori which, although an integral part of language revitalisation, was less overt in the MTS's initial years where quantity was prioritised.

Despite this change only becoming law in November 2013, recent choices made by the MTS suggest it pre-empted this change and is already moving towards 
ensuring it is more accountable and conscious of its te reo content being of a highquality. This can be seen with the commissioning of programming such as SpongeBob SquarePants, which by being altered specifically for the MTS and by being broadcast in different dialects of te reo then it could be argued that this ensures that the mana (strength) of the language and people is upheld. It can also be seen in its focus on creating programming that archives the language. A recent example of this is Iwi Anthems which first aired in 2013 and is dedicated to screening and preserving the haka and waiata of iwi throughout New Zealand. The increased attention to language learning programming, indicated by the dedicated since 2012 of a daily five hour time slot for this purpose, also reflects an increased focus on quality as it provides learners with the tools to articulate the language correctly. The change made to the MTS's legislation in 2013 suggests the future imperatives of the MTS are likely to expand on this progress towards safeguarding the integrity of te reo, and ensure the Service not only includes substantial amounts of te reo Māori content but that this content protects the 'Māoriness' of the language.

\section{Conclusion}

In order for a language to be revitalised it must be a used part of the everyday. The MTS can contribute to this by providing a schedule that predominately broadcasts in te reo Māori, allowing recognition of the language to strengthen via increased use, which the 2003 MLS acknowledges is a sound technique for language revitalisation. However, the MTS not only ensures this is achieved by providing a schedule which is predominantly in te reo Māori and through year-on-year increases its te reo content, but also contributes to language uplift by providing programming for all levels of te reo Māori speakers. As chapter one and the 2003 MLS highlight, if te reo Māori is to be revitalised, opportunities for language learning and strengthening language skills must also be prvoided. Both of these areas of programming have expanded since the Service first broadcast, reflecting the MTS's commitment to language revitalisation and government imperatives. In providing extensive te reo content for all speakers, studies suggest that the MTS has been successful in encouraging people to the language and strengthening their te reo use and skills (TPK 2008; TPK 2011). Although providing content in te reo Māori is important, this chapter highlights that for some stakeholders, other factors such as quality are also crucial to language 
revitalisation and therefore stakeholders' interests are a factor in shaping the MTS's policy.

The quality of te reo broadcast by the Service was an issue raised by the TKOM Report and reinforced by Māori stakeholders in the Report, who believed having no provisions for quality created the risk that the MTS may entrench te reo Māori that compromised the language. Recent steps have been taken to address this in the MTS's governing policy documents and this focus on quality is likely to be a key imperative of the Service in future Statements of Intent and Annual Reports. This change has also demonstrated the influence of stakeholders on the Service, in this case Māori language experts, and the role they have in shaping policy. What this discussion also reflects is that as the MTS grows and consolidates itself within the New Zealand television landscape, the MTS's focus will change. These changes will occur in response to it achieving goals, as new issues as a result of its actions are brought to light, and, as the following chapters will highlight, as changes to the environment in which it operates occur. According to Stephens (2004), before the establishment of the MTS, approximately only 15 hours of Māori programming was screened per week on television (p. 108). With the launch of the MTS this situation has changed significantly because in 2012 each week on the MTS's two channels approximately 111 hours of Māori programming was screened (MTS, 2012b, p. 11). As the MTS has significantly increased quantity, it now has the opportunity to focus on the quality of its te reo content and this is likely to become a key measure of the broadcaster's contribution to language revitalisation. 


\section{Chapter Three: Strategies for Audience Engagement and Language Revitalisation}

\section{Introduction}

In order for the MTS to achieve its primary aim of contributing to the promotion of te reo Māori, the MTS has had to implement a number of strategies. Although chapter two argues the MTS works to strengthen and revitalise te reo Māori by providing a television schedule that includes extensive te reo Māori content, this chapter will argue that the presence of this schedule alone cannot revitalise a language. People must watch the programming present on the MTS in order for the language to be revitalised. To demonstrate how the MTS engages audiences, the focus of this chapter is on the provision in the MTS Act 2003 that requires the MTS to appeal to a "broad viewing audience" (sec 8.1). The chapter argues that broad appeal is a crucial aspect of language revitalisation. For the MTS broad appeal refers to audience size, as well as a diverse audience of both Māori and non-Māori of various age groups. The chapter also considers the objective placed on the broadcaster by the MTS Act 2003 that it must be "technically available throughout New Zealand and practically accessible to as many people as reasonably possible" (sec 8.2(d)). Discussion of these imperatives and challenges to them demonstrates the importance of audience engagement strategies to language revitalisation and that the MTS is shaped by the pressures and tensions of its operating environment.

It could be argued that the imperative to appeal to a broad viewing audience is at odds with the MTS's language revitalisation objective. This is because appealing to a broad viewing audience has the potential to compromise the quality and quantity of te reo Māori on the broadcaster by encouraging the broadcaster to make programming for the largest common denominator. This argument is captured by the TKOM (2009) review which states that the MTS "cannot be encouraged to dilute its Māoriness by deferring to the Pākehā mainstream" (p. 16). However, the first section of this chapter argues that appealing to a broad viewing audience is beneficial for the MTS's language revitalisation aims. The MTS's Statements of Intent and Annual 
Reports are used to show that the MTS has branded itself as an inclusive broadcaster, for all New Zealanders and how this breaks down notions of the broadcaster being separatist will be discussed. Document analysis and discussion of the MTS's schedule is used to demonstrate that the MTS has ensured its programming caters to a broad viewing audience. The examples of ANZAC Day and sports coverage are discussed to show how the MTS uses content with national appeal to naturalise te reo Māori in the national imaginary. These strategies are integral to the revitalisation process because, as chapter one acknowledges, when a language is not a part of the everyday and its use is marginalised (as occurred in New Zealand in the early to mid-20 ${ }^{\text {th }}$ century) this accelerates its loss. This chapter also argues that these strategies of broad appeal have not come at the expense of targeting Māori, children, fluent speakers and those learning te reo. The Amendment that removes this imperative to broadcast to a broad viewing audience is also considered and it is argued that this change suggests a greater confidence in the MTS's ability to deliver on its mandate of language and cultural revitalisation.

The second half of this chapter argues that gaining more prominence in the MTS's governing policy documents in an era of technological change, is ensuring audiences are able to access the broadcaster and engage with its content. The MTS Act 2003 requires the broadcaster to be available to as many New Zealanders as possible. This chapter considers how this was achieved in the initial years of the MTS's broadcasting. It then discusses how the advent of digital technologies has complicated the transmission process and opened up a number of new opportunities with regard to transmission. From this, the latter section of this chapter discusses how the MTS has embraced new technologies to not just further its transmission capabilities (broadening its audience reach) but how this and other digital technologies enable the broadcaster to enhance its language revitalisation function. Specifically, the last section of this chapter discusses how the MTS is using the internet to encourage audience engagement. This chapter argues that the technological shifts in the television industry might enable the MTS to deliver more comprehensibly on its language revitalisation mandate and that these shifts reflect that the MTS must respond to the greater environment in which it exists. 


\section{Appeals to a Broad Viewing Audience}

In each SOI from 2004-2011 one of the MTS's major objectives has included the imperative to appeal to a "broad viewing audience" or "all New Zealanders" (MTS, 2004 b, p. 13). This need to appeal to a broad viewing audience during this period is also emphasised in the MTS's Annual Reports. Its first Annual Report stated that the channel aimed to be an "inclusive channel with something for everyone" (MTS, 2004a, p.6) and further reports reaffirmed this imperative through language such as "appeal to both Māori and non-Māori viewers" (MTS, 2006b, p. 13) and "grow the widest possible audience" (MTS, 2011b, p. 5). These statements suggest that for the MTS, appealing to a broad viewing audience refers to both growing its audience size and ensuring this audience is one that consists of both Māori and non-Māori and viewers of varying demographics. These statements highlight that the imperative placed on the broadcaster by the MTS Act 2003 to appeal to a "broad viewing audience" is a function the MTS has privileged from 2004-2011. However, the following section will demonstrate that this imperative serves multiple functions besides allowing the Service to meet its legislative aims.

In the MTS's policy documents the imperative is clearly linked to its role as a tool for the revitalisation of te reo Māori. The MTS is aware that in order for te reo Māori to be revitalised, it must be normalised and naturalised and that crucial to this is all New Zealanders seeing and hearing the Māori language on television. This is emphasised in the MTS's 2010 Annual Report, which argues:

The power of the media, in particular television, is integral to raising the profile and awareness of Māori language. Broadcasting it directly into the homes of New Zealanders, especially at times when people are available to watch, can only serve to grow knowledge, achieve normality, promote acceptance, and endorse our language as a taonga to be valued, embraced and spoken. (p. 5)

The importance of garnering a broad viewing audience for language revitalisation is also emphasised in statements such as the MTS must work to ensure the "development of consistent and engaged audiences" because "the exposure of Māori language programming to all levels of speakers and non-speakers will help to ensure" that the MTS successfully contributes to the revitalisation of te reo Māori (ibid., p.14). Finally, the MTS realises people must be given the opportunity and resources to learn 
the language via the broadcaster which is a key part of the Government's 2003 MLS. While providing language learning programming (discussed in chapter two) is one means through which this is achieved, the MTS must also make sure that language acquisition is made possible in its general programming. The MTS acknowledges this in its 2005 Annual Report, which states:

Normalisation of te reo Māori will occur if people are given the opportunity to increase their knowledge and understanding. Given the small percentage of fluent te reo Māori speakers in New Zealand, we must find ways in which to ensure more New Zealanders are able to access and understand our programmes. We will continue existing and implement new initiatives such as increasing levels of English sub-titling, captioning and sign posting, to meet the needs of our non-fluent viewers. (p. 14)

This normalisation of the language is important as it has the potential to encourage people to the language and acquire te reo Māori skills. Some argue broadcasting in English and subtitling programming was not the purpose of the broadcaster as it was created for Māori speakers. However, as the following chapter will discuss further, the majority of New Zealanders (both Māori and non-Māori) are not fluent in te reo and consequently a balance must be found between broadcasting content for fluent and non-fluent speakers in order for the language to be revitalised (RNZ, 2014). Therefore, the MTS's policy documents suggest the MTS is aware that attracting and maintaining a broad viewing audience throughout its schedule is crucial to language uplift because, in doing so, the MTS works to strengthen the broader recognition of the Māori language and perhaps expands its use.

There is, however, other motivations for the focus on broad (particularly nonMāori) appeal in the MTS's governing policy documents. When these statements are considered in relation to the environment from which the MTS emerged, it could be argued that the need to appeal to a non-Māori audience is related to a long standing hostility towards things Māori in New Zealand's mediated public sphere. As noted in chapter one, the MTS emerged into an environment that was unsympathetic towards the broadcaster. Furthermore, because of the preceding ATN debacle, much pressure was placed on the MTS to ensure the same mistakes were not made. The broad viewing imperative could also have been deployed to overcome notions of the broadcaster being separatist or only for Māori. Separatist discourse is an issue the MTS has had to overcome because as many scholars (Abel 1997; Smith \& Abel 2008; 
Spoonley and Hirsch 1990; Walker 2004) acknowledge, Māori initiatives are often positioned as for 'them' (Māori) and outside of, or in opposition to, the national 'us'. While appealing to a broad viewing audience in order to counter negative and separatist understandings of things Māori and encouraging people to watch the Service is one possible reason for pursuing this imperative, the following chapter argues that this broad viewing audience can also be useful in ensuring the future of the Service. Consequently, this provides another reason for the prioritisation of this imperative.

It is also worth noting that the imperative to attract a "broad viewing audience" included in the MTS Act 2003 is not necessarily because of the key role that a broad viewing audience for the Service can have in language revitalisation. Instead it could be argued that this imperative, along with the role the MTS is meant to play in accordance with the MTS Act 2003 of enriching "New Zealand's society, culture and heritage" (MTS Act, 2003, sec 8.1), was a result of the Labour Government's "nation building agenda" that was in place at the time of the legislation's enactment (Skilling 2010). Under Prime Minister Helen Clark, a key priority of the Labour Party was to foster a sense of nationalism and the Government identified broadcasting as a means through which this could be achieved (Lawn \& Beatty 2005; Skilling 2010a). Regardless of its initial intentions, the MTS has used this imperative to meet its statutory requirements of appealing "to a broad viewing audience" and enriching "New Zealand's society, culture and heritage," while simultaneously using it to achieve its primary aim to "promote te reo Māori me ngā tikanga Māori" (MTS Act, 2003, sec. 8).

In order to generate this broad viewing audience the MTS has concentrated on branding itself to the New Zealand public as an inclusive broadcaster. Jo Smith and Sue Abel (2008) acknowledge that the MTS's “tactic of naturalising te reo and tikanga Māori extends itself to every level of the channel's organisation, including the station promotion" (p. 5). The MTS's original tagline is "mā rātou, mā mātou, mā koutou, mā tātou" (for them, for us, for you, for everyone). The MTS in its Briefing to the Incoming Ministers (2011c) explains that this tagline "effectively summarises our intent that Māori Television be the 'face of New Zealand' and a television organisation which offers something for all New Zealanders" (p. 8). Branding itself in this way 
breaks downs notions of the broadcaster being separatist or only for Māori. The MTS recognises it must overcome such discourse:

Māori Television's success in promoting and revitalising te reo and tikanga Māori lies not just in our ability to reach Māori viewers, but in our ability to also engage with non-Māori New Zealanders and encourage them to join us on our journey. With this in mind, Māori Television has set about ensuring that all New Zealanders are aware that this channel belongs to each of them. (MTS, 2006b, p. 3)

Branding discourse that focuses on the MTS as being for everyone, all New Zealanders and the 'face of Aotearoa New Zealand', attempts to overcome such anxieties about separatism and encourages all New Zealanders to watch the MTS. However, as the following chapter will highlight there are tensions in such branding because, as the earlier TKOM (2009) quote argues, in broadcasting to all, or to a Pākehā mainstream audience, this has the potential to dilute the Māori aspects of the broadcaster (p. 16).

Although branding is one means through which the MTS creates inclusivity, the primary way the MTS attempts to do this is by ensuring its television schedule is well balanced, with content which appeals to a variety of audiences. The importance of the schedule in doing this is articulated in the 2006 Annual Report, which states "significant focus has gone into achieving a schedule that will not only attract viewers but also retain them," encouraging them to view other programmes on the Service (p. 16). The MTS does this by taking already proven television formats and re-crafting them in a Māori way through the use of te reo and tikanga. Programmes where this can be seen include: the game show It's in the Bag; the talent show Homai Te Pakipaki; the cooking show Kai time on the Road; and reality television renovation programme Mitre 10 DIY Marae (Smith 2006; Smith \& de Bruin, 2012). Broadcasting programmes that use already established television formats, which audiences are familiar with, enables audiences to more easily engage and understand the programmes, despite their Māori aspects. This helps the language revitalisation process in two ways. Firstly, it normalises and naturalises te reo Māori for a broad viewing audience. Secondly, as Smith and Abel (2008) note, the MTS's programming aimed at a broad viewing audience, "incorporates and plants a language 'seed' that might encourage non-Māori speakers to the language" and to te ao Māori more generally (p. 6). Presenting te reo Māori in the schedule in such a way that a broad viewing audience 
can engage with it is important because research shows that "100 per cent te reo Māori programmes are a barrier to viewing for the general population" (both Māori and non-Māori) (RNZ, 2014). By broadcasting in a mix of English and te reo Māori, as well as by subtitling content, the MTS makes content more accessible to viewers with little or no knowledge of te reo Māori (MTS, 2006b, p. 14). Creating a cultural schedule for a mainstream audience shows an attempt by the MTS to naturalise and normalise te reo Māori for viewers, increasing recognition of the language and by extension enhancing the mana (prestige) of te reo. Additionally, appealing to all can also work as an incentive to encourage viewers to actively learn te reo Māori.

In order to attract audiences with its programming the MTS also attempts to do what other broadcasters do not. Smith and Abel (2008) argue that the MTS's current affairs programme Native Affairs is a key example of this, as it was first aired in 2007, at a time when news media in New Zealand was under severe threat (p. 5). The MTS also differentiates itself from other broadcasters by broadcasting locally produced content in quantities unseen on other New Zealand FTA networks. In 2012 the MTS's schedule consisted of 96 per cent locally produced content across both channels (MTS, 2013b, p. 11) and the MTS's flagship channel's schedule consisted of 73 per cent locally produced content (NZoA, 2013b, p. 8). This is significantly more than other New Zealand FTA broadcasters, with TV One and TV3's schedule's in 2012 being comprised of 50 per cent and 33 per cent locally produced content respectively (ibid.). These actions (and those discussed below) have resulted in the MTS being labelled by some as New Zealand's default public service broadcaster. Statements made at the final reading of the MTS Act Amendment Bill 2013 illustrate this. MP Tau Henare stated "I think many people would argue at the moment that Māori Television has become the default state broadcaster in New Zealand" (in Hansard, 2013). MP Rino Tirikatene believes that the MTS "is, by default, our New Zealand state broadcaster" (ibid.). While the MTS being positioned as New Zealand's default public service broadcaster creates potential tensions with its cultural revitalisation imperatives, the use of this as a strategy for garnering audiences will first be outlined and the tensions of this discussed in the following chapter. For now, in filling gaps in the market, particularly with locally produced and public service content (to be discussed in more detail below), the MTS is able to capture a disenfranchised audience hungry for public service content. 


\section{Programming with National Appeal}

Another way in which the MTS has worked to capture a disenfranchised audience and position itself as New Zealand's default public service broadcaster is through providing programming with national appeal. Providing programming with national appeal also further breaks down notions of Māori initiatives being separatist and, as chapter four will expand on, has the potential to counter the negative attitudes held by some that surround the MTS's launch. In producing programming with national appeal, but producing this programming in a Māori way, the MTS is contributing to the revitalisation of te reo Māori as it is making te reo part of the national imagery and attracting viewers who ordinarily may not watch the MTS. This has the potential to strengthen recognition of the Māori language, a key technique for language uplift identified by the 2003 MLS.

The MTS's ANZAC Day coverage is a compelling example of this strategy in action. ANZAC Day is an annual New Zealand national public holiday held on 25 April designed to commemorate all New Zealanders killed in war, and to honour returned service-men and service-women. Since 2006, the MTS has differentiated itself from other broadcasters by ensuring coverage of the event dominates its schedule on this day. This attracts people to the Service as this in-depth coverage is not found elsewhere on other New Zealand television broadcasters. This is key to attracting a broad audience as it grows the audience and creates an audience of Māori and nonMāori by appealing to national sentiment. Each year this coverage is presented from the perspective of te ao Māori with a large portion being spoken in te reo Māori (Abel, 2013a, p. 208). Abel (2013a) provides evidence of this claim in her comments on the MTS's 2007 ANZAC Day coverage:

Co-presenter Julian Wilcox spoke in Māori as often as he did in English, and his English was usually an addition to, rather than a translation of, his address in te reo. A Māori presence was also foregrounded in the wide use of Māori sources telling ANZAC Day stories. When such sources spoke in te reo, English subtitles were not always provided. (ibid.)

Privileging te reo Māori by not always translating or subtitling te reo, as well as by using it as frequently as English, is important as it contributes to its normalisation. Furthermore, not translating or sub-titling all aspects of the programming has the potential to invite people to be more attentive to the language being spoken and to its 
context ${ }^{2}$. Although it could be argued that providing coverage which, at times, the majority of the audience cannot understand, could turn away viewers, it would seem that the audience response to this coverage has been positive. Many non-Māori contacted the MTS to acknowledge their appreciation of the ANZAC Day coverage (Abel, 2013a, p. 201; 2013b, p. 117). One viewer (when referring to the 2007 ANZAC Day coverage) stated "in my mind ANZAC Day 2007 was Māori TV's coming of age. Well done. Kia Kaha [be strong]" (Abel, 2013a, p. 201). Furthermore, Abel (2013b) notes in her research on the MTS's 2008 ANZAC Day coverage that the viewers in her largely non-Māori data set "either understood te reo or were very prepared to not understand all the commentary so long as enough subtitles were provided to enable them to understand most of what was going on" (Abel, 2013b, p. 118) ${ }^{3}$. The MTS itself also acknowledges that ANZAC Day coverage has been integral to increasing its audience, with high audience numbers on this day. This growth in its ANZAC Day audience year-on-year has the potential to encourage audiences back to the broadcaster and entrench te reo Māori and te ao Māori in the national imaginary. In its 2006 Annual Report it stated that the:

2006 ANZAC Day broadcast was clearly the channel's most successful programming initiative, particularly with regard to its level of appeal to many New Zealanders. And we must not fail to recognise the success of the strategy behind the broadcast; that being its use as a positive mechanism to promote te reo and te ao Māori. (p. 6)

Interest in the Service's ANZAC Day coverage continues to grow as the MTS's 2013 ANZAC Day audience grew by 37 per cent from 2012, with 470,000 people tuning in throughout the day (MTS, 2013b, p. 4). Given this, the MTS's strategy to engage viewers by providing coverage of national events (especially those not covered extensively by other channels) has worked successfully to increase viewers. This in turn, as the MTS acknowledges, can be used as a "positive mechanism to promote te reo and te ao Māori” by exposing more people to the language (MTS, 2006b, p. 6).

\footnotetext{
${ }^{2}$ This invokes Barry Barclay's notion of "talking in". Talking in can be understood as privileging one's own language and the idea that Māori have the right to communicate with each other in their own language (see Barclay, 1990).

${ }^{3}$ Abel's data set consisted of 312 email and online responses to Māori Television's 2008 ANZAC Day coverage. Of those 312 viewers, Abel notes that, "[a]bout 30 of these responses were clearly from Māori viewers because of the names given or because identification as Māori was part of the content of the message. A similar number identified themselves as Pākehā/European/non-Māori. It was clear from context that the majority of the remainder were from non-Māori viewers" (Abel, 2013b, p. 117).
} 
The MTS has also used sports often not covered by other FTA broadcasters to grow and diversify its audience. Sport is an integral part of New Zealand's national identity (Turner 2004) and the MTS has used this attachment to sport as a strategy to attract viewers. This strategy was acknowledged in its 2006 Annual Report which states that "sport is a key strategy to attract audiences to Māori Television and to build wider audience appeal" (p. 17). One of the first ways it implemented this strategy was by branding itself as the channel for New Zealand basketball coverage. This started with its coverage of the New Zealand Tall Blacks' series decider against the Australian Boomers in 2006. This strategy to attract viewers through coverage of New Zealand basketball was further advanced in 2008 when the MTS secured the rights to the Breakers games (the only New Zealand basketball team in the Australian National Basketball league). Promotional discourse surrounding this event claimed that "once neglected by the major networks basketball was given a new lease of life on Māori Television" (MTS, 2014b). Although pay-for-view network SKY has since taken back coverage rights of the Breakers, the MTS utilised the coverage of the Breakers' games strategically by broadcasting the commentary of selected matches in te reo Māori (ibid.). This emphases that not only does the MTS use sport to appeal to a broad viewing audience, but it also uses this strategy to expose a wide and potentially new audience to te reo Māori in order to naturalise and revitalise it.

While coverage of the Breakers was a key initiative in the MTS's use of sports programming, the most notable example of this strategy was the MTS's 2011 Rugby World Cup (RWC) coverage. The MTS saw the RWC as an opportunity for language uplift, arguing that its coverage would bring "a unique Indigenous point of view to the coverage" and "result in language and audience benefits" (MTS, 2010b, p. 6) by giving "new viewers a compelling reason to tune in and stay with Māori Television during the tournament and beyond" (ibid., p. 10). Due to these reasons, the MTS made a bid for the exclusive RWC FTA rights. However, barriers from both the public and political arena prevented the MTS from securing exclusive rights. Jo Smith and Stephen Turner (2013) argue that "public outcry" occurred due to the prospect of 10 per cent of the commentary being in te reo Māori (p. 280). Others argued that the MTS's limited transmission (only 90 per cent of the New Zealand population via UHF) did not make it the preferable choice, despite FTA broadcasters TV3 and Prime also experiencing similar transmission restrictions (ibid.). Further dissent was added 
when right-wing media and political commentator Michael Laws said to his RadioLive listeners “that he'd trust Māori Television's ability to broadcast the Rugby World Cup as he would a small child with a knife" (MTS, 2014b). Issues were also raised over the financial backing that was given by TPK and the Ministry of Māori Affairs to support the MTS's bid which led to the in-power National Party providing financial backing in support of state-owned TVNZ's bid (Smith and Turner, 2013, p. 280).

What these arguments do not consider is that the MTS has positioned itself as a channel for New Zealand rugby. Beginning in 2004 with its broadcasting of the Māori All Blacks' Churchill Cup win, the MTS has become the home of the Māori All Blacks. It broadcasts their matches and has screened a number of documentaries and feature stories on the team (MTS, 2014b). Alongside providing a space for Māori rugby, it also broadcast provincial New Zealand rugby games of varying levels, such as the Auckland inter-rugby club Fox Memorial Shield game and Pacific rugby tournament the Pacific Rugby Cup (ibid.). Recently, it has also become the only FTA broadcaster which screens coverage of rugby league team the Warriors matches. All of these actions highlight that the MTS is dedicated to providing a space for New Zealand rugby on its channels.

Considering the important role the MTS has played in supporting local rugby, the negative political, public and industry environment surrounding its RWC bid seems unwarranted. Eventually, to resolve the tensions outlined above, and to prevent a bidding war, a three-way deal was struck between the primary FTA New Zealand broadcasters (TVNZ, TV3 and the MTS). This resulted in the MTS being awarded the rights to air all 48 RWC matches, more than any other New Zealand FTA broadcaster. Despite the negative attitudes towards the broadcaster that surrounded their bid, the MTS's RWC coverage attracted significant audiences. During the RWC the MTS delivered te reo and tikanga Māori to the largest audiences in its history with 2.6 million viewers watching the MTS's broadcasts in both September and October 2011 (MTS, 2012b, p.4). The MTS also believe that their coverage raised the status of te reo Māori as their 2012 Annual Report states "comprehensive coverage of the tournament also attracted over 560,000 new viewers" (ibid.). Attracting such large 
audiences allowed the MTS to raise recognition of te reo because as their 2012 Annual Report acknowledges:

During the Rugby World Cup, a specific Māori language strategy was developed to maximise the opportunity, both in the lead up period and during the tournament itself. This included bi-lingual broadcasts on Māori Television, 100\% Māori language broadcasts on Te Reo, the development of special Māori language tutorials for broadcast during the games and viewer competitions to encourage language acquisition. (ibid.).

The attraction of new viewers to the Service, and the broadcasting of commentary in te reo, as well as its other language learning strategies during this time, contributed to language revitalisation by increasing recognition and by providing people with the opportunity to learn the language. These are key techniques for language revitalisation as outlined in the 2003 MLS. Therefore, the RWC coverage was particularly significant as an event to attract new viewers and placed te reo Māori into the national imaginary, normalising te reo Māori. Thus, this recognises the value of sport and national events as a mechanism for language uplift for the broadcaster.

The MTS continues to focus on sport as a method to attract audiences and expose them to te reo Māori. The most recent example of this is the MTS securing the FTA rights to broadcast select games from the ASB Netball Championships. The MTS started screening delayed coverage of one game in each round on the Te Reo channel in March 2014. The commentary is entirely in te reo Māori and illustrates the MTS's commitment to increasing its broad viewership not just for its flagship channel, Māori Television, but also for its second channel, Te Reo. This is supported by the MTS's General Manager of Programming Haunui Royal, who says "the agreement to screen the netball championships marks a significant step forward for the Te Reo Channel" (Mentjox, 2014). Therefore, the MTS continues to recognise the importance of sport as a programming tool which can be used to differentiate itself from other channels, appeal to a broad viewing audience, and encourage that audience to continue to tune into the MTS, while exposing them to te reo Māori. In the process te reo is normalised and naturalised, and New Zealanders are provided with the opportunity to use the language.

\section{Language Learners, Fluent Speakers, Children and Youth}


While being an inclusive broadcaster requires the MTS to utilise programming that appeals to the masses, it also requires the MTS to ensure that it has programming suitable for those learning te reo Māori or wishing to improve their te reo Māori, those fluent in te reo Māori, and children and youth. As the previous chapter acknowledges, the MTS has a number of programmes that are aimed at providing for all levels of language learners. Additionally, the implementation in 2012 of a day-time programming schedule dedicated to language acquisition, as well as language acquisition programming being made available online (to be discussed in detail below) means that all those wishing to use the Service as a site for language learning are catered for. Children's programming has continued to grow since the genesis of the MTS (as highlighted in chapter two) and this growth is likely to continue with the launch of Dora the Explorer, SpongeBob SquarePants and Nia's Extra Ordinary Life. Like children, young adults are a key target group as they are integral to the language revitalisation process because of their ability to more easily learn new languages and they ensure that the language remains intergenerational. While the MTS has always had programming content in its schedule that could appeal to youth, such as sports programme Code or comedy show Hardcase, until recently they had no content that was specifically targeted at youth only. The launch of the program Swagger in 2014 is evidence of the MTS's effort to cater to this group. Swagger allows youth to tell their stories on Māori Television by sending in videos via various social media apps including Snapchat, Instagram and Facebook (MTS, 2014b). While these examples demonstrate that the MTS does not sacrifice niche audiences in order to appeal to the masses, the following section highlights that the Service also caters for fluent speakers.

Although some argue that appealing to a broad viewing audience compromises the channels' core audience, te reo speakers, the MTS provides significant content targeted at speakers of te reo. The MTS's flagship channel, Māori Television offers content that could appeal to those fluent in te reo Māori, such as current affairs programmes like Native Affairs and the cultural content seen in programmes like The Kapa (where contestants are mentored by New Zealand's top Kapa Haka performers and perform and compete against others to be crowned Kapa Haka champions). However, in order to cater for those who want more immersion programming, the Te Reo channel provides this as it is a te reo immersion channel 
targeted at fluent speakers. Additionally, although the Te Reo channel is primarily aimed at those fluent in te reo Māori the MTS is also working to make it more appealing to a wider audience, who want a more immersive Māori experience or the opportunity to better their language skills. This strategy can be seen through the 2014 integration of programming into the Te Reo schedule which would appeal to those not just fluent in te reo Māori, including the ASB Netball Championship games, and children's programmes Dora the Explorer and SpongeBob SquarePants. Furthermore, as the number of those that are fluent or who can speak conversational te reo Māori increase, which the 2006 and 2011 TPK Reports' acknowledge the MTS is contributing to, then this has the potential to grow the MTS's audience as these audiences will be more inclined to engage with other content offered by the broadcaster.

\section{Audience Statistics}

Audience statistics are not the MTS primary measure of success, as the Service will always be measured by how well it contributes to language revitalisation. However, as the section above demonstrates, the MTS views attracting an audience of Māori and non-Māori as still important for naturalising and normalising the language. A discussion of audience statistics highlights that the MTS has been successful in garnering a diverse audience of Māori and non-Māori. In the MTS's 2012 Annual Report it highlighted that on average 64 per cent of Māori aged 5+ per month watched the broadcaster and on average 46 per cent of all New Zealanders 5+ per month tuned in (p. 11). Furthermore, Jim Mather noted that in 201277 per cent of the MTS's audience was non-Māori (cited in Abel, 2013b, p. 112). The MTS has also noted in its Annual Reports that the audience of the Service continues to grow yearon-year. Additionally, the MTS's monthly cume (the number of people who tuned into the Service in a month) demonstrates that many New Zealanders are watching the Service with 1.4 million viewers tuning in each month on average in 2013 (Nielsen, 2014). That is over a quarter of the New Zealand population. These statistics demonstrate that the MTS has a diverse audience of Māori and non-Māori and that the audience while not a majority of New Zealanders is still significant and continues to grow. 
Yet, when the MTS's audience share is considered in relation to rival FTA broadcasters, the potential impact of the Service on revitalising te reo Māori through broad appeal could be contested. The MTS's audience share (that is the number of viewers watching television at a given time) in 2013 was less than 1 per cent. Compared to other mainstream FTA broadcasters in the same year this is comparably less. In 2013 TVNZ's total audience share was 38.4 per cent and TV3's was 15 per cent (Nielsen, 2014). The MTS's low audience share has the potential to reduce its ability to revitalise te reo Māori because the more people who watch the Service and do so more frequently, the greater impact the MTS has. However, it must be remembered that the MTS's primary aim is not to be a mainstream broadcaster, but to revitalise te reo Māori. Given that over a quarter of New Zealanders view the Service each month and that this audience believes its content is positive for language revitalisation (demonstrated by the 2006 and 2011 TPK reports), then this thesis suggests the MTS is delivering on its mandate of cultural revitalisation by balancing broad appeal with cultural content.

\section{Removal of Broad Viewing Audience Imperative}

In the MTS's most recent Statements of Intent $(2012-2015 ; 2013-2016)$ there has been a rearticulation of the MTS's imagined audience. In the 2012-2015 and the 2013-2016 Statements of Intent, emphasis is no longer on how the MTS will appeal to and grow a broad viewing audience; instead the documents state that the MTS now aims to grow its Māori speaking audience and use the Te Reo channel to target "core and committed learners" of te reo Māori (MTS, 2013a, p. 9). When these Statements of Intent are considered in relation to the MTS Amendment Act 2014 it could be argued that the MTS pre-empted the legislative changes. The MTS Amendment Act 2014 has removed the imperative placed on the MTS to attract a "broad viewing audience" and has instead replaced this with a focus on prioritising audiences whose first language is Māori, people who have a high level of proficiency in te reo Māori and all those learning te reo Māori, especially young people and children ( $\sec 8.2$ (c)). When this is considered in relation to recent programming choices outlined above, such as the daily schedule devoted to language learning and the launch of SpongeBob SquarePants, this further exemplifies that the MTS is shifting towards focusing on 
growing its Māori speaking audience as opposed to placing a broad viewing audience as it primary focus.

This change could be argued to have a negative impact on the Service's audience size and diversity, and therefore its ability to promote te reo Māori but when recent actions taken by the MTS are considered, this seems unlikely. Firstly, in the past ten years the MTS has already expanded its content targeted at the groups identified in the MTS Amendment Act 2014. It has inserted more language learning programming, children's programming and programming targeted at fluent speakers in to its schedule - yet still the MTS's audience has grown (MTS, 2012b, p. 4). Furthermore, the MTS is not removing content but often adding content to the schedule, placing new content alongside old. For instance, in 2013 the MTS screened its tenth season of Marae DIY but also the first season of Iwi Anthems. This example suggests that the change in legislation is unlikely to dramatically affect the content offered in the MTS's schedule and instead may encourage the MTS to further expand its cultural content with shows like Iwi Anthems. While the MTS has devoted extensive time to ensuring that it provided programming for all viewers in its initial years (when establishing an audience was necessary), now that an audience has been established it seems reasonable that the MTS can concentrate on niche audiences and fluent speakers. However, just like these niche groups and fluent speakers were not forgotten in its first ten years, its broad viewing audience, and the importance of this audience for language uplift, is likely to remain relevant for the broadcaster. When the following chapter's discussion of funding and political and public attitudes towards the Service is outlined, this will further highlight that due to the MTS being inherently linked to the Crown this provides additional justification for the continued presence of content with broad appeal on the Service. This is illustrated by the addition to the MTS 2013-2016 "major objective" which now resolves to "significantly contribute to the revitalisation of te reo me ngā tikanga Māori so that it can be valued, embraced and spoken by all New Zealanders" (p. 9). The addition of "spoken by all New Zealanders" suggests the MTS is aware that in order to revitalise te reo Māori, it must continue to appeal to all New Zealanders. However, it also represents a shift in discourse to a more specific imagined New Zealand identity of te reo speakers. Additionally, if the New Zealand television industry remains deregulated and commercially driven, without a public service broadcaster (and 
there seems no reason why this will not be the case), the MTS will continue to act as New Zealand's default public service broadcaster. This will allow it to remain attractive to those viewers who appreciate the public service and local content of the broadcaster, which is less available elsewhere on New Zealand television screens. When considering this commercial environment in which the MTS exists it must also be noted that due to the number of competing channels (exacerbated by the growth of technology in television discussed below) then in order to have an audience it must continue to remain attractive. In appealing to a broad viewing audience then this would allow it to remain competitive in this environment. Finally, the removal of the "broad viewing audience" imperative also suggests that the MTS has successfully secured its identity onscreen with a consistent and significant Māori and non-Māori audience that continues to grow. Therefore, the removal of the objective to appeal to a broad viewing audience from the MTS's legislation is likely to have a minimal effect on the broadcaster's wide audience which is needed for the MTS to achieve its overarching imperative of te reo Māori revitalisation.

\section{Access in a Digital Era}

While attracting a broad viewing audience is one way the MTS contributes to language uplift, ensuring the MTS can be accessed by the largest possible audience is also crucial to achieving the aims of the Service. As noted, the MTS Act 2003 requires the MTS to be "technically available throughout New Zealand and practically accessible to as many people as reasonably possible" (sec 8.2(d)). The reason for this is clearly articulated in the MTS's 2007 Annual Report, which argues that "ultimately and most importantly to revitalise te reo Māori" the MTS must be delivering its content "to as many New Zealanders as possible" (p. 3). If this is achieved then the content provided by the Service will have maximum impact. Despite access having always been a core practical consideration of the broadcaster, the way in which this maximum audience engagement is achieved has changed since Māori Television first aired in 2004 as a result of the proliferation of digital technologies.

In the MTS's first SOI (2003-2004), which was developed prior to the MTS going to air, audience access was a core goal for the broadcaster. In this SOI there were two objectives that pertained to this goal. The first was that the MTS wished to ensure 70 per cent of the population had access to the MTS via UHF coverage and, 
secondly, that 100 per cent of the population had access to the MTS via satellite coverage (MTS, 2003, p. 9). By the end of 2004, the MTS was available to 100 per cent of the population via satellite and to 82 per cent via UHF (MTS, 2004a, p. 8). In the following two Statements of Intent, emphasis was placed on increasing access to the MTS via UHF. The 2005 Annual Report noted the MTS was committed to increasing FTA UHF coverage throughout the country by establishing new UHF transmission sites (p. 14). This resulted in moderate (approximately 5 per cent) gains being made in 2005 and 2006 in the amount of the population with access to the MTS (MTS, 2006 b, p. 26). In 2006, however, a shift occurred away from the objective to increase access via UHF to a focus on digital strategies.

Despite being accessible to a large proportion of the New Zealand population within its first two years on air, the MTS recognised there were limitations to its ability to expand further via UHF. Specifically, its 2005 Annual Report notes UHF "can and does create reception and tune-in issues for viewers, particularly those living in rural areas" (p. 14). In order to overcome this disadvantage the 2006-2007 SOI and the 2006 Annual Report acknowledged that while the advent of digital broadcast technologies impact on the New Zealand television environment was unknown, the MTS was optimistic about the potential opportunities a digital television environment could create. According to the MTS's policy documents, the broadcaster believed changing New Zealand's television transmission from analogue to digital would improve the coverage and reception of the MTS, eliminating the inherent reception disadvantage the Service was experiencing as a result of analogue transmission (ibid.). This change in how television was to be delivered into the homes of New Zealanders also created the opportunity for the MTS to broadcast on the same platform as all other New Zealand FTA broadcasters and offered the potential to add additional channels to the Service (ibid.). Given this, when it was announced that the Government and broadcasters would be working towards a digital switch over to Freeview (New Zealand's digital transmission platform which first launched in May 2007), the MTS was in full support of this.

The MTS's 2006 Annual Reports posed the question: "how does free-to-air digital television improve our ability to deliver on our key objective of revitalising and normalising the use of te reo Māori?" (p. 10). In answer to this, the MTS noted 
that the pending arrival of Freeview presented "interesting opportunities for Māori Television to reach a much wider audience" because "by being alongside the other broadcasters on the Freeview platform, Māori Television is likely to be more accessible to a significantly greater number of viewers" (ibid.). Māori Television's high placing on the electronic programming guide (EPG), as channel five, also "means that we [the MTS] will be right alongside the main FTA broadcasters on the remote controls of viewers" which normalises it in the television schedule by being only a quick channel change away from its mainstream rivals (MTS, 2012b, p. 9). This highranking on the EPG for many, was as important for the broadcaster to gain audiences as the reach of the Service's transmission. In addition to this, the switch to digital transmission also enabled the MTS to have the option of becoming a multi-channel broadcaster. To that end, the 2007-2008 SOI announced that the development of a second channel was underway (p. 3) and in the 2007 Annual Report it was confirmed the MTS would launch a new channel, to be called Te Reo (p. 4). As noted, Te Reo first aired in 2008 and broadcast only in te reo Māori, enabling the MTS to better meet the needs of fluent speakers and committed learners of te reo Māori (ibid.). It would appear from the MTS's Annual Reports and Statements of Intent that the switch from analogue to digital transmission, which was completed in New Zealand in December 2013, provided the MTS with a number of opportunities to increase its audience size, prominence and, consequently, its ability to contribute to language revitalisation.

Aside from the switch from analogue to digital television transmission, other recent technological advances have also impacted on the television industry. Primarily, the television industry is witnessing an increasingly fragmented audience. This change is captured by the MTS's 2008 Annual Report, which states:

Television and other technological developments are having significant impacts on traditional methods of broadcasting. The proliferation of digital television channels, Internet broadcasting developments and a raft of other new technologies are giving audiences more and more information and entertainment options to choose from. (p. 4)

Despite audience fragmentation being less of a concern for the MTS than commercial broadcasters - because of the unique cultural content that the Service offers not being widely available elsewhere - embracing new technologies is beneficial for other reasons besides countering audience fragmentation. Accordingly, to counter the 
potential impact of audience fragmentation and to enhance its language revitalisation imperatives in this environment, the MTS has employed a number of strategies to negotiate the pressures of a digital environment on the broadcaster.

In response to this changing environment, the MTS launched a strategy in its 2008-2009 SOI to ensure that it engages audiences via "every viable platform" (p. 13). The first stage of this strategy was achieved with the launch of Te Reo in 2008 and with the presence of both channels on Freeview and New Zealand's largest pay-forview network, SKY (MTS, 2008b, p. 4). With these two outcomes achieved, the 2008 Annual Report noted the MTS would now look towards enhancing its capabilities through on-demand broadcasting and a heightened presence on the Internet (ibid.). In 2009 the MTS's website was re-launched and in its first year 2,799 hours of ondemand video content was uploaded to the site (MTS, 2010b, p. 20). This content was not geo-blocked, meaning the MTS's programmes could be viewed throughout the world, something previously impossible with terrestrial television transmission. This was important as it allowed Māori not in New Zealand access to their culture and contemporary issues and events salient to them. As a result of this heightened online presence, the MTS recorded from June 2008-June 2009 visits to the site grew by 68 per cent, with views coming primarily from New Zealand and Australia (ibid.). Consequently, this increased growth in website use supports the notion that audiences are making use of engaging with content online and as a result, the MTS should continue to enhance its online presence. However, this should not come at the expense of traditional linear broadcasting practice as this continues to be the MTS's audience's primary means of engagement with the Service.

Following the re-launch of the MTS's website in 2009, the MTS attempted to expand its online presence in other ways. In the 2011-2014 SOI, it announced a further enhanced digital strategy which sought to increase access to content online and embrace social media and new technologies (p. 17). This strategy would focus on moving the MTS from a 'traditional broadcaster' "to that of a multi-dimensional media company offering a choice of platforms and options" (MTS, 2011b, p. 5). In 2013 the MTS again re-launched its website in order to keep pace with advances in digital technologies and this website "provided viewers around the world with greatly enhanced access to its most popular programming and latest in news and 
current affairs, on any device" (MTS, 2013b, p. 4). Alongside this increased accessibility the new website:

[F]ocuses on creating a stronger dual-language offering and also includes the opportunity to provide feedback in real time, comment on selected news stories and share what is going on with a 'Share Your News' function. It features increased social media engagement with viewers able to recommend, share and tweet almost all of its online content. (ibid.)

It is also now possible to engage with the MTS via its YouTube channel, which was launched in 2013, and through following the MTS and its journalists on Facebook and Twitter. These developments illustrate that the MTS is continuing to ensure it expands its viewer outreach, enabling the Service to draw the largest audience possible.

\section{Enhancing Language Revitalisation}

Not only has the MTS been able to use new technologies to grow and maintain audiences, and thus contribute to increased recognition and the normalisation of te reo Māori, but these new technologies also enable the MTS to enhance its contribution to language revitalisation in other ways. Firstly, as acknowledged in chapter one, in order for a language to be revitalised it must be a 'living language' and exist in all areas of the everyday. Since the internet and mobile technologies are increasingly the ways in which people are engaging with the world, this increased presence of the MTS in digital space is crucial to ensuring there is a Māori presence in this digital world. This is supported by the TKOM (2009) report, which acknowledges:

Television is primarily a medium of entertainment. By itself, it cannot keep a language and its culture alive. People do that. For the moment, television only represents and portrays language. This will change in the future as technology enables viewers to be interactive with the media. (p. 8)

The need to embrace new technologies in order to successfully revitalise te reo Māori is also supported by Māori language activist Dr. Koro Ngāpō. Ngāpō believed that "in order to revitalise the language, it had to be merged with modern technologies" (in Carson, 2012). Ngāpō argued that "we've got to make Māori sexy again" and television, social media and smart phone apps should be used to promote te reo Māori as that is what makes a language "sexy" or "relevant for everyday New Zealanders" (ibid.). Therefore, although the prominence of television in the home 
may be contested due to discourses of fragmenting audiences, the expansion of digital television does not jeopardise the language revitalising function of television but can, in fact, enhance it.

The MTS has embraced new technologies in a number of ways which serve to further contribute to its objective of language revitalisation through up-skilling and education. Firstly, by making its language learning programmes available online, language learning can now be conducted at one's own pace and schedule, enhancing these programmes' effectiveness. Additionally, extra language learning resources are provided online which cannot be offered as part of the television schedule. The MTS website offers podcasts and discussion forums which can be used alongside language programmes to enhance language learning. Also, the MTS has embraced these digital technologies to engage youth which, as acknowledged, is a key demographic in the language revitalisation process. The most obvious example of this is the new television show Swagger which uses various social media apps including Snapchat, Instagram and Facebook to engage with young adults. Another example is the launch of Nia's Extra Ordinary Life, which is New Zealand's first web series for children.

Given these technological changes to the television industry since the MTS Act 2003 was enacted, the legislative imperatives placed on the MTS have also had to evolve in order to allow the MTS to be best positioned for this new broadcast environment. The TKOM report recommended changes that would reflect the environment in which the MTS now operates. Specifically, recommendation ten of the report suggests the MTS Act 2003 is "amended to affirm that the Service is given mandate to broadcast on all multi-media platforms" as this would align the broadcaster with the contemporary environment in which it functions (TKOM, 2009, p. 19). Another issue identified was that section 8 of the Act stipulates that the majority of Māori-language programming be broadcast in primetime. However, the TKOM report acknowledges that in a multi-platform, digital environment, primetime as a concept is being contested. Therefore, the amount of te reo Māori broadcast during primetime does not need to be stipulated by the MTS Act 2003 (ibid., p.15). Instead, the report recommended the MTS Act 2003 require the MTS "to broadcast an aggregate minimum of 50 per cent te reo Māori across all their platforms and channels" (ibid.). When these recommendations were reviewed, they resulted in 
some changes to the legislation. The MTS Amendment Act 2014 states that the MTS "may provide a range of content and services on a choice of delivery platforms", recognising that the MTS must be enabled to operate in a multi-platform digital environment (sec. 8.4). There was however, no change to the imperative that the MTS during primetime "broadcast mainly in te reo Māori"(MTS Act, 2014, sec. 8.2(c)) which, as the statistics discussed in chapter two highlight, the MTS continues to achieve every year. This is likely because, although embracing new online technologies is important, the MTS still considers 'traditional' or linear broadcasting its primary means of transmission. It states in its 2012 Annual Report that traditional broadcasting will remain the primary service provided by the MTS for the foreseeable future; however, the digital options available to viewers will continue to be expanded alongside its traditional broadcasting (p. 8). These changes to the MTS Act 2003 reflect that the MTS is now situated in a multi-platform, digital environment, and alongside maintaining its traditional linear broadcasting schedule, it must continue to negotiate the pressures that a digital environment places on the Service by engaging with new technologies to expand on its language revitalisation function.

\section{Conclusion}

Since 2004 the MTS has shifted its focus in who it perceives to be its target audience, as well as how it engages with this audience. Although audience ratings are crucial to any broadcaster's success, for the MTS ratings success is not for commercial ends but to ensure the MTS is able to achieve its language revitalisation function. Attracting a broad viewing audience (both in terms of numbers and diversity) allows a minority language to be normalised and enables it to become part of the national imaginary. This is important for language revitalisation because, as chapter one argues, language is integral to a community's identity, and as a social phenomenon, needs to be used and heard on a daily basis. The MTS has created a schedule that appeals to a diverse audience of Māori and non-Māori, language learners and those fluent in te reo, as well as children and youth. While the MTS's audience share remains lower than its other FTA rivals, its audience continue to grow; the MTS stated in its 2012 Annual Report that its audience for that year was the largest to date (MTS, 2012b, p. 4). Furthermore, the MTS has ensured that as many New Zealanders as possible are able to access this schedule, further enhancing the language revitalisation potential of the MTS and 
further supporting the Government's 2003 MLS by strengthening recognition of the language.

Since Māori Television first aired in 2004 there has been a shift in how it targets this audience. In the early years, the primary aim of attracting a broad viewing audience was achieved by creating a schedule with broad appeal and by ensuring the channel could be accessed by as many people as possible. More recently, there has been a shift to engaging audiences not only via the television schedule but also via multiple platforms such as social media and the MTS website. This highlights that the MTS is engaging with new technologies to reach the widest audience. In doing so, the MTS also creates new opportunities for language revitalisation. Most recently the MTS has entered a new phase of audience appeal, one that focuses on enhancing its offerings for niche and Māori speaking audiences. This change suggests that the MTS's initial phase of audience consolidation has been achieved and now the Service is able to expand on the language needs of its audiences without disenfranchising them. The new digital environment makes this increasingly possible as it provides a space where more content for different groups can be provided such as language learning podcasts or web series targeted at specific demographics. Despite a shift in the MTS's policy documents discourse, from targeting a broad viewing audience to targeting an audience of Māori speakers, as well as changes in how audiences are engaged with, this chapter highlights that the MTS is conscious that it must continue to provide a comprehensive television schedule. This is because it continues to be the primary means of audience engagement, even in a digital age. This chapter also argues that while a change from targeting a broad viewing audience to targeting te reo speakers has occurred, the MTS is likely to continue to provide content with broad appeal due to the important function of this to language revitalisation. Although the reason for this change in target audience is likely the consequence of the MTS moving beyond its initial years of audience consolidation, reasons for this change will be examined further in chapters four and five, when different stakeholders' agendas, including Māori and the state's aspirations for the Service are considered. 


\section{Chapter Four: The Impact of Socio-Political, Cultural and Economic Pressures}

\section{Introduction}

As the previous chapters highlight, providing programming that promotes te reo Māori is only one aspect of the MTS's language revitalisation strategy. Other strategies that focus on inclusivity and accessibility must be implemented in order for the language to be naturalised in the national imaginary. Chapter four expands on this notion by considering how the socio-political, cultural and economic environment of the MTS also creates pressures which the MTS must negotiate in order to be effective at revitalising te reo Māori. In addition to the major objective to "significantly contribute to te reo and tikanga Māori being increasingly valued and embraced," in 2005 the MTS added a second major objective to its SOI, which reads, "develop as an independent national Māori channel that is successful with an assured future" (MTS, 2005a, p. 8). This chapter argues that the presence of the phrase "assured future" is a result of the social, political, cultural and economic pressures which impact the Service given its current non-commercial funding structure. It also argues this is a necessary objective in order to enable the Service to effectively contribute to the promotion of te reo Māori. Additionally, this chapter highlights how establishing an assured future for the Service has required the implementation of various strategies including financial prudence and diversification of funding, creating political and cultural capital and through shifting governance to Māori. These strategies have been the result of the socio-political, cultural and economic conditions of the MTS.

Establishing an assured future for the MTS is necessary to language revitalisation for three reasons. Firstly, and most obviously, without the MTS existing it is unable to continue its unique schedule that it brings to the New Zealand television industry, hindering the uplift of te reo and sending it back to a time when te reo Māori was rarely seen or heard on New Zealand television screens. Secondly, if the MTS is uncertain about its future operations, this makes it difficult for it to make long term planning decisions which are necessary for the Service to be efficient and 
effective in its language revitalisation. Finally, the strategies the MTS uses to create an assured future are also important in creating positive attitudes towards the broadcaster and te ao Māori generally. This is crucial to language uplift because if a language and culture is not normalised or accepted it cannot be given the opportunity to flourish. While this chapter illustrates why and how the MTS has created an assured future for itself to carry out language revitalisation, the potential broader benefits of this strategy are discussed in the following chapter.

This chapter primarily considers how the MTS has developed different strategies to create an assured future for the Service and how these strategies are shaped by its negotiation of social, political, cultural and economic pressures. The chapter firstly discusses the MTS's inherent link to the state due to the Treaty and its funding structure. It discusses the precariousness of this relationship given state and public attitudes towards the broadcaster, as well as government attitudes towards public service broadcasting (PSB). This discussion provides a basis for understanding why the MTS has the assured future imperative in its policy documents and how the MTS is trying to create an assured future for itself through diversifying its sources of funding. As a result of the MTS's limited ability to change its funding circumstances, the following section of this chapter considers how the MTS has generated political and public goodwill for the Service through being a financially prudent and inclusive broadcaster. This works to break down negative stereotypes of things Māori, framing Māori in a positive way. This chapter also considers how the strategies the MTS has implemented for language revitalisation and its assured future impact on its Māori audience. It will also discuss how its inclusive strategy creates tensions with some Māori aspirations for the Service. This chapter then considers how Māori interests have been prioritised in recent policy documents. It examines the transfer of spectrum rights into Māori hands, which was a result of the MTS Amendment Act 2014 and an alteration to the MTS's 2013-2016 SOI which the phrase "assured future" has been removed from. This chapter argues that this change is likely the result of the MTS largely achieving the aim of embedding itself in the New Zealand television landscape, as well as the result of the MTS moving into a new phase of strategies for language uplift that relate to changes in the technological environment. 


\section{The MTS and the State}

The MTS is inherently linked to the state as a result of the Treaty of Waitangi and its reliance on state funding. The MTS was the consequence of more than three decades of protest by Māori against the state over the recognition of Treaty principles. Due to the MTS being the consequence of a Treaty claims process, this means that it will always be linked to the state. Furthermore, due to the commercially driven nature of the New Zealand television industry, the MTS would be unable to exist without state legislation and funding. Since the genesis of the broadcaster the MTS's funding structure has remained relatively unchanged. The MTS is primarily a state-funded broadcaster. Direct funding is allocated to the MTS through two state agencies; the Department of Māori Affairs and Te Māngai Pāho, which is the Crown entity responsible for making funding available for broadcasting that promotes Māori language and culture (Broadcasting Amendment Act, 1993, sec.53(b)). In the MTS's first year on air 99 per cent of its funding came from these two state organisations (MTS, 2004a, p. 37). In 2004 the Ministry of Māori Affairs supplied 11.5 million in funding, while TMP supplied 8.9 million in direct funding. ${ }^{4}$ Since 2004 the amount of funding from the Crown as a percentage of the MTS's total income has decreased. According to the MTS's 2013 Annual Report, state funding made up 84 per cent of the MTS's total income in 2012, with it receiving 16.6 million from the Department of Māori Affairs and 16.1 million in direct funding from TMP (p. 20). Although these figures show total state funding has increased since 2004, the MTS has also diversified its revenue portfolio which is why state funding only made up 84 per cent of its total revenue in 2012. Besides direct state funding, the MTS also generates income through advertising and other production funding means such as sponsorship and contestable funding mechanisms NZoA and TMP. However, these sources of revenue remain a minor source of income, as total revenue generated by advertising was only six per cent in 2012 and that funded from sponsorship and contestable funding mechanisms only made up approximately eight per cent of the MTS's total revenue in 2012 (MTS, 2013b, p. 20). Therefore, despite a general increase since 2004 in the total income of the broadcaster, and diversification in the MTS's revenue

\footnotetext{
4 This does not include the funding it received from TPM's contestable funds which are available to all broadcasters and producers for the purpose of producing Māori television content. The MTS can access this funding but this figure is included in the MTS's contestable funding figure.
} 
portfolio, the MTS's overall funding structure remains relatively unchanged with the state being its majority funder.

This accountability to the state as a result of the Treaty and its funding model is important to consider because, as chapter one highlights, the state has often failed Māori even when there was an active need for Treaty principles to be upheld. The ATN experiment is an example of this, as its failure highlighted that the state did not provide adequately for the Service despite a Waitangi Tribunal ruling. Furthermore, the negative media coverage of the attitudes of some within Parliament, which were aired in the media surrounding the MTS's launch, such as Gerry Brownlee's comment that a National-led Government would close the broadcaster down when it came to power, further highlight the precarious environment in which the MTS exists (Abel, 2011, p. 129). Additionally, media scrutiny of the broadcaster, such as that which Ranginui Walker (2004) documented surrounding its emergence, present in headlines like "Māori TV must clean up its Act" and "Audit of Māori projects called for", can be further detrimental for the Service (Walker, 2004, p. 376). This is because, due to the MTS being largely government funded, it would take a brave government to support an initiative that was represented by media as widely unsupported by the tax-paying public. As a consequence of this inherent link between the MTS and the state this chapter considers how this relationship conditions the actions of the broadcaster. It examines how the MTS has negotiated this relationship, and the tensions and pressures it creates, to better allow the Service to deliver on its cultural revitalisation imperative.

\section{Public Service Television in New Zealand}

While government and public attitudes towards the broadcaster and Māori initiatives are factors that help shape the MTS's governing policy, because of its reliance on state funding, government attitudes towards PSB is another factor that should be taken into account when considering how the MTS's governing policy is shaped. Under the Clark-led Labour Government a number of PSB initiatives were implemented. While the MTS was one of these initiatives, as it is a publically funded broadcaster with cultural mandates, the creation of the TVNZ Charter in the same year represents another. The TVNZ Charter was intended to provide TVNZ with basic guidelines for increasing the quantity and quality of public service programming on the network; 
yet, as the following discussion will highlight, TVNZ was not provided with adequate funding to properly carry out this mandate. The establishment of public service television channels TVNZ 6 \& 7 in 2006 were also part of the Labour-led Government's public service agenda. In 2006 TVNZ was provided with funding from the state to broadcast two commercial-free digital channels, TVNZ 6 and 7. Both channels embraced public service values with TVNZ 6 broadcasting children's and family programming and TVNZ 7 carrying extended news and current affairs programming. When these three PSB initiatives are considered, it would seem that the Labour-led Government was particularly supportive of upholding PSB ideals.

Since the current National-led Government came to power in 2008, two of these PSB initiatives have been discontinued. In 2010 the TVNZ Charter funding was redistributed to NZoA; however, this action was undertaken before the Charter was formally disestablished in 2011 (Thompson, 2012, p. 108). The \$15 million per year Charter funding was used to create a second NZoA contestable fund, the Platinum Fund, which was to be used to enable the commissioning of more PSB type content (ibid). While this action is not entirely at odds with PSB ideals, it does reflect a move towards a more free-market based approach to PSB as it enabled government money to be acquired by commercial producers for commercial ends. Furthermore, despite TVNZ's channels $6 \& 7$ providing comprehensive public service schedules that were not seen elsewhere on New Zealand television, the Labour-led Government only allocated five years of funding for the channels (which was re-arranged and stretched to cover six years of broadcasting) and did not establish a long-term funding arrangement. Consequently, Thompson (2011) notes, "Labour's fiscal reluctance to formally hypothecate the funding arrangements meant that any subsequent government could easily dismantle the arrangements" (p. 5). This eventuated when the National-led Government came to power in November 2008 and did not renew funding for the two channels, resulting in the closure of TVNZ 6 in February 2011 and TVNZ 7 in June 2012.

From this discussion, it could be assumed that these actions represent the ideological preferences of the National-led Government; a neo-liberal government unsympathetic to PSB. However, although government benevolence towards PSB is certainly a factor in funding, Thompson (2011) argues that attributing the closure of 
these channels and reallocation of Charter funding to government ideological difference is too simplistic. Instead, Thompson (2011) largely attributes the closure of TVNZ 6 and 7 to inter-ministerial contestation and the influence of the macroeconomic environment on government imperatives. Specifically, Thompson (2011) notes the National-led Government came to power during the 2008 global financial crisis which led the Government to enforce strict fiscal austerity (p. 5). Consequently, Thompson (2011) argues that despite evidence suggesting an effort was made by Cabinet to renew funding for TVNZ 6 and 7, ultimately the Government's effort to reduce debt and spending, enforced by Treasury as a result of the global economic recession, was more important than the funding for the channels (p. 7-8). Similarly, a discussion of the remit that TVNZ was required to uphold under the Charter highlights that its abolishment can also not simply be read as occurring as a result of a government unsupportive of PSB ideals. As Trisha Dunleavy (2010) highlights, the TVNZ Charter "was seriously flawed by its requirement that TVNZ deliver 'public service' at the same time as maintain its commercial profitability," two objectives that were irreconcilable on its small budget (p. 14). She argues:

Rather than seeking to reduce the influence of commercialism on TVNZ, the 2003 Act instead placed its 'commercialism' and new 'public service' obligation in a binary relationship. Accordingly, the 2003 Act set TVNZ up to fail in two ways: first by failing to make provision for the Charter's many non-commercial implications and second, by requiring it to deliver the Charter without compromising the profitability it had demonstrated through the 1990s. While the first ensured that a chartered TVNZ would never be able to fully deliver on the intended expectations, the second left it little choice but to prioritise commercialism over 'public service' when direct conflicts between these objectives arose. (Dunleavy, 2010, p. 4)

The Charter's inability to achieve its function without some change to the funding or profits of TVNZ, as well as the tight fiscal environment in which the National-led Government came to power, provides an alternative understanding of why the Charter funding was reallocated. It could be argued that the National-led Government's reallocation of funding to NZoA would provide a more successful way of achieving public service content than had occurred under the TVNZ Charter, without a radical change to TVNZ's mandate or increased funding. Therefore, while the removal of these PSB mechanisms and the allocation of funding to NZoA could be attributed to a change in Government to one less sympathetic to a social-democratic 
approach to broadcasting, the arguments presented by Dunleavy and Thompson suggest a more holistic approach is needed to understand the decisions.

Additionally, even though the MTS was established under the Labour-led Government during a period of expansion of public service initiatives, the MTS (unlike the Charter and TVNZ 6 and 7) is supported by legislation that would be extremely difficult to repeal. The MTS was not just the result of a government favourable towards Māori broadcasting but, as discussed in chapter one, was the outcome of three decades of protest and legal battles between Māori and the state for recognition of the state's obligation to Māori broadcasting as guaranteed by the Treaty. Therefore, this would make it significantly more difficult for a government less sympathetic towards PSB to disestablish the MTS, especially considering the current Government is in coalition with the Māori Party. However, the MTS is not immune to the PSB environment. Since the current Government came to power in 2008 the MTS's government funding has remained unchanged (MTS, 2012b, p. 8). Furthermore, the closure of TVNZ 6 \& 7 and the removal of Charter funding in 2010, as well as the global financial crisis resulting in the reallocation of PSB funding, are all decisions that would have likely cautioned the MTS given its reliance on state funding for operation. Therefore, this hostile PSB environment, and the macro-economic forces which condition it, is likely to have influenced the MTS's governing policy and thus provides a context for understanding the presence of the "assured future" imperative in the MTS's policy documents. As the following section will demonstrate, it also provides additional reasons for why the Service has tried to reduce its reliance on state funding.

\section{Assured Future and Financial Independence}

Consideration of the MTS's reliance on state funding, the environment from which the broadcaster emerged and the situation of PSB in New Zealand, is integral to understanding why the MTS emphasises that it needs to become an independent broadcaster with an assured future. The MTS acknowledges in its Statements of Intent and Annual Reports that relying on government funding in order to operate as a business creates uncertainty for the future of the broadcaster. This argument is captured in the 2005 Annual Report which states “Māori Television's reliance on government to provide funding creates a high level of uncertainty" (p. 16) and the 
2009 Annual Report which argues that the MTS's reliance on government funding does not provide long-term stability (p. 13). Given the negative attitude within the political arena surrounding the MTS's launch, the current Government's treatment of PSB outlined above, and that the MTS is primarily funded by the state, these circumstances are likely to have caused uncertainty for the broadcaster. Specifically, the uncertain future that this environment creates could be seen as the reason for its "assured future" objective present in its Statements of Intent from 2005-2012.

In order to address this uncertainty, and create an assured future for the broadcaster, the MTS saw itself as needing to become a financially independent broadcaster. This is articulated in the 2005 Annual Report which states "it is our eventual goal to be independent of direct government funding" (p. 9). The MTS came up with a number of ways in which this was to be achieved in its business strategies. Primarily, it saw increasing commercial revenue as a way of creating financial independence from the state. This is evident in such discourse as "focus on maximising advertising sales" (MTS, 2009b, p. 12) and "we will continue to look for opportunities to maximise commercial revenues" (MTS, 2011a, p. 18). The MTS also acknowledged long-term funding arrangements as another way in which this could be achieved, stating that "a funding model that will enable long-term stability and growth" is required (MTS, 2009b, p. 13). The Annual Report also acknowledge programme sponsorship and accessing more contestable funding as other means for becoming financially independent. However, as the following section evaluates, the extent to which the MTS has been able to implement these aims, and therefore achieve its ultimate goal of an assured future through financial independence, has been limited.

Although the MTS's documents emphasise that the Service needs to diversify its revenue portfolio through undertaking commercial initiatives, the ability of this business strategy to remove the MTS's dependence on government funding is limited. Firstly, the amount of revenue garnered from advertising is minimal. In 2012, advertising made up 6 per cent of the MTS's total revenue despite an active effort by the MTS to increase its income earned from advertising revenue (MTS, 2013b, p. 20). Given this statistic, advertising revenue is not likely to reach a point where the MTS no longer needs state funding. Secondly, advertising revenue is volatile and creates 
uncertainty. This was seen in 2009 when the expected advertising revenue target was not met, which the MTS attributed to the economic recession (MTS, 2009b, p. 45). Additionally, a new challenge the MTS faces is the fragmentation of audiences which can also reduce advertising revenue by splitting audiences across platforms. Finally, if the MTS were to prioritise its commercial aims over its language revitalisation imperative, this would likely compromise its cultural mandate. The TVNZ Charter example demonstrates this risk because, as discussed, the Charter was intended to provide TVNZ with basic guidelines for increasing the quantity and quality of public service programming on the network; however, this was to be done while maintaining the network's commercial performance and with minimal government funding. TVNZ was unable to do both under the Charter and consequently, commercialism was prioritised over public service (Dunleavy, 2010, p. 4). Although the MTS's mandate is the inverse of the TVNZ Charter situation (its governing objective is cultural uplift not a dual mandate that includes commercial profit), if the MTS were to prioritise the objective of being a financially independent broadcaster, the Charter example suggests this would most likely lead to a compromise in its cultural mandate as the two are irreconcilable objectives.

It must be emphasised, however, that the MTS is aware of this tension. It often notes when discussing its strategic plan that commercial opportunities must enhance, not detract from its ability to achieve its primary imperative of contributing to te reo Māori me ngā tikanga Māori revitalisation. The MTS's awareness of the tension between commercial and cultural imperatives can be seen in statements such as, "we will continue to look for opportunities to maximise commercial revenues, and this will be undertaken in such a way that it will not be at the expense of cultural values or legislative commitments" (MTS, 2010a, p. 16) and "our greatest challenge is to integrate our reo and tikanga objectives with competing commercial imperatives" (MTS, 2005b, p. 9). Furthermore, not only is the MTS aware of this tension, it has consistently prioritised language revitalisation imperatives over commercial ones. For example, in 2012 it eliminated infomercials and the associated commercial revenue and replaced these with a daily five hour block of Māori language tuition programming (MTS, 2012b, p. 8). It is also judicious in its choice of advertisement, limiting the amount of advertising on the broadcaster to a maximum of 4 minutes of advertising per hour (MTS, 2014a). This is comparably less than other FTA New 
Zealand broadcasters where advertising occupies approximately 14 minutes per hour on these channels (NZoS, 2014). Therefore, although the MTS prioritised achieving an assured future through diversification of its revenue portfolio, it does so with an eye to its language revitalisation imperatives.

Other methods of funding aside from direct state funding and advertising also pose their own limitations. Firstly, like advertising revenue, revenue from sponsorship makes up only a small per cent of the MTS's overall revenue. Despite the MTS creating sponsorship partnerships for programmes, including Mitre 10 for Marae DIY and the Ministry of Business, Innovation and Employment for Project Mātauranga, the percentage of revenue generated through sponsorship is minimal with it making up less than 8 per cent of the MTS's entire income in 2012 (MTS, 2013 b, p. 20). As with advertising revenue, it would be unlikely that the MTS would be able to grow sponsorship revenue to a point where it could sustain the broadcaster.

Secondly, although the MTS has suggested in its governing policy documents the need to diversify its revenue by accessing more contestable funding, the ability of the MTS to do this via NZoA is limited. As with other New Zealand public funding initiatives, NZoA is vulnerable to changes in government attitudes (whether ideological or as a result of external pressures) towards funding for public service television. NZoA's funding illustrates this, as in the past five years there has been a slight decrease in funding (when adjusted for inflation), despite at times being the only funding mechanism for New Zealand television content (NZoA 2009; 2010; 2011; 2012; 2013a). Furthermore, the MTS's mandate to broadcast programming that promotes te reo Māori does not entirely align with NZoA's mandate. According to the NZoA website, NZoA is required to make programming that is "value for money". This requires it to give consideration to audience reach and because of this ratings are an important consideration for NZoA when allocating funding. Thus, other FTA broadcasters are more appealing for NZoA content with their higher audience share. In addition, although NZoA has a Māori Language Strategy, this strategy's focus is for Māori programmes mainly in English, made for a general audience which includes Māori. The NZoA website states that "we promote the Māori language by normalising use for audiences not fluent in Te Reo." It must be noted that this does 
not exclude the MTS from accessing NZoA funding. For example, in 2009 the MTS's screened its first 'high-end' drama series, Kaitangata Twitch. The show consisted of 13 episodes and while broadcast predominantly in English it also featured te reo and tikanga Māori content, and was partially funded by NZoA who contributed 3.5 million to its production (NZoA, 2009, p. 51). However, NZoA's focus on programming for a general viewing, non-fluent in te reo audience does limit the MTS's access to NZoA funding given its mandate of contributing to te reo Māori me ngā tikanga revitalisation. It is important to note that NZoA is not intentionally excluding funding for te reo Māori programming. When NZoA was established, TMP, a separate institution which offers contestable funding for Māori programming in te reo and targeted at an audience of te reo speakers, was also established. Finally, while raising revenue via NZoA would alleviate some dependence on direct state funding, the MTS would not be able to obtain an assured future from this revenue because this is project-based, not long term funding. Therefore, the funding available to the MTS via $\mathrm{NZoA}$ is limited, volatile and in high demand, making it an unreliable funding source on which to create an assured future.

Despite the limitations posed by these revenue generating strategies, TMP does provide some substantial relief. As acknowledged, TMP is the government institution responsible for the funding of Māori language programming and because of this purpose a large proportion of the MTS's funding comes from this agency or content made for the MTS by other production firms with funding from TMP. In 2012 the MTS received $\$ 16$ million in allocated funding from TMP (TMP, 2013, p. 19). Although the MTS's proportion of allocated funding from TMP has remained relatively unchanged since 2005, the amount of funding the MTS receives from TMP's contestable funds (that is, the funds available to all broadcasters and producers for Māori content) has the tendency to fluctuate. However, naturally the majority of TMP's contestable funding, despite being available to other FTA broadcasters and New Zealand producers, is largely allocated to the MTS. This is evident when TMP's Annual Reports from 2004-2013 are examined. These show that over three-quarters of its contestable television funds are allocated to the MTS each year, and this figure does not include the contestable funds that are allocated to independent producers who make Māori content that is also largely screened on the MTS. Although this gives the MTS some certainty, as it is the primary institution eligible for this funding, the 
TKOM report and the MTS's Annual Reports have highlighted that long-term funding arrangements would be more beneficial for the MTS. The TKOM Report (2009) stated, “the panel agrees with MTS's assertion that a better and more assured balance between direct and contestable funding from Te Māngai Pāho must be found, along with an extension of the annual appropriation from one to three years" (p. 4). The TKOM (2009) report recognised the benefits of such arrangements stating that "certainty of funding has a major influence on the capacity of any broadcasting service's activities" (p. 23). Establishing long-term funding arrangements has the potential to reduce the MTS's anxieties over its future and the stresses that changes in the funding of public service television in New Zealand often place on the broadcaster. To date, a change to the funding relationship between TMP and the MTS has not been established, but will likely continue as a relevant way in which the MTS can achieve an assured future in an uncertain environment.

\section{Alternative Strategies}

To overcome the limits of diversifying its revenue portfolio discussed above, the MTS has tried to create an assured future for itself by creating political and public goodwill towards the Service. Without political and public goodwill the MTS could not exist. This is because without state legislation and state funding the channel could never have been established. Concomitantly, as New Zealand is a democratic state it would take a brave government to fund something that was strongly opposed by the taxpaying public. To create support for the Service, the MTS has attempted to break the stereotype that circulates in both the political and public arena that Māori 'are irresponsible with tax-payer funding' and instead has built up an image as a financially successful organisation (Walker, 2004, p. 376). The MTS have done this by maintaining an operating surplus every year since it launched (MTS, 2013b, p. 4). This surplus has allowed the MTS to further prove its financial prudency by using its surplus for re-investment such as returning on loans in advance (MTS, 2004a, p. 7) and to pay for future undertakings, such as the transition to digital transmission (MTS, 2013b, p. 4). Establishing a reputation as a finically prudent organisation not only enables the MTS to meet their legislative imperative of being a cost-effective organisation but also generates political and public support by showing they can be 'trusted with tax-payers money' (Walker, 2004, p. 376). Furthermore, former long 
term CEO (February 2005-October 2013) Jim Mather's high media profile has created additional political and public goodwill as he has led the organisation with integrity and avoided any scandals involving him. This again emphasises that the MTS can be 'trusted' with public funding, breaking down stereotypes of things Māori.

Additionally, the MTS has demonstrated it is a value for money organisation, which has generated further political support for the organisation. Firstly, the MTS have consistently delivered high-quality programming at a production cost well below that of national and international rates. The 2011 Annual Report highlighted this as it outlines that the average cost for the MTS to produce one hour of programming is $\$ 15,561$ (p. 14). This is less than programmes commissioned for the MTS by independent producers which cost on average per programming hour $\$ 44,000$. The MTS's costs are also significantly less than international public service television broadcasters' costs, which on average spend $\$ 46,000$ per programme hour (ibid.). The MTS has continued to be competitive since 2011, reducing costs further, as in 2012 the average cost per-hour of in-house programming produced by the MTS was $\$ 12,537$ (MTS, 2013b, p. 12). While this provides one tangible measure to support the argument that the MTS is a 'value for money' organisation, another measure is its contribution to the economy. Research undertaken by Business and Economic Research Limited "found that the total economic impact of Māori Television and its associated independent producers in the year to June 2008 was estimated to be the employment of 570 full-time equivalent people and a contribution to New Zealand's GDP of $\$ 41.2$ million" (MTS, 2009b, p. 8). Given that the MTS received 32.6 million in total funding from the state in 2008, these economic returns would indicate that the MTS is generating a positive return on the public funding invested in the MTS. Again, this further sustains the argument that the MTS is a 'value for money' organisation (ibid.) By continuing to be a financially prudent organisation, the MTS breaks down the stereotype that Māori initiatives 'waste tax payers money' (Walker, 2004, p. 376). In turn this strengthens the argument that the MTS is using these finances as a means of guaranteeing for itself an assured future as such statistics generate political and public goodwill towards the channel.

\section{Broad Viewing Audience}


While being a financially prudent organisation is one way in which the MTS works to create an assured future for itself, the consideration of the MTS's imperative to be an inclusive broadcaster for all New Zealanders also provides another way for the MTS to establish for itself an assured future. Although, as noted, the MTS's inclusive imperatives of attracting a "broad viewing audience" and contributing to "New Zealand culture" are imposed by the state via the MTS's governing legislation and, as chapter three highlights, can cause tension with the MTS's cultural mandate, these imperatives also create public and political goodwill towards the Service, further securing its future. The extent to which the MTS is aware of the relations between state and public sentiment towards the broadcaster, and its assured future can be seen in a statement made by former CEO of the MTS (August 2003-November 2004), Ani Waaka. Waaka explained in an interview with Sue Abel that in the MTS's start-up phase the broadcaster was concerned with its "assured future" (Abel, 2011, p. 130). She argues the feeling at the MTS at this time was that "there were many people just waiting for them to fail, or to close them down" (cited in Abel, 2011, p. 130). Although Waaka is speaking about the start-up phase and initial months of the broadcaster, it is important to note that the "assured future" objective remained in the MTS's governing policy until its most recent SOI, despite the Service meeting its objectives year-after-year (as statistics throughout this thesis highlight). This relationship between attitudes towards the MTS and its future is also articulated in the 2005 SOI which states that building a broad, loyal viewing audience will ensure the MTS a place in the broadcasting landscape (p. 3). Furthermore, former CEO (February 2005October 2013) Jim Mather, at the World Indigenous Broadcasters Conference (WITBC) in 2008, stated that "we've gained political capital because of how inclusive we've been, and we've brought people along on the journey" (cited in Abel, 2011, p. 134). The notion of "political capital" deployed by Mather draws on Pierre Bourdieu notion of capital. For Bourdieu capital "includes material things (which can have a symbolic value), as well as 'untouchable' but culturally significant attributes such as prestige, status and authority" which Bourdieu argues can be used as a means of exchange to make gains for a person or group (Harker et al. cited in Webb, Schirato and Danaher, 2002, p. 22). In this context, Mather's use of the phrase "political capital" suggests that an appeal to everyone can garner government support, as a government is more supportive of an initiative if all New Zealanders benefit from it and this has benefits 
for the broadcaster. Lastly, both the government and the MTS are aware of how obtaining a broad viewing audience also helps to prevent against discourses of separatism. Abel (2013b) notes how Māori initiatives have often been labelled as separatist, however, in articulating itself for everyone, this helps to "break down any barriers held by non-Māori towards a Māori initiative," discouraging calls of separatism and increasing public and political support (p. 113-114). The need for the broadcaster to garner political and public support is further supported by Abel (2011) who argues that attracting and maintaining a broad viewing audience "has the potential to reduce the number of naysayers at the same times as it builds up a body of non-Māori who would support the broadcaster if there should be moves to close it down" (p. 134). Therefore, while the previous chapter argues that the imperative of appealing to a broad viewing audience is important because it generates an inclusive audience for the broadcaster enabling te reo Māori to be uplifted in New Zealand, this section highlights that this audience also generates public and political goodwill towards the Service and that this is key for the Service to remain a fixture in the television landscape.

\section{Political and Cultural Capital}

A discussion of the contemporary environment in which the MTS operates exemplifies that the MTS has been successful in generating political and cultural capital through its inclusive strategy. Ten years on since the MTS was first launched, the non-Māori audience of the broadcaster is largely supportive of the channel. This public support is indicated by the large non-Măori audience the channel has. Evidenced in the 2011 Annual Report which states that of the MTS's two million viewers, three-quarters of them are non-Māori (p. 4). This significant non-Māori audience suggests the MTS has been successful at appealing to a broad viewing audience. However, while audience size is one measure of non-Māori sentiment towards the broadcaster, recent studies in non-Māori attitudes towards the MTS's programming also exemplifies a positive sentiment felt by many non-Māori New Zealanders towards the broadcaster. When commenting on the MTS's extensive ANZAC Day coverage one non-Māori stated that "the stories were real New Zealand community stories and the way they were presented reflected what we are as New Zealanders" (cited in Abel, 2013b, p. 118). This comment suggests that the MTS has 
been successful in fostering a sense of national identity amongst non-Māori and this is what makes the Service attractive to them. However, as Abel (2013b) points out, ANZAC Day is already an event encoded with nationalism (p. 118). Given this, it is important to consider how other programming that is not overtly inclusive in nature also appeals to the non-Māori viewer. This is demonstrated by Richard Turner's investigation into how a non-Māori audience responds to the MTS programme Kai Time on the Road. Turner (2011) found that:

Where Kai Time gains its popularity is that it 'caters for the New Zealand palate'. For Elsa 'its New Zealand food made by New Zealand people'. The 'local' nature off the show was something of immense appeal. It was argued to be a New Zealand show, hosted by New Zealand people, using New Zealand ingredients, creating tradition and contemporary dishes. ( $p$. 91)

It would seem that despite the use of te reo Mãori in much of the MTS's programming and the unique Māoriness of its programming (including its ANZAC Day coverage and Kai Time on the Road), the non-Māori audience are willing to embrace these aspects for the sake of seeing what they considered good quality, local programming that is limited elsewhere on New Zealand television screens.

Within the sphere of State a more positive attitude towards the MTS has also developed since the broadcaster first aired in 2004. Despite a National Government threatening to disestablish the MTS when they came to power, when the National Party did come to power in 2008 the Service was not removed. In fact, since the National Government has been in power they have shown support for the broadcaster. This support was most recently demonstrated in the final reading (November 2013) of the MTS Act Amendment Bill. National Party representative Nicky Wagner stated that the National party supported the Bill as the changes contained in the Bill would "empower and enhance the MTS and allow Māori Television to better protect Māori language and culture for the long term" (in Hansard, 2013). In its final reading, support from the National-led Government and Opposition (primarily the Labour and Green parties) allowed the Bill to pass swiftly through Parliament. A number of MPs commented on the importance of the broadcaster in its contribution to reo Māori revitalisation and Māori cultural uplift (ibid). In addition, support from a largely non-Māori audience is also useful politically for Māori in two ways. Firstly, as acknowledged, having a non-Māori audience that is 
supportive of the channel creates what Mather termed "political capital", as the government is more likely to fund something if the tax-paying public also supports it (cited in Abel, 2011, p. 134). It also creates political capital in another sense. Abel (2013b) argues that having a large non-Māori audience can be beneficial for the channel because "a large and sympathetic Pākehā audience for Māori Television has the potential to lead to political gains for the Indigenous population" (p. 112). Having a broadcaster that is perceived politically in a positive light reflects on te ao Māori positively and provides Māori with the potential to make other political gains. This is of particular importance to language revitalisation because, as chapter one highlights, in order for a language to be revitalised it must be an accepted part of the everyday and not just heard on television. Therefore, creating positive attitudes towards te ao Māori has the potential to naturalise te reo Māori in other sectors and provides a greater incentive to give more funding to Māori for Māori to fund other te reo Māori initiatives, an idea that the following chapter will expand on. In being an inclusive and prudent broadcaster, the MTS has been able to gain public and political support which shows a radical difference in the attitudes from which the MTS emerged. This strategy of inclusiveness and the environment it has created has thus resulted in a more assured future for the Service, as well as contributed to the naturalisation of te reo Māori.

\section{Māori Attitudes' and the MTS}

Despite the positive support for the broadcaster that the MTS has generated amongst the non-Māori public and within the state, when its inclusive imperatives are considered in relation to what some Māori wanted for the channel, tensions emerge. One criticism that has been directed at the Service is that the MTS is not the broadcaster for Māori that Māori fought for. One reason for this Abel (2013b) argues, is that although Māori did see the MTS as having a role in normalising and revitalising te reo Māori, she argues that there are a number of Māori who do not see this as the Service's only role (p. 116). This is supported by MP Te Ururoa Flavell as he stated that "so much of Māori Television's programming seem[s] to be addressed to a nonMāori audience, informing them about aspects of Māori culture that Māori themselves already knew" (cited in Abel, 2011, p. 133). When these statements are considered together, it would seem that for some Māori the Service was to not only 
for uplift of the language, but be a means of communication between Māori over Māori issues. The agitation felt by some Māori at this dual role of catering for Māori audience while also appealing to a broad viewing audience was also expressed in the TKOM report. Specifically, it warned that the MTS in "appealing to many people beyond the Māori audience can dilute the 'Māoriness' of the message'” (TKOM, 2009, p. 13). Māori have also criticised the Service in respect of the Te Reo channel. While this channel was created to ease the tensions between broadcasting to Māori versus a non-Māori audience, in some ways it could also work to exacerbate this tension. This is because it could be seen as the MTS meeting the goals of Māori while using the flagship channel for an audience for who the broadcaster was not created. Furthermore, for some Māori the MTS was seen as a potential mechanism for Māori self-determination and they believe the broadcaster in appealing to a broad audience might compromise this potential (Abel, 2013b, p. 116). Although the MTS's decision to focus on appealing to a broad viewing audience through inclusive programming has created political and cultural capital and an audience for language uplift, this decision has potentially come at the cost of meeting Māori aspirations for the channel, creating dissatisfaction towards the broadcaster amongst some Māori.

The imperative to appeal to a broad viewing audience, while causing tensions with what some Māori wanted for the Service, can also work to achieve Māori aspirations for the broadcaster. Abel (2013b) argues that the MTS is not overtly political as it does not hold "the Crown to account" or "actively promotes the call of many Māori for self-determination" (p. 116). However, she also argues that having an Indigenous broadcaster enables the MTS to gain the leverage needed to support other Indigenous initiatives (ibid.). Furthermore, Mather argues that although selfdetermination is "probably not one of Māori Televisions objectives", he does note that as a flagship Māori organisation one of its implicit roles is promoting "Māori success" (cited in Abel, 2013b, p. 117). In doing so, it could be argued that this can further Māori causes as it gives Māori greater political leverage and public support for Māori initiatives. Additionally, appealing to a broad viewing audience is necessary to meet the needs of those Māori who saw the purpose of the broadcaster as revitalising Māori language and culture. This is because, as chapter three argues, essential to the revitalisation of a language and culture is the normalisation of it within the hegemonic culture. This is occurring through the MTS garnering a broad viewing 
(non-Māori) audience. Additionally, given the latest census data, which shows that only 21.3 per cent of Māori "could hold a conversation about a lot of everyday things in te reo Māori," if the MTS were to broadcast entirely in te reo Māori, this would also marginalise Māori as not all Māori would be able to engage with the broadcaster (Statistics New Zealand, 2013). Given these arguments, it would appear the MTS's objectives are not entirely at odds with that of Māori objectives.

A recent example where Māori tensions over the purpose of the broadcaster were played out was in the media coverage of what has become known as the 'Kōhanga reo scandal'. The Kōhanga reo scandal emerged into the New Zealand mediascape following the MTS's flagship current affairs programme Native Affairs' investigation into spending discrepancies in one branch of the Kōhanga Reo National Trust. The Kōhanga Reo National Trust is a Māori organisation responsible for overseeing the funding and operations of Māori immersion pre-schooling. Some Māori believed that the MTS, as an organisation which was created for the intentions of supporting Māori and to counter mainstream media images of things Māori, should not have investigated the Kōhanga Reo National Trust and should not have brought its funding discrepancies to light. Comments directed at the Service such as "just leave it alone" and "why is a Māori organisation investigating another Māori organisation?" that the MTS received following the airing of the Native Affairs show in October 2013 exemplify this sentiment (Steward, 2013). Co-leader of the Māori Party Tariana Turia also showed her dissent for the broadcaster's decision to air the show. In an interview with Radio Waatea Tuira "questioned whether Māori Television has forgotten its original purpose" (UMA, 2013). She also stated:

For many of us who fought to get Māori TV, our firm belief was we wanted something that promoted mauriora [Māori wellness], the things that were important for us as a people, to paint the side of a picture so you wouldn't get the impression 90 percent of our people were mad, bad or sad, which is how we are portrayed by the rest of the media. (ibid.)

While this sentiment suggests that for some the investigation was going against the principle of the channel as a site where positive images of Māori are depicted, others had a different perspective. Native Affairs presenter Mihingarangi Forbes believed that keeping Māori organisations tika (correct) was one of the MTS's roles, as the Service is "uniquely placed to look at Māori institutions because we understand what 
they are trying to do, and often have sympathy for their aims. But we won't let them hide behind tikanga if they are not tika" (Steward, 2013). These comments clearly highlight that within Māoridom there are differing perspectives over the purpose of the broadcaster and the MTS must continuously negotiate these differing views.

Despite disagreement amongst Māori over the purpose of the broadcaster, engaging with these debates enables the MTS to position itself so as to align more closely with different Māori views for the Service. A recent change to the MTS's legislation could allow the broadcaster to engage with more Māori interests for the Service. While statements of inclusiveness still exist in the most recent SOI, for example "significantly contribute to the revitalisation of te reo me ngā tikanga Māori so that it can be valued, embraced and spoken by all New Zealanders" (MTS, 2013a, p. 9) there is a less overt focus on inclusiveness in the most recent MTS's governing policy documents. In 2013 the documents increased focus on how the MTS can support different groups to engage with the Māori language. The 2014 MTS Amendment Act has removed the imperative to govern to a "broad viewing audience" and replaced this with the requirement to prioritise an audience whose first language is Māori, people who have a high level of proficiency in te reo Māori and all those learning te reo Māori, especially young people and children (MTS Act, 2014, sec 8.6). This change encourages the MTS to focus more on broadcasting for Māori learners and speakers, and this potentially reflects some Māori aspirations for the Service when the previous discussion is considered. The absence of the phrase "assured future" from the MTS's 2013 SOI suggests that despite still being reliant on government funding, the anxiety over the removal of this funding because of negative attitudes towards the broadcaster in government and the public arena appears to have eased. Instead of the MTS prioritising the establishment of an assured future, this has been replaced by the imperative to be "relevant, effective and widely accessible" (MTS, 2013a, p. 9). This change could also reflect the MTS's awareness that in a digital environment its focus should be on ensuring its audience has multiple options for engagement. Based on this, it may seem that the MTS now exists in a more stable socio-political economy compared to that from that which it emerged. By being an inclusive broadcaster it could be argued that this has further created an environment where itself and te ao Māori are framed in a more positive light, the benefits of which will be expanded on in chapter five. However, there are still a 
number of socio-political pressures that condition the broadcaster's actions and, as chapter five will demonstrate, the MTS must remain mindful of these different stakeholders' interests which, as an Indigenous broadcaster in a settler-nation, it cannot avoid.

As the previous chapter highlights, for those who worry what effect the removal of the MTS's inclusive mandate may have on its non-Māori audience, Abel (2013b) argues that this change is likely to have minimal effect on the non-Māori audience and, in fact, its non-Māori audience is likely to continue to grow (p. 116). This is because the MTS already broadcasts a substantial amount of its programming in te reo Māori (more than its statutory requirement), indicating "there is no necessary conflict between broadcasting in te reo and attracting a Pākehā audience as research to date suggests that this audience happily copes with the subtitles on the Māori Television's channels programming" (ibid.). If the New Zealand television industry remains deregulated and commercially driven, without a public service broadcaster, the MTS will also continue to act as New Zealand's default public service broadcaster. This would allow it to remain attractive to those who appreciate the public service and locally produced content provided by the MTS. Therefore, the change in legislation is likely to have a minimal effect on the non-Māori audience and the public and political support for the service that this has the potential to generate.

\section{Spectrum}

Creating a sound financial strategy and broad viewer base, in conjunction with the contribution made by the MTS to language uplift, all help the Service to establish an assured future. However, there is one further issue addressed in a number of governing policy documents that was deemed necessary in order for an assured future to be guaranteed. The MTS argued that in order for it to carry out its functions, its spectrum rights needed to be under Māori control. This was highlighted in the 2009 Annual Report which states that "retention and long-term renewal of the UHF management right is critical to the future sustainability and development of Māori Television" (p. 13). This governance issue is important for the Service's long term planning as without assurance over the future of spectrum, the MTS's ability to plan for the future was hindered. The reason for such doubt becomes evident when the history of communication spectrum and Māori rights are considered. Long-time 
Māori language activist and Māori Television Service board member Piripi Walker argues in his article "Why Māori Seek Share of 4g Spectrum" that ownership of communication spectrum is a right guaranteed to Māori by the Treaty; yet, like many other Māori rights, Māori have had to battle and at times employ legal means to ensure this right to ownership was upheld. Walker (2013) cites numerous examples of times that Māori have had to remind the government of their Treaty rights with regard to communication spectrum. Including in 1989 with the Wai 150 Claim and the sale of radio spectrum; again in 1996 and 1999 when the Crown prepared the 3G frequencies for cell phones for auction; and most recently with $4 \mathrm{G}$ spectrum which again has resulted in Māori having to employ the Waitangi Tribunal to have their rights upheld (Walker, 2013).

Ownership of the communications spectrum through which Māori can spread their voice emerged as a key issue in a number of Annual Reports, evident in discourses that claim that the extension of the MTS UHF management right "is critical to safeguarding Māori Television's future" (MTS, 2007b, p. 14) and that "retention and long-term renewal of the UHF management right is critical to the future sustainability and development of Māori Television" (MTS, 2008b, p. 13) and issues "relating to spectrum and UHF management rights, require clarification and resolution" (MTS, 2011b, p. 6). It was also an issue addressed by the TKOM (2009) report which stated that "to provide more certainty for the future and to facilitate long term business planning, Māori control of the existing UHF frequencies should remain secure, and in perpetuity" (p. 4). This is because "despite the fact of the Treaty settlement to ensure the preservation, protection and promotion of Māori language as a taonga, the panel believed that there is an unacceptable risk that MTS may have their spectrum allocation reduced" (TKOM, 2009, p. 20). To counter this, the Report recommended that "the Crown should transfer 'freehold' ownership of the spectrum to [Te Putahi Paoho] TPP" (the Māori Television Electoral College and organisation responsible for protecting Māori stakeholder interests in the MTS). It also recommended that these rights should be transferred to TPP for 20 years which is normal practice under the Radio Communications Act 1989 (TKOM, 2009, p, 20-21). This was recently addressed by the MTS Amendment Act 2014, which "transfers spectrum management rights from the Crown to Te Putahi Paoho...who will issue a national set of digital spectrum licenses to Māori Television covering a twenty year 
period" (Sharples, 2014b). This gives the guardianship rights of the MTS to Māori and was argued to "also provide certainty of tenure for the Māori Television Service about access to the necessary spectrum licences for it to undertake its business now and into the future" (ibid.). Therefore, this most recent change in 2014 to the governance of spectrum allocation further enforces the MTS's place in the New Zealand mediascape by increasing the role of Māori representatives in the governance of their broadcaster.

\section{Conclusion}

Creating an assured future for the MTS was a key priority of the broadcaster from 2005-2012. This chapter argues this was primarily the result of the negative public and political environment which surrounded the Service's emergence and initial years, and was perpetuated by the National-led Government's treatment of PSB and the freezing of government funding in response to the recession. Although the MTS wished to achieve an assured future by being a financially independent broadcaster, the MTS's heavy reliance on state funding, and the limitations to changing this, made this unrealistic. Additionally, because of the MTS's presence being predicated on Treaty claims with regard to language, the ability of the MTS to achieve an assured future through independence from the state is unattainable. Consequently, the MTS has had to employ other methods for achieving this goal and has tried to do so by proving that the MTS is a financially prudent broadcaster, breaking stereotypes that Māori are irresponsible with tax-payers money and showing that the MTS is a 'value for money' organisation which uses state funding responsibly. Furthermore, the MTS has used its inclusive strategies to create political and cultural capital so that if there were any move towards disestablishing the Service, this would be met with resistance from both Māori and non-Māori stakeholders. Although at times these strategies have created tensions with what some Māori wanted for the Service, generally the MTS has contributed to a more positive environment for Māori through promoting te reo Māori and elevating images of Māori success, ideas which will be expanded on in the following chapter. Furthermore, the recent change in the MTS Amendment Act 2014 regarding the target audience suggests the MTS is shifting towards becoming a service that more clearly prioritises Māori language learners' interests over general viewing audiences'. This is likely to ease the tension between 
broadcasting for a general viewing audience versus the needs of its Māori audience. Finally, the recent change to the MTS Amendment Act 2014, which now places the MTS's spectrum rights within Māori representatives' hands, has also further embedded the MTS in the New Zealand television landscape. The absence of the major objective of creating an assured future for the broadcaster from its 2013 SOI suggests that this has largely been achieved, allowing the Service to continue to enhance its work of te reo Māori revitalisation. Despite these achievements there are still further steps towards creating an assured future that need to be taken, such as creating long-term funding plans that would enable greater forward planning. This chapter's consideration of the wider economic, socio-political and cultural pressures on the MTS to deliver its mandate reflects that the MTS must work with and against these pressures as an Indigenous broadcaster inherently linked to the state. 


\section{Chapter Five: The MTS and its Function in the Māori Language Sector}

\section{Introduction}

On 28 March 2014 the MTS celebrated its tenth year on air. Unlike the launch of the broadcaster in 2004 where the New Zealand Herald ran weekly negative stories about Māori Television, absent from the coverage of the MTS's ten years on air was a feeling of negativity towards the broadcaster (MTS, 2014b). While the main FTA broadcasters ignored the occasion (which is unsurprising given that the MTS is now a competitor), a number of print media outlets acknowledged the milestone. The tone of these articles was mostly celebratory, congratulating the MTS on a 'job well done' (Armstrong, 2014) and commenting on how it has "enriched the country's culture over the past 10 years" (Grant, 2014). In reflecting on the MTS's first ten years a number of articles considered the contribution the MTS has made to the Mãori language sector and to the New Zealand broadcasting industry. Similarly, this chapter considers what the larger impact of the MTS has been for te reo Māori revitalisation in New Zealand. It also discusses how its language revitalisation strategies have impacted Māori and what the presence of the MTS has done for the New Zealand television industry. It is argued that the MTS is integral to te reo Māori revitalisation as its strategies of language revitalisation have made a contribution to the wider Māori language sector, as well as positively influenced te ao Māori, and the New Zealand broadcasting industry.

This chapter first examines the current state of te reo Māori in New Zealand and how, according to various reports the Government-wide Māori language sector has made little progress as a cohesive sector to actively support the uplift of te reo Māori, despite having the 2003 MLS in place. The following section argues that even with minimal sector-wide effort, the MTS has continued to pursue the uplift of te reo Māori and, because of this, exemplifies the potential for what a more cohesive Māori language sector could do for the revitalisation of te reo Māori. This chapter also considers the important role the MTS has played in advancing Māori rights which has 
further positive language implications, as well as how the MTS has ensured the New Zealand television industry has locally produced content in its television schedules.

\section{Language Revitalisation}

Given that this thesis has argued that the MTS's principal function is to contribute to language revitalisation, and that this extends to every aspect of the broadcaster's business strategy, it must be asked: has the MTS succeeded in revitalising the Māori language? The most recent census data shows the proportion of Māori fluent in te reo has fallen nearly five per cent since 2006, which suggests the MTS has not been successful in revitalising te reo Māori (Statistics New Zealand, 2013). However, other research acknowledges that the MTS is contributing to language revitalisation. TPK's 2006 Report on the Health of the Māori Language found that 95 per cent of Māori and 70 per cent of non-Māori agreed that the MTS was a "good thing" for the revitalisation of te reo Māori (TPK, 2008, iv). Another study by TPK in 2011 which looked at the role of the MTS in the revitalisation of te reo Māori found a relationship between viewing the MTS and Māori language usage. It found that "those people who are using the Māori language more than they did twelve months earlier have consistently higher rates of Māori Television viewership than others" (TPK, 2011, p. 2). Also, the report found that 78 per cent of Māori viewers who had tuned into the Service had done so for the purpose of language learning (ibid., p. 3). Additionally, Pita Paraone, the Chief Executive of He Puna Whakarauora (a research unit created by the Māori Language Commission dedicated to the regeneration and revitalisation of te reo) believes the MTS "has made an enormous contribution to the revitalisation of te reo" (cited in Deane, 2014). Furthermore, if we consider the argument made in chapter one, a more nuanced answer appears. Even though language experts see great value in media (especially television) for language uplift, television alone cannot revitalise a language (Fishman, 1997, p. 90). As Dave Armstrong (2014) points out in an article celebrating ten years of the MTS, "surely revitalising the Māori language is the job of government, schools, kōhanga reo, parents and iwi as well?" In order to address this issue and to provide a more holistic answer to whether or not the MTS has contributed to te reo Māori revitalisation, a return to a discussion of the Government's 2003 MLS is needed. 


\section{Government MLS 2003-2014}

Following the launch of the 2003 MLS, many of the organisations involved did little to implement its objectives. In 2007 the Auditor General's Report on the progress of the 2003 MLS found that while some organisations seemed to be implementing the strategy and embracing its tenets as part of their organisational structures, this was not seen across all organisations (p. 7-8). While many of the organisations, including the MTS, made reference to the plan in their policy documents (such as in their Statements of Intent), the strategy had envisioned the organisations would make their own relevant goals and targets to contribute to the objective. By 2007 this had not occurred. The Auditor General's report also found that the government organisation responsible for overseeing the co-ordination of the strategy (TPK) was not appropriately supporting the implementation of it (ibid., p. 6).

In accordance with the Government's review process, in 2008/09 a much needed review of the 2003 MLS was implemented. This review was carried out by TPK and Te Taura Whiri i te Reo Māori and presented to the Minister of Māori Affairs in June 2009. Although the Review noted that there was a number of successes that had occurred in the Māori language sector since 2003 (including the launch of Māori Television in 2004), it also found this sector was developing largely independently with little cohesive planning or resource sharing. Given this, the Report recommended three new aims, which it considered necessary in order to speed up the revitalisation of te reo Māori:

- Revising the goals of the Language Strategy so that they reflected the five sectors that would carry them out (education, broadcasting, archives, arts and culture, community);

- Agencies participate in the outcomes of their sector;

- Te Taura Whiri i te Reo Māori become the primary organisation for developing the plan of action across organisations

Despite this report being released in 2009, there was no move by the Government to implement this strategy and instead another report was released in 2010. This report was carried out by the Ministry of Māori Affairs which also reviewed the MLS and the state of the Māori language sector. The report, titled 'Te Reo Mauriora', was commissioned because the Wai 262 report claimed that between 2001-2006 the number of Māori speakers had declined (from 25.2 per cent to 23.7 per cent) despite the MLS being implemented in 2003 (Te Paepae Motuhake, 2010, p. 10). In response 
to this, the Report focused on what needed to be done to reverse the decline of te reo Māori. The Report primarily argued that key to te reo Māori language revitalisation is participation by Māori and therefore funding for Māori language should be targeted at communities and organisations that are Māori, giving Māori the tools to revitalise their language (p. 7). This Report was accompanied by the release of the Wai 262 Claim in 2011, which also further stressed the need for something to be urgently done about the state of te reo Māori. Despite such reports, the Māori language sector and MLS has remained in limbo with little direction from government being provided to the organisations that were to implement the strategy.

Finally, in mid-December 2013 (six years after the first evaluative report on the 2003 MLS) it was announced by government that a new MLS strategy had been formulated. The strategy focuses on "supporting language learning in the home and in the family" and "oversee[ing] the transfer of control of te reo Māori back to its tribunal origins, and to become the mechanism for mobilising whānau and iwi to reclaim rangatiratanga o ō rātou ake reo tuku iho - their traditional dialects" (TPK, 2013). It also focuses on strengthening the relationship between government and iwi with regard to language revitalisation and making government agencies accountable to the goals of the new strategy (ibid.). Key proposals in it include:

- that a Māori/Iwi Electoral College called Te Mātāwai be established which would govern Taura Whiri i te Reo Māori and TMP;

- Te Mātāwai takes on the role and function of TPP in respect to Māori Television;

- Te Mātāwai makes two appointments to the Board of NZ on Air;

- Te Mātāwai host an annual Crown-Māori Te Reo Forum.

The strategy is to receive approximately $\$ 44.7$ million in funding. Following this announcement, in early 2014 the proposed strategy was taken out for consultation hui. Following these discussions, it will be reviewed before being submitted to Cabinet for final approval.

\section{The MTS and the Government Māori Language Sector}

Despite this lack of co-ordination and direction provided by government, especially in the 2003 MLS's initial stages, a number of the MTS's Statements of Intent acknowledge the importance of the MTS in contributing to the 2003 MLS and show that the MLS is an important organising factor for the Service. This is evident in such 
discourse as "we also advance the Government's Māori language and Māori broadcasting strategies" (MTS, 2004b, p. 16); "Māori Television is one of several key initiatives supporting the Government's Māori language Strategy. Māori Television has developed this Statement of Intent while mindful of the goals of the strategy" (MTS, 2005a, p. 1); and "Māori Television is committed to ensuring that it contributes to the achievement of the Māori Language Strategy" and "Māori Television is guided by the vision of the Māori Language Strategy" (MTS, 2013a, p. 6). It even uses its Statements of Intent to show how specific actions of the Service are linked to the MLS. For example, the 2013-2016 SOI argues the MTS will strengthen language skills (goal one) through broadcasting in te reo, broadcast language learning programmes to strengthen education opportunities (goal three) in Māori language, and contribute to the recognition (goal five) of the Māori language through its online availability (p. 67). In doing so, the MTS is reiterating that it is a key agent of language revitalisation which further legitimates the Service by showing its active contribution to government plans and legislative policy.

Although aligning with the Government's MLS is important for a cohesive language sector and to justify the MTS's funding, the MTS has acknowledged the need for its own MLS, as outlined in chapter two. This strategy would complement government aims, but the MTS needs to develop its own Māori Language strategy so that it has something to measure its success as a key organisation responsible for language revitalisation (MTS, 2010b, p. 10). As previously highlighted, in creating its own MLS, the MTS has engaged with a number of agencies responsible for the protection of te reo Māori, including Te Taura Whiri i te Reo Māori, TMP, TPK, and Ngā Aho Whakaari. This shows the MTS has been instrumental in demonstrating that vital to language uplift is a co-ordinated MLS and Māori language sector, with resource sharing and clear organisational objectives. In engaging with other organisations and actively contributing to a Māori language sector the MTS is further demonstrating its role in language uplift, justifying its funding. Although the MTS's Māori language plan has not been released yet, when the following discussion of recent proposed changes to the Government's MLS are considered, it seems likely that the MTS will release their strategy once a new government MLS is announced. This will be so it can align its own goals more closely with the Government's MLS, as it has done before. 
When shifts in the Māori language sector are discussed with regard to the most recent legislative changes, it could be argued that the changes to the MTS Act 2003 reflect the Government's current Māori language sector aims. These legislative changes reflect an increased focus on providing a television service that is for Māori speakers, not a broad viewing audience, as well as ensuring the tikanga or integrity of the language is upheld. They also ensure that the MTS, specifically with regard to spectrum, is placed in Māori ownership, reflecting a move towards guaranteeing the organisation has more direct Māori management. Like the 2003 MLS and the creation of the MTS Act 2003, when these changes are considered in relation to the newly proposed Government MLS, it could be argued that these changes are a result of the current Government's attitude towards language revitalisation. This attitude is one where Māori are given the tools and agency to revitalise their language. What this argument does not reflect, however, is that the MTS has continued to contribute to the uplift of te reo Māori despite the lack of clear government objectives on what the MTS's role in this strategy is. When this is considered in relation to the most recent statistics, which note that the number of Māori fluent in te reo Māori has decreased, it could be argued that without the MTS te reo Māori would be in an even more precarious state.

\section{The MTS and te reo Māori Revitalisation}

Despite little co-ordination in the New Zealand Māori language sector or government direction, the MTS has continued to prioritise the revitalisation of te reo Māori as the organising factor of all its strategic outcomes and the effect of this has potential benefits for the wider Māori language sector. Firstly, the MTS has created a diverse schedule that prioritises te reo Māori content and has continued this over ten years. This was a first for the New Zealand television industry and has allowed the language to be naturalised and normalised in the televisionscape. By being an inclusive broadcaster the MTS has a growing audience that consists of both Māori and nonMāori viewers who are supportive of the channel. This audience, in watching the Service, whether this be for the purpose of learning or improving their te reo Māori or not, benefit and learn from the language learning strategies that exist in all of its programming. In doing this in a financially prudent way the MTS has also shown that Māori organisations can be a success and that language revitalisation does not have 
to come at a significant cost to the tax-paying public. These strategies also create political and public goodwill towards the Service which further raises the profile of te reo Māori. Additionally, the MTS has provided an industry to foster further revitalisation. As already noted, the MTS, as of June 2008, employed 520 fulltime staff, providing a space where speakers of te reo Māori are valued. Finally, in working with other government agencies to develop its own language strategies, the MTS has also demonstrated the benefits of having a co-ordinated MLS. These strategies for language revitalisation have not only ensured that the MTS upholds its own mandate of promoting te reo Māori, but the strategies themselves have had a positive effect on the entire Māori language sector. This is because they highlight that it is possible to revitalise te reo Māori in a cost-effective way and raise the profile of the Māori language.

\section{Māori and the MTS}

The MTS has also been instrumental in promoting Māori success which can further benefit te reo Māori uplift. As chapter one identified, prior to the establishment of the MTS, mainstream media largely ignored Māori and if they were represented it was a token cultural gesture or in a negative way (Abel 1997; 2008; Fox 2001; Stephens 2004; Walker 2004). This coverage has resulted in Māori and te ao Māori often being perceived in a negative light, present in problematic discourses such as 'Māori initiatives waste tax-payer money' (Smith \& Abel, 2008, p. 3). However, as Mather stated in an interview with Sue Abel, the MTS is "a flagship Māori organisation that promotes Māori language and culture but more widely Māori success" (Abel, 2013b, p. 117). Promoting Māori success by providing counter images to the negative stereotypes often portrayed in the mainstream media is crucial to breaking these negative discourses. One event where this difference in narratives can be seen between the MTS and mainstream broadcasters, is Waitangi Day. While the mainstream media focuses on the conflicts of the day (Abel 1997; MTS 2014), the MTS balance this by highlighting the celebrations that occur and the importance of the day in its coverage (MTS, 2014b). Portraying Māori in a positive light and promoting Māori success in its schedule creates the potential for Māori to make other political gains. This argument is presented by Jo Smith (2013) in the article "Māori Television's Indigenous Insistence" which considers how "increased Indigenous 
visibilities hold a potential political power" (p. 106). The Service creates this increased "potential political power" by enhancing the political and cultural capital of things Māori which is important for those Māori who saw the purpose of the MTS as for more than just revitalising the language. For those Māori who do see the Service's primary goal as language revitalisation, the promotion of Māori in a positive manner, and the impact this has on New Zealand ideologies, is likely to create a government and public which is more responsive to making provisions for language revitalisation in other areas of New Zealand policy besides broadcasting. This is key to the revitalisation of te reo Māori because as chapter one highlights, language revitalisation cannot occur through the MTS alone; it requires change in both the policies and attitudes of New Zealand.

\section{New Zealand Television}

The MTS has also had a significant impact on the New Zealand broadcasting sector. As argued in chapter three, the MTS has used other networks' lack of PSB programming and coverage of national events such as ANZAC Day as a means for attracting viewers, by differentiating itself from other FTA broadcasters. Since the MTS has begun broadcasting such programming, and attracting significant audiences as a result, other FTA broadcasters have also increased their coverage of national events in order to attract audiences. ANZAC Day is a key example of this because, even though no other broadcaster devotes as much of their schedule to the coverage of ANZAC Day as the MTS does, TVNZ and TV3's coverage has increased significantly since 2006 when the MTS first aired its full ANZAC Day schedule (Armstrong, 2014; Grant 2014). Due to New Zealand's small population, balancing cost versus public value is an issue that all New Zealand FTA broadcasters face and consequently, for FTA commercially driven broadcasters this has always resulted in the prioritisation of cheaper imported content over locally produced (Dunleavy, 2005, p. 1-2). The MTS, in having a schedule that has always been comprised of over 80 per cent locally produced content, demonstrates to other broadcasters that it is possible to be both cost-effective and provide locally produced content. This has the potential (especially if the viewership of the MTS continues to increase) to encourage FTA broadcasters to increase their locally produced content. It is also interesting then to note here, that it is often Māori initiatives that work to ensure the presence of locally produced 
content on New Zealand televisions screens. This was first seen with the Wai 150 Claim in 1989, which attempted to halt the commercialisation of New Zealand's broadcast sector. It was seen again with the sale of the third channel warrant which resulted in TV3 having to ensure that it broadcast locally produced content. Now, as a result of the Treaty of Waitangi, the presence of the MTS has ensured that New Zealand FTA broadcasters continue to maintain and grow their locally produced content. Therefore, Māori initiatives are important for ensuring locally produced content is present on New Zealand television screens and the MTS has been integral to this.

It is unlikely that the quantity of Māori programming shown on the MTS will ever be seen on other FTA broadcasters given that they have different mandates. However, since the MTS launched, Māori production companies have emerged throughout the industry which provide a valuable training ground for Māori talent. This allows for the production of more programming from the perspective of te ao Māori. Therefore, as the capacity of people with skills in the production of programming from a te ao Māori perspective grows, one could expect an increase in Māori programming on other FTA mainstream broadcasters in the future, especially if the number of te reo speakers increases.

\section{Obstacles Ahead}

The MTS has contributed to increasing local and cultural content on New Zealand television screens. It has also strengthened the mana of things Māori, yet challenges to the broadcaster still remain. The challenges the MTS has faced in establishing itself as a permanent fixture of the New Zealand television environment (mainly political and public opposition to the Service) have not entirely disappeared. The environment in which the MTS exists continues at times to elide Māori rights and scrutinise the MTS. A recent example of this is the 2012 Water Rights Claim where Māori attempted to assert their Treaty rights in relation to New Zealand waterways and were ignored by government despite a favourable ruling for Māori by the Waitangi Tribunal (Ruru, 2012). This example also highlights the fact that even when one institution of power is supportive of Māori initiatives (in this case the Waitangi Tribunal) this support is not always shared by another (in this example the National Party). As a result, these types of power struggles will continue to inform the 
environment in which the MTS exists. Furthermore, the MTS is still under the mainstream media's watch and is conscious of how its decisions are portrayed in the media. When the MTS's CEO Jim Mather resigned in October 2013 the mainstream media's coverage of the search for a new CEO reflected negatively on the MTS. The mainstream news coverage focused on divisions within the MTS over who was to be appointed, as well as the 'detrimental' position that this indecision over the new CEO had left the broadcaster in. Evidence of this is exemplified by headlines taken from the New Zealand Herald in late 2013 such as "Māori TV staff protest CEO option", "Māori TV fails" and the Dominion Post headline, "Resignation over Māori TV hiring woes." These articles go on to suggest that the hiring process had been "fraught with controversy" (Drinnan, 2013b), an "absence of information" (ibid.) and is resulting in destabilising factions amongst staff (Rutherford 2013; Drinnan, 2013b). Again these arguments draw on the common problematic discourse that Smith and Abel (2008) argue circulates in New Zealand of "Māori inability to manage public institutions" (p. 3). It is interesting to consider the irony present in these arguments, given that in 2003 the mainstream media heavily criticised the MTS for not taking more care and consideration in appointing its CEO at the time, when it was unearthed that former CEO John Davy had no legitimate qualifications for the position despite this being the fault of the hiring agency. Therefore, this latest mainstream media story highlights that despite operating for ten years, the MTS continues to have to prove itself and is always under the mainstream media's scrutiny making it vulnerable to public opinion. Additionally, these examples also highlight that the MTS must continue to negotiate its practices in relation to the broader socio-political environment in which it operates.

\section{Conclusion}

The MTS was created for the purpose of contributing to the revitalisation of te reo me ngā tikanga Māori through broadcasting. Although since the broadcaster first launched in 2004 the amount of Māori fluent in te reo Māori has decreased by almost 5 per cent, the MTS has still made a valuable contribution to the Māori language sector in a number of ways. It could be argued that without its contribution the Māori language would be in an even more precarious state. Since the Government's MLS was launched in 2003, little progress has been made towards an effective and co- 
ordinated Māori language sector in New Zealand. Recent changes suggest that by placing the revitalisation tools in the hands of Māori via Te Mātāwai, this will allow the Māori language sector to progress in a more effective and transformative manner.

To date, the MTS has also been beneficial for the Māori language sector as a whole, as it illustrates that comprehensive strategies for language revitalisation are beneficial to the uplift of te reo Māori. The MTS has increased the symbolic value of te reo Māori amongst both Māori and non-Māori which provides the Government with an incentive to continue to persevere with the difficult task of minority language revitalisation. Concomitantly, by being a successful Māori organisation the MTS has created the potential for Māori to make gains in other areas of language revitalisation aside from broadcasting. In embedding itself in the television landscape as the default public service broadcaster, the MTS encourages other FTA broadcasters to increase their public service content, as well as provides the skills necessary for increased Māori content on other FTA broadcasters to occur. If this were to eventuate, it would have a further positive impact on the uplift of te reo Māori allowing it to become further naturalised in the national imaginary and New Zealand media organisations. Despite the 2013 census highlighting a decrease in the number of te reo speakers, TPK's 2006 and 2011 studies on the MTS's positive contribution to language revitalisation suggest that without the Service the Māori language would be in a more dangerous state. Therefore, the MTS's strategies of language revitalisation have been integral to the Māori language sector, Māori and the New Zealand television industry. 


\section{Conclusion}

The Treaty of Waitangi guarantees Māori protection of their taonga, including te reo Māori. If the state does not take active steps to ensure the protection of their taonga, then the Treaty will remain an "incomplete project" (Smith \& Abel, 2008, p. 2). The establishment of a Māori television service was deemed necessary to uphold Treaty principles by contributing to the protection of te reo Māori. This is because of the function of television as a tool for the revitalisation of minority languages (Bell 2010; Benton 1985c; David 2010; Fishman 1997; 2001; Hartley 1999; 2008; Lysaght 2010). In the MTS's first ten years of operation, the primary organising imperative of its governing policy documents has been to ensure the Service contributes to the revitalisation of te reo Māori. Analysing the discourse of the MTS's governing policy documents (mainly its Statements of Intent and Annual Reports) since 2003 has demonstrated that the Service has ensured its programming, financial, and audience engagement strategies all contribute to language revitalisation. To meet its legislative requirements it has had to work with and against socio-political, cultural and economic pressures. Analysis of the MTS's governing policy documents, combined with literature on the role of television in language revitalisation, Māori media and the New Zealand television industry, has been used to demonstrate that the MTS's strategies for language revitalisation are the result of its negotiation of competing pressures. This thesis also argues that changes to the wider environment of the MTS and the prioritisation of different stakeholders' interests has shaped the Service's strategies for language revitalisation. Primarily, a shift has occurred from the MTS focusing on language programming quantity to language programming quality, and prioritisation of te reo speakers over a broad viewer base.

In order to counter the situation of Māori content on television prior to the establishment of the MTS, where according to Fox (2001) "the number of Māori or Māori-related programmes on television was less than one per cent of the total broadcast time" in 1993 (p. 261), the MTS has ensured that te reo Māori is prioritised in its schedule. It has also guaranteed that it provides content that benefits the language revitalisation process. In its first year on air the MTS broadcast approximately 2884 hours of original Māori programming, of which more than 50 
per cent was in te reo Māori (MTS, 2004b, p. 28-29). Furthermore, this programming catered for all levels of language speakers and those learning te reo Māori Since 2004 the MTS has increased its content significantly, and in 2012 it broadcast 5807 hours of programming, of which 57 per cent was in te reo Māori (MTS, 2013b, p. 11). In 2008 a second channel was added to the Service, Te Reo, which broadcasts entirely in te reo, further elevating the language in New Zealand's mediated public sphere. The MTS has also expanded programming for groups that are crucial to language uplift, including programming for children, those learning te reo and fluent speakers. Targeting children is central to language uplift because, as chapter one argues, they are highly receptive to new languages and there is a need for intergenerational speakers to ensure te reo Māori survives. Additionally, the 2003 MLS strategy highlights that television programming for those learning te reo is necessary in order to increase the number of te reo speakers and fluent speakers. Offering media that might improve these learners' skills allows the language to remain dynamic. Perhaps most importantly, prioritising te reo Māori in its schedule is crucial to language revitalisation because, as chapter one argues, in order for a language to be revitalised it must be heard as part of the everyday, thus normalising and naturalising the language.

However, the MTS operates within a broader context which means that simply inserting te reo Māori into the New Zealand television schedule will not substantially revitalise a language. This is because, as Richard Benton (1985a) argues, language is a "social phenomenon" and therefore must be heard, used and valued by many in order to be revitalised (p. 4). Given this, for television to have a substantive impact on language revitalisation it must have a large and diverse audience, for who the language becomes normalised and naturalised. This will allow te reo Māori to be used and valued by this audience and beyond. The MTS's inclusive strategy, which breaks down notions of Māori separatism and provides content with broad appeal, has attempted to create a large and diverse audience. It has endeavoured "to 'zig' where other channels 'zag'" (Smith \& Abel, 2008, p. 5) by dwarfing other FTA broadcasters in its public service and locally produced content. It has also distinguished its programming from other FTA offerings by providing comprehensive coverage of national events and it has used already popular and proven programming formats with the intent of attracting a broad viewer base. The MTS has established a diverse 
audience with this strategy; in 201277 per cent of its audience was non-Māori (Mather cited in Abel, 2013b, p. 112). Although this strategy has created an audience of Māori and non-Māori viewers and continues to grow the MTS's audience year-onyear (MTS, 2012b, p. 4), the MTS's undertaking to appeal to a majority audience through a minority language is difficult. As a result, despite the growth in audience, the MTS's audience numbers still remain substantially less than those of their mainstream rivals. As in 2013 the MTS's audience share was less than one per cent of total audience share (Nielsen, 2014). Even though the MTS may never surpass its counterparts, it must continue to expand and grow the Service in order to further contribute to te reo Māori revitalisation.

To expand its language offerings in the current television ecology the MTS must engage with digital technologies. An example of the MTS reacting to this environment is its early involvement with digital transmission which provided Māori Television with a high rating on the Electronic Programming Guide, meaning it is right alongside other mainstream broadcasters. This close proximity has the potential to benefit the MTS as through channel-surfing this environment conditions circumstances in which the MTS might insert "incremental shifts" into the national imaginary, thus naturalising and normalising te reo Māori (Smith, 2006, p. 35). The launch of the Māori language immersion channel, Te Reo, in 2008 was made possible by the establishment of the digital Freeview platform and represents another way in which the MTS has been able to enhance its language offerings through embracing the digital environment. Due to the proliferation of digital platforms, the MTS must ensure that it uses audience fragmentation by engaging with audiences via its website, YouTube channel and social media apps. This is acknowledged in the recent change to the MTS's legislation which now recognises the need to engage audiences across multiple platforms in the hope that increased media access will benefit language uplift (MTS Act, 2014, sec 8.4). As chapter three demonstrates, the MTS has already begun to use this digital environment to engage viewers and expand its language revitalisation offerings. For example, the MTS's website provides additional language learning resources, programming is uploaded online so people are able to watch in accordance with their own schedule and content can also be accessed through various social media apps. This further naturalises and contemporises te reo 
Māori. As such, the MTS has responded to the changing conditions of the television industry to ensure it continues to meet its cultural revitalisation imperatives.

To be an effective mechanism for language uplift the MTS has had to engage with political and public perceptions of things Māori. The MTS's emergence - like many things Māori - was troubled, with mainstream media and the political arena actively hostile to the Service with common stereotypes of 'Māori inability to manage public institutions' being invoked (Smith \& Abel, 2008, p. 3). To address this the MTS has worked tirelessly to create an image of financial prudence and as a value for money organisation that promotes Māori success while consistently achieving its primary goal of contributing to language revitalisation. Although financial security is difficult for a non-commercial broadcaster, the MTS continues to find ways to reduce its reliance on state-funding due to the uncertainty that this dependence creates. It has done this through prudent spending and the diversification of its revenue portfolio including pursuing sponsorship opportunities, advertising and long-term funding arrangements, but never at the expense of its cultural mandate. The MTS has also deployed inclusive strategies to build up a viewership of non-Māori so that if there were moves to disestablish the Service this would be met with resistance from both Māori and non-Māori. Evidence of this can be seen in the fact that 77 per cent of the MTS's audience was non-Māori in 2012 (Mather cited in Abel, 2013b, p. 112). In enhancing the political and cultural capital of its organisation's image, the MTS has worked to safeguard an assured future for the Service.

It is important to be critical of how the inclusive strategy of a broad viewing audience has potentially come at the expense of Māori visions for the Service. Some voices from the Māori language sector argue that the Service should first and foremost be for Māori, and therefore should not make content targeted at a broad viewing audience. In contrast to this view, this thesis argues that these inclusive strategies were integral to achieving Māori visions for the Service in the initial phase of the broadcaster's emergence, as they provide a successful image of Māori which can lead to greater Māori political and language gains. This is because inclusive strategies naturalise the language for all New Zealanders and encourage people to the language. However, recent changes in the MTS's legislation suggests the Service is shifting towards being a broadcaster that more closely reflects the desires of those 
who believe the Service at present is not doing enough for the revitalisation of te reo. Recent changes to the MTS's governing policy documents include a change to the wording of the MTS Act 2003 so it now accounts for language quality (language and its correct use and articulation) (Sharples, 2014a). Some language advocates believe this change will ensure the 'Māoriness' or integrity of the language (TKOM, 2009, p. 13). It also includes a change to the target audience, from a broad viewing audience to a focus on those learning te reo, children and fluent speakers (MTS Act, 2014, sec. 8.1). This latter change is thought to make the Service more closely aligned with its primary aim of language revitalisation which is why many Māori petitioned and protested the state for the Service to be established. Although these changes are likely to affect the Service's focus, it must be noted that the MTS did not ignore these interests before the change to its legislation. The MTS has always provided content in its schedule for language learners, children, and fluent speakers and has worked with iwi and institutions such as Te Taura Whiri i te Reo Māori to ensure the integrity of the language. These legislative changes are not likely to dramatically change the broadcaster's actions but a more nuanced shift in its programming may occur, allowing it to more closely align with Māori interests.

Despite the contribution the MTS had made in increasing the presence of te reo Māori in New Zealand, normalising the language and generating interest in it, te reo Māori remains under threat. It is not yet widely used, and thus "remains a minority language broadcast on two niche channels" (TKOM, 2009, p. 8). While the latest census statistics suggest the Māori language is still able to be saved as speakers of the language remain, the critical mass of fluency needed to revitalise the language is yet to be reached as its existence is dependent on many thousands of new speakers (ibid.). Furthermore, the MTS must continue to negotiate an environment that at times continues to elide Māori rights and scrutinises the MTS's actions, including its spending, operations and contribution to language uplift. Additionally, as a state funded broadcaster the MTS will remain vulnerable to changes in government funding and government attitudes towards PSB, which are often in response to economic conditions. Therefore, challenges remain for the MTS and it must continue to expand and find new ways to contribute to a national imaginary that includes te reo Māori while continuing to negotiate the pressures that condition its existence. 
Yet, television itself cannot keep a culture alive. As chapter one argues, language revitalisation requires the involvement of a myriad of institutions and due the MTS's inherent link to the state as a result of the Treaty of Waitangi, the support of the state and therefore, New Zealand public, is also needed. Although the Government launched a sector wide MLS in the same year that the MTS Act 2003 was enacted, the MLS was largely forgotten and has had a limited effect, with the number of te reo Māori speakers decreasing since the launch of the strategy (Statistics New Zealand, 2013). Various government reports have noted when criticising the current Māori language sector that the tools for language revitalisation must be in Māori hands if language revitalisation is to be achieved. The Te Mātāwai proposal relieves some of these tensions by proposing the overseeing institution of the broadcaster be a Māori institution. The recent transfer of spectrum rights to Te Putahi Paoho reflects a further initiative to safeguard the future of the channel and Māori language by placing the tools for representation in Māori hands. One could be sceptical that such actions are simply the Government trying to rid themselves of responsibility, however the Government must continue to uphold Treaty principles by providing adequate funding and support where necessary for te reo Māori revitalisation. Other sectors including health, business, justice, and education also need to contribute to language uplift. Providing a coherent and co-ordinated language strategy across these sectors is essential for change to occur.

As Rosalind Gill (2007) argues, in order to understand a document, the wider context in which it is produced must be taken into account, as discourse is not neutral but shaped by the environment in which it is created (p. 58-59). Discourse analysis of the MTS's governing policy documents suggest the Service provides a range of strategies for te reo Māori revitalisation which enable it to meet its legislative obligations, as well as to respond to community and industry stakeholders. These strategies include building an audience for its language programming content, operating as a financially prudent Māori organisation, and developing programming strategies in light of technological shifts. This thesis argues that these strategies contribute to the naturalisation and normalisation of te reo me ngā tikanga Māori within the national imaginary, and incorporate key tactics for language revitalisation as set out in the 2003 MLS to do so. It also identifies a shift from the MTS's focus on language programming quantity to language programming quality, and a shift to the 
prioritisation of te reo speakers over a broad viewer base. These more recent language programming strategies are considered in relation to current changes in language revitalisation activities. In revealing the competing pressures faced by the broadcaster, this thesis highlights the role the MTS has played in increasing the symbolic value of te reo Māori, despite the number of speakers of te reo decreasing since the broadcaster first aired. Evidence of this increased symbolic value was seen in the 2011 TPK report which found that the MTS is "motivating and promoting people to use their Māori language skills" (TPK, 2011, p. 4). This points towards the MTS having a "marked positive contributing impact on Māori language revitalisation" (ibid.). As a result, it could be argued that without the Service te reo Māori would be in a more precarious state. It took more than thirty years of protest by Māori against the state before the broadcaster first aired on 28 March 2004 and in its first ten years the Service has done much for increasing the symbolic value of the Māori language. As the MTS grows and develops it is likely to continue to contribute to te reo Māori revitalisation but only by effectively negotiating the technological, socio-political, cultural and economic pressures that condition its existence as a minority language television broadcaster within a settler-nation. 


\section{Reference List}

Abel, S. (1997). Shaping the news: Waitangi day on television. Auckland, New Zealand: Auckland University Press.

Abel, S. (2008). Tūhoe and 'terrorism' on television news. In D. Keenan (Ed.), Terror in our midst? Searching for terror in Aotearoa New Zealand (pp. 113-128). Wellington, New Zealand: Huia Publishers.

Abel, S. (2011). The (racial) political economy of Māori television. Australian Journal of Communication, 38(3), 125-138.

Abel, S. (2013a). Māori Television, Anzac day, and constructing "nationhood". In B. Hokowhitu \& V. Devadas (Eds.), The fourth eye: Mãori media in Aotearoa New Zealand (pp. 201-216). Minneapolis, MN: University of Minnesota Press.

Abel, S. (2013b). Māori television, its Pākehā audience and issues of decolonization. Studies in Australasian Cinema, 7(2\&3), 111-121.

Armstrong, D. (2014, March 31). Māori Television keeps others honest. Stuff.co.nz. Retrieved May 7, 2014, from http://www.stuff.co.nz/dominionpost/comment/columnists/dave-armstrong/9885918/Maori-Televisionkeeps-others-honest

Auditor General. (2007). Implementing the Mãori language strategy. Wellington, New Zealand: Office of the Auditor-General.

Barclay, B. (1990). Our Own Image. Auckland, New Zealand: Longman Paul.

Bell, A. (2010). Advocating for a threatened language: The case for Māori on television in Aotearoa/New Zealand. Te Reo 53, 3-26.

Benton, R. (1985a). The Māori language and beyond. Wellington, New Zealand: New Zealand Council for Educational Research/Te Wāhanga Māori.

Benton, R. (1985b). The place of the Mãori language in the education system. Wellington, New Zealand: New Zealand Council for Educational Research/Te Wāhanga Māori.

Benton, R. (1985c). The role of television in the survival of the Māori language. Wellington, New Zealand: New Zealand Council for Educational Research/Te Wāhanga Māori.

Benton, R. \& Benton, N. (2001). RLS in Aotearoa/New Zealand 1989-1999. In J. Fishman (ed.), Can threatened languages be saved? (pp. 423-450). Clevedon, UK: Multilingual Matters.

Broadcasting Act, No. 25. (1989). Retrieved March 25, 2014, from http://www.legislation.govt.nz/act/public/1989/0025/latest/DLM155365.ht $\mathrm{ml}$

Broadcasting Amendment Act, No. 69. (1993). Retrieved March 25, 2014, from, http://www.legislation.govt.nz/act/public/1993/0069/latest/whole.html 
Burns, D. (1997). Public money private lives: Aotearoa television - the inside story. Auckland, New Zealand: Birkenhead.

Carson, J. (2012, July 4). Māori language must be 'sexy'. Stuff.co.nz. Retrieved March 25, 2014, from http://www.stuff.co.nz/national/7337742/Maori-languagemust-be-sexy

David, J. (2010). Clear signals: Learning and maintaining Aboriginal language through television. In S. Hafsteinsson and M. Bredin (Eds.), Indigenous screen cultures in Canada (pp. 35-52). Winnipeg: University of Manitoba Press.

Deane, S. (2014, March 28). Channel's battle to help save te reo. The New Zealand Herald. Retrieved May 7, 2014, from http://www.nzherald.co.nz/nz/news/article.cfm?c_id=1\&objectid=11227758

Drinnan, J. (2013a, September 3). Māori TV staff protest CEO option. The New Zealand Herald. Retrieved March 25, 2014, from http://www.nzherald.co.nz/business/news/article.cfm?c_id=3\&objectid=111 18425

Drinnan, J. (2013b, September 11). Māori TV fails to appoint new CEO. The New Zealand Herald. Retrieved March 25, 2014, from http://www.nzherald.co.nz/business/news/article.cfm?c_id=3\&objectid=1112 2596

Dunleavy, T. (2005). Ourselves in primetime. Auckland, New Zealand: Auckland University Press.

Dunleavy, T. (2008). New Zealand television and the struggle for 'public service'. Media Culture Society, 30(6), 795-811.

Dunleavy, T. (2010, 8 September). Television New Zealand and the Charter: the Uneasy Reconciliation of Public Service Commercialism. Paper presented at the bi-annual RIPE conference, University of Westminster, UK. Retired March 25, 2014, from the http://ripeat.org/wp-content/uploads/tdomf/1826/Dunleavy

Dunleavy, T., \& Joyce, H. (2011) New Zealand film and television: Institution, industry and cultural change. Chicago, IL: Intellect.

Fishman, J. (1991). Reversing language shifts. PA, USA: Multilingual Matters.

Fishman, J. (1997). In praise of the beloved language: A comparative view of positive ethnolinguistic consciousness. Berlin, Germany: Walter de Gruyter.

Fishman, J. (2001). Why is it so Hard to Save a Threatened Language? In J.A. Fishman (Ed.), Can Threatened Languages be Saved? (pp. 1-22). Clevedon, UK: Multilingual Matters.

Fleras, A. \& Spoonley, P. (1999). Recalling Aotearoa: Indigenous politics and ethnic relations in New Zealand. Auckland, New Zealand: Oxford University Press.

Fox, D. (1992). The Māori perspective of the news. In M. Comrie \& J. McGregor (Eds.), Whose News? Palmerston North, New Zealand: Dunmore Press. 
Fox, D. (2001). Honouring the treaty: Indigenous television in Aotearoa. In J.

Farnsworth \& I. Hutchison (Eds.), New Zealand Television: A reader (pp. 260269). Palmerston North, New Zealand: Dunmore Press Limited.

Gill, R. (2007). Gender and the media. Cambridge, UK: Polity Press.

Grant, N. (2014, March 23). Celebrating Maori Television. The New Zealand Herald. Retrieved May 7, 2014, from

http://www.nzherald.co.nz/television/news/article.cfm?c_id=339\&objectid=1 1223925

Hansard and Journals. (2013, November 19). Māori Television Service (Te Aratuku Whakaata Irirangi Māori) Amendment Bill: Second reading, instruction to committee, in committee, third Reading. New Zealand Parliamentary Debates, 695, 14921.

Hartley, J. (1999). Uses of television. London, UK: Routledge.

Hartley, J. (2008.) Television truths. Oxford, UK: Blackwell Publishing.

Horrocks, R. The history of New Zealand television: An expensive medium for a small country. In R. Horrocks \& N. Perry (Eds.), Television in New Zealand:

Programming the nation (pp. 20-43). Melbourne, VIC: Oxford University Press.

Hourigan, N. (2002). New social movement theory and minority language media campaigns. European Journal of Communications, 16(1), 77-100.

Lawn, J. \& Beatty, B. (2005). Getting to Wellywood: National branding and the globalisation of the New Zealand film industry. Postscript 24(2-3), 122-139.

Lysaght, R. (2010). Teanga \& Tikanga: A comparative study of national broadcasting in a Minority language on Māori television and Teilifís na Gaeilge [Post-doctoral dissertation]. University of Auckland, Auckland, New Zealand. Retrieved June 1, 2014, from

https://researchspace.auckland.ac.nz/bitstream/handle/2292/6729/whole.pd f?sequence $=2$

Pihama, L., \& Mika, C. (2011). The Treaty of Waitangi and policy in Māori broadcasting. In V. Tawhai \& K. Gray-Sharp (Eds.), 'Always speaking': The Treaty of Waitangi and public policy (pp. 175-189). Wellington, New Zealand: Huia Publishers.

Pihama, L. (n.d.). The monitoring and evaluation of the Màori Television pilot project: Report to Te Māngai Pāho and Aotearoa Television Network. Auckland, New Zealand: Research Unit for Māori Education

Māori Television Service (Te Aratuku Whakaata Irirangi Māori) Act, No 21. (2003) Retrieved March 25, 2014, from, http://www.legislation.govt.nz/act/public/2003/0021/latest/DLM193696.ml

Māori Television Service (Te Aratuku Whakaata Irirangi Māori) Amendment Act, No.99. (2014). Retrieved March 24, 2014, from, http://www.legislation.govt.nz/bill/government/2012/0044/latest/whole.htm l 
McLeod, J. (2014). New Zealand public television, public service and everything in between: The success and struggles of New Zealand on Air and public television [Master of Arts thesis]. Victoria University Wellington, Wellington, New Zealand.

Mentjox, L. (2014, February 19). Maori Television announces deal to screen ANZ Championship netball on Te Reo channel [Press release]. Retrieved April 22, 2014, from http://www.maoritelevision.com/about/media/maori-televisionannounces-deal-screen-anz-championship-netball-te-reo-channel

Middleton, J. (2010). Ka rangona te reo: The development of Māori-language television broadcasting in Aotearoa New Zealand. Te Kaharoa, 3(1), 146-176.

Ministry of Justice. (2011, July 2). Ko Aotearoa tēnei: Report on the Wai 262 claim released [Press release]. Retrieved 25 June, 2014, from, http://www.justice.govt.nz/tribunals/waitangi-tribunal/news/wai-262-koaotearoa-tenei-report-on-the-wai-262-claim-released

Moriarty, M. (2009). Normalising language through television: The case of the Irish language television channel, TG 4. Journal of Multicultural Discourses 4(2), 137-149.

MTS. (2003). Statement of Intent 2003-2004. Auckland, New Zealand: Author.

MTS. (2004a). Pūrongo-ā-tau Annual Report 2004. Auckland, New Zealand: Author.

MTS. (2004b). Statement of Intent 2004-2005. Auckland, New Zealand: Author.

MTS. (2005a). Pānui Whāinga Statement of Intent 2005-2006. Auckland, New Zealand: Author.

MTS. (2005b). Pūrongo-ā-tau Annual Report 2005. Auckland, New Zealand: Author.

MTS. (2006a). Pānui Whāinga Statement of Intent 2006-2007. Auckland, New Zealand: Author.

MTS. (2006b). Pūrongo-ā-tau Annual Report 2006. Auckland, New Zealand: Author.

MTS. (2007a). Pānui Whāinga Statement of Intent 2007-2008. Auckland, New Zealand: Author.

MTS. (2007b). Pūrongo-ā-tau Annual Report 2007. Auckland, New Zealand: Author.

MTS. (2008a). Pānui Whāinga Statement of Intent 2008-2009. Auckland, New Zealand: Author.

MTS. (2008b). Pūrongo-ā-tau Annual Report 2008. Auckland, New Zealand: Author.

MTS. (2009a). Pānui Whāinga Statement of Intent 2009-2010. Auckland, New Zealand: Author.

MTS. (2009b). Pūrongo-ā-tau Annual Report 2009. Auckland, New Zealand: Author.

MTS. (2010a). Pānui Whāinga Statement of Intent 2010-2013. Auckland, New Zealand: Author.

MTS. (2010b). Pūrongo-ā-tau Annual Report 2010. Auckland, New Zealand: Author.

MTS. (2011a). Pānui Whāinga Statement of Intent 2011-2014. Auckland, New Zealand: Author. 
MTS. (2011b). Pūrongo-ā-tau Annual Report 2011. Auckland, New Zealand: Author.

MTS. (2011c), November). Briefing to the incoming Minister of Māori Affairs and Minister of Finance. Retrieved May 7, 2014, from

https://www.maoritelevision.com/sites/default/files/attachments/Briefing\%2 0to\%20Incoming\%20Ministers\%202011.pdf

MTS. (2012a). Pānui Whāinga Statement of Intent 2012-2015. Auckland, New Zealand: Author.

MTS. (2013a). Pānui Whāinga Statement of Intent 2013-2016. Auckland, New Zealand: Author.

MTS. (2012b). Pūrongo-ā-tau Annual Report 2012. Auckland, New Zealand: Author.

MTS. (2013c, November 14). Popular children's shows to air on Māori Television in te reo [Press release]. Retrieved May 7, 2014, from,

http://www.maoritelevision.com/about/media/popular-childrens-shows-airmaori-television-te-reo

MTS. (2014a). Sales and advertising. Retrieved 25 June, 2014, from

http://www.maoritelevision.com/about/sales-advertising

MTS (producer). (2014b, March 28). Through the Lens [Television Film]. Auckland, New Zealand: Māori Television

New Zealand Parliament. (2014). The Māori language: selected events from 18002013. Retrieved June 25, 2014, from http://www.parliament.nz/en-nz/parlsupport/research-papers/00PLSocRP2013041/the-m\%C4\%81ori-languageselected-events-1800-2013

Nielsen. (2014). Rating point. Retrieved 25 June, 2014, from http://www.ratingpoint.co.nz/Home

Norris, P., \& Pauling, B. (2011). NZoA an evaluative study 1989-2011. Retrieved March 25,2014 , from http://www.nzonair.govt.nz/media/65429/nza4022\%20evaluative\%20study \%20doc\%20final\%20web.pdf

NZoA. (2009). Annual Report 2008-2009. Retrieved March 25, 2014, from http://www.nzonair.govt.nz/corporate-document-library/annual-report-20082009/

NZoA. (2010). Annual Report 2009-2010. Retrieved March 25, 2014, from http://www.nzonair.govt.nz/corporate-document-library/annual-report2009/

NZoA. (2011). Annual Report 2010-2011. Retrieved March 25, 2014, from http://www.nzonair.govt.nz/corporate-document-library/annual-report2010/

NZoA. (2012). Annual Report 2011-2012. Retrieved March 25, 2014, from http:// www.nzonair.govt.nz/corporate-document-library/annual-report-2011-12/

NZoA. (2013a). Annual Report 2012-2013. Retrieved March 25, 2014, from http: // www.nzonair.govt.nz/corporate-document-library/annual-report-2012-13/ 
NZoA. (2013b). 2012 local content New Zealand television. Retrieved March 25, 2014, from http://www.nzonair.govt.nz/research/all-research/local-content-report2012/

NZoA. (2014). 2013 local content New Zealand television. Retrieved March 25, 2014, from http://www.nzonair.govt.nz/document-library/local-content-report2013/

NZoS. (2014). History of TV. Retrieved October 1, 2014, from http://www.nzonscreen.com/static/history_of_tv

NZoS. (2013a). Koha. Retrieved September 4, 2013, from http://www.nzonscreen.com/title/koha-1980/series

NZoS. (2013b). Tangata Whenua. Retrieved on September 3, 2013, from http://www.nzonscreen.com/title/tangata-whenua-1974/series

RNZ. (2014, March 31). Language learners crucial, says TMP. Radio New Zealand. Retrieved May 7, 2014, from http://www.radionz.co.nz/news/te-manukorihi/240083/language-learners-crucial\%2c-says-tmp

Ruru, J. (2012). Māori rights over water. Māori Law Review. Retrieved, May 7, 2014 from http://maorilawreview.co.nz/2012/09/maori-rights-in-water-thewaitangi-tribunals-interim-report/

Rutherford, H. (2013, September 11). Resignation over Māori TV hiring woes. Stuff.co.nz. Retrieved May 7, 2014, from http://www.stuff.co.nz/national/9149371/Resignation-over-Maori-TV-hiringwoes

Sharples, P. (2013a, November 20). Māori television service amendment bill passed [press release]. Retrieved May 7, 2014, from http://www.scoop.co.nz/stories/PA1311/S00383/maori-television-serviceamendment-bill-passed.htm

Sharples, P. (2013b, December 16). Change of governance proposed in Māori language strategy [Press Release]. Retrieved March 25, 2014, from http://www.tpk.govt.nz/en/newsevents/news/change-of-governanceproposed-in-maori-language-strategy/

Skilling, P. (2010). The construction and use of national identity in contemporary New Zealand politics. Australian Journal of Political Science, 45(2), 175-189.

Spoonley, P., \& Hirsh, W. (1990). Between the lines: Racism in the New Zealand media. Auckland, New Zealand: Heinemann Reed.

Smith, J. (2006). Parallel Quotidian Flows: Māori Television on Air. New Zealand Journal of Media Studies. 9(2), 27-35.

Smith, J. (2013). Māori Television's Indigenous insistence. Studies in Australian Cinema, 7(2\&3), 101-110.

Smith, J. \& Abel, S. (2008). Ka whawhai tonu mātou: Indigenous television in Aotearoa/New Zealand. New Zealand Journal of Media Studies, 1(1), 43-56. 
Smith, J. \& de Bruin, J. (2012). Survivor-styled indigeneity in two reality television programmes from Aotearoa/New Zealand. Australian Journal of Popular Culture, $1(3), 297-311$.

Smith, J \& Turner, S. (2013). Indigenous inhabitations and the colonial present. In Graham Huggan The oxford handbook of postcolonial studies. Oxford, UK: Oxford University Press.

Statistics New Zealand. (2002). 2001 Survey on the health of the Māori language. Wellington, New Zealand: Author.

Statistics New Zealand. (2013). 2013 Quick census stats about Māori. Retrieved June 25, 2014, from http://www.stats.govt.nz/Census/2013-census/profile-andsummary-reports/quickstats-about-maori-english/maori-language.aspx

Stephens, T. (2004). Māori television. In R. Horrocks \& N. Perry (Eds.), Television in New Zealand: Programming the nation (pp. 107-115). Melbourne, VIC: Oxford University Press.

Steward, I. (2013, October 13). Māori TV takes on Kōhanga Reo. Stuff.co.nz. Retrieved June 25, 2014, from http://www.stuff.co.nz/national/education/9277115/Maori-TV-takes-on-TeKohanga-Reo

Te Paepae Motuhake. (2011). Te Reo Mauriora. Wellington, New Zealand: Te Puni Kōkiri.

Thompson, P. (2011). Neoliberalism and the political economies of public television policy in New Zealand. Australian Journal of Communication, 38(3), 1-16.

Thompson, P. (2006). Approaches to measuring quality in broadcasting. Auckland, New Zealand: Unitec School of Communication.

Thompson, P. (2012). Last chance to see? In M. Hirst, S. Phelan, \& V. Rupar (Eds.) Scooped: The politics and power of journalism in Aotearoa New Zealand (pp. 96-113). Auckland, New Zealand: AUT Media

TKOM. (2009). Review of the Māori television service Act 2003. Wellington, New Zealand: Te Puni Kōkiri.

TMP. (2004). Annual report 2003-2004. Wellington, New Zealand: Author.

TMP. (2005). Annual report 2004-2005. Wellington, New Zealand: Author.

TMP. (2006). Annual report 2005-2006. Wellington, New Zealand: Author.

TMP. (2007). Annual report 2006-2007. Wellington, New Zealand: Author.

TMP. (2008). Annual report 2007-2008. Wellington, New Zealand: Author.

TMP. (2009). Annual report 2008-2009. Wellington, New Zealand: Author.

TMP. (2010). Annual report 2009-2010. Wellington, New Zealand: Author.

TMP. (2011). Annual report 2010-2011. Wellington, New Zealand: Author.

TMP. (2012). Annual report 2011-2012. Wellington, New Zealand: Author. 
TMP. (2013). Annual report 2012-2013. Wellington, New Zealand: Author.

TMP. (2014). Event timeline. Retrieved June 25, 2014, from http://www.tmp.govt.nz/event-timeline

TPK. (2008). Te oranga o te reo Māori: The health of the Māori language in 2006. Wellington, New Zealand: Author.

TPK \& Te Taura Whiri i te Reo Māori. (2003). Te rautaki reo Māori: The Mãori language strategy. Wellington, New Zealand: Te Puni Kōkiri.

TPK \& Te Taura Whiri i te Reo Māori. (2009). Report to the Minister of Māori Affairs: Review of the Māori language strategy. Wellington, New Zealand: Author.

TPK. (2011). Impact of Mãori Television on the Māori Language. Wellington, New Zealand: Author.

TPK. (2013, December 16). Change of governance proposed in Māori language strategy [Press Release]. Retrieved 24 May, 2014, from

http://www.tpk.govt.nz/en/newsevents/news/change-of-governanceproposed-in-maori-language-strategy/

Turner, R. (2011). Non-Māori viewing of Māori Television: An empirical analysis of the New Zealand broadcast system [Master of Arts thesis]. Massey University, Auckland, New Zealand.

Turner, S. (2004). Representing the Country: Adidas Aotearoa. Television in New Zealand: Stephens, T. (2004). Māori television. In R. Horrocks \& N. Perry (Eds.), Television in New Zealand: Programming the nation (pp. 94-102). Melbourne, VIC: Oxford University Press.

Waitangi Tribunal. (1986). Te Reo Mãori Claim: Wai 11. Wellington, New Zealand: Department of Justice.

Waitangi Tribunal. (1990). Claims concerning the allocation of radio frequencies: Wai 26 \&150. Wellington, New Zealand: Department of Justice.

Waitangi Tribunal. (2010). Chapter five: Te reo Māori. Ko Aotearoa tenei: Te taumata tuatahi - A report into claims concerning New Zealand Law and Policy Affecting Maori Culture and Identity (pp. 387-490). Wellington, New Zealand: Department of Justice.

Walker, P. (2013, March). Why Māori seek share of 4g spectrum. Stuff.co.nz. Retrieved April 18, 2014, from http://www.stuff.co.nz/dominionpost/comment/8375562/Why-Maori-seek-share-of-4G-spectrum

Walker, R. (2004). Ka whawhai tonu matou struggle without end. Auckland, New Zealand: Penguin.

Webb, J., Schirato, T. \& Danaher, G. (2002). Understanding Bourdieu. London, UK: Sage Publications.

UMA. (2013, October 22). Minister Tuira loses heart in Māori Television [Press Release]. Retrieved June 25, 2014, from http://www.waateanews.com/Waatea+News.html?story_id=NTY4Nw== 
